\title{
Anorexia in cancer
}

Citation for published version (APA):

Krause, R. (1980). Anorexia in cancer. [Doctoral Thesis, Maastricht University]. Rijksuniversiteit Limburg. https://doi.org/10.26481/dis.19800125rk

Document status and date:

Published: 01/01/1980

DOI:

10.26481/dis.19800125rk

Document Version:

Publisher's PDF, also known as Version of record

\section{Please check the document version of this publication:}

- A submitted manuscript is the version of the article upon submission and before peer-review. There can be important differences between the submitted version and the official published version of record.

People interested in the research are advised to contact the author for the final version of the publication, or visit the DOI to the publisher's website.

- The final author version and the galley proof are versions of the publication after peer review.

- The final published version features the final layout of the paper including the volume, issue and page numbers.

Link to publication

\footnotetext{
General rights rights.

- You may freely distribute the URL identifying the publication in the public portal. please follow below link for the End User Agreement:

www.umlib.nl/taverne-license

Take down policy

If you believe that this document breaches copyright please contact us at:

repository@maastrichtuniversity.nl

providing details and we will investigate your claim.
}

Copyright and moral rights for the publications made accessible in the public portal are retained by the authors and/or other copyright owners and it is a condition of accessing publications that users recognise and abide by the legal requirements associated with these

- Users may download and print one copy of any publication from the public portal for the purpose of private study or research.

- You may not further distribute the material or use it for any profit-making activity or commercial gain

If the publication is distributed under the terms of Article $25 \mathrm{fa}$ of the Dutch Copyright Act, indicated by the "Taverne" license above, 

Promotores: $\quad$ Prof. Dr. J.M. Greep

Prof. Dr. J.E. Fischer (Cincinnati, U.S.A.)

Referenten: Prof. Dr. H.M. van Praag, Utrecht

Prof. Dr. J.A. van Rossum, Nijmegen

Prof. Dr. P. Visser, Amsterdam

Het klinisch en experimenteel onderzoek werd verricht op de afdelingen interne geneeskunde en chirurgie en het Laboratorium voor Chirurgische Fysiologie van het Massachusetts General Hospital en Harvard Medical School in Boston, Massachusetts, U.S.A. 


\section{Anorexia in cancer}

\section{Proefschrift}

ter verkrijging van de graad van Doctor in de Geneeskunde aan de Rijksuniversiteit Limburg te Maastricht op gezag van de rector magnificus Prof. Dr. W.H.F.W. Wijnen, hoogleraar in de Fakulteit der Geneeskunde, en volgens besluit van het College van Dekanen.

De openbare verdediging zal plaatsvinden op 25 januari 1980 om 16 uur des namiddags in de aula van de Rijksuniversiteit.

door

R. Krause

geboren te Burgkirchen, Oostenrijk. 
"People are most extraordinarily ingenious; what will they discover! Serotonin in walnuts and bananas and in jelly-fish and in carcinoids in brain (all) leaves me with a sense of bewilderment, and fear that some will ask me what serotonin does".

Irvine H. Page, 1965 


\section{Contents}

\section{Acknowledgements}

\section{Introduction}

Part $1 \quad$ Literature and hypotheses

Chapter 1: Literature study on the control of normal 16 feeding behaviour

1.1. Central mechanisms

1.1.1. Anatomical approach 16

1.1.2. Physiological approach 19

1.1.3. Central neurotransmitters 21

1.1.4. Special senses 22

1.2. Alimentary tract factors $\quad 24$

1.3. Hormonal mechanisms 27

1.4. Mechanisms based upon homeostasis 28

1.4.1. Thermostatic control 28

1.4.2. Glucostatic control 29

1.4.3. Lipostatic control 30

1.4.4. Osmostatic control 31

1.4.5. Aminostatic control 32

Chapter 2: The impact of cancer on feeding control 35

2.1. Central control systems 35

2.2. Alimentary tract factors 36

2.3. Hormonal systems 36

2.4. Mechanisms based upon homeostasis 37

2.4.1. Thermostatic control 37

2.4.2. Glucostatic control 37

2.4.3. Lipostatic control 38

2.4.4. Osmostatic control 39

2.4.5. Aminostatic control 39

2.5. Other hypotheses on anorexia in cancer. 40 
Part II The experiments 43

Chapter 3: Plasma and brain amino acids in Walker-256 44 bearing rats.

3.1. Introduction 44

3.2. Materials and methods 46

3.3. Results 47

3.4. Discussion 52

3.5. Conclusion 55

3.6. Summary 55

Chapter 4: What determines brain concentrations of tryptophan in the normal and the tumorbearing animal?

4.1. Introduction 56

4.2. Materials and methods 57

4.3. Results 58

4.4. Discussion 62

4.5. Conclusion 71

4.6. Summary 71

Chapter 5: The impact of altered brain TRP levels on 72 serotonin metabolism.

5.1. Introduction 72

5.2. Materials and methods $\quad 72$

5.3. Results 74

5.4. Discussion 75

5.5. Conclusions 75

5.6. Summary 77

Chapter 6: Evidence to support the role of serotonin in feeding behaviour and cancer anorexia.

6.1. General aspects of serotonin as a central neurotransmitter.

6.2. Serotonin and behaviour $\quad 81$

6.3. Serotonin and feeding behaviour 82

6.4. Serotonin and cancer anorexia 86

6.5. Conclussion 91 
Chapter 7: General discussion

Summary

95

Samenvatting

References

106

Curriculum vitae 


\section{Acknowledgements}

Many people have been involved in realizing this thesis and it is impossible to thank everyone in person for their great help. I would like to take advantage of this occasion, however, to express my gratitude towards those without whom this would not have been started.

Prof. Co Greep, your legendary dynamic personality and stimulating enthusiasm have been a most valuable help. while I acknowledge profound gratitude for offering me the opportunity to spend eighteen months in the U.S.A. to work on the subject of my choice under the most desirable conditions.

I also would like to express my gratitude to Prof. Joe Fischer for the same reasons and for his kind hospitality in his laboratory, clinic, team and his family. Your teaching meant a great deal to me and I do admire your lucency and tenacity as a teacher.

I also acknowledge gratitude to Prof. Visser, Prof. van Praag and Prof. van Rossum for their critical reading of the manuscript. Prof. Lemmens, you made it possible for me to begin my training as a surgeon, and I feel deeply grateful for this privilege.

I also would like to express my deep appreciation towards Dr. Jacques Daniëls for his enlightening introduction into surgery. Your professional skill and erudition were a great pleasure to witness.

Peter Soeters and Howard James, your fine teaching qualities, tremendous theoretical and technical knowledge and your friendly personalities have been of great support to me.

I also thank my colleagues at the Massachusetts General Hospital: Herbert Freund, Vinzenzo Ziparo, Christopher Humphrey and Bengt Jeppsson for their pleasant collaboration and good conversation and my colleagues at St. Annadal Hospital in Maastricht for their willingness to suffer the inconvenience caused by my involvement in this thesis.

I feel much obliged to Gerda Haemers. Nicole Castermans, and Marcia van Puijenbroek for their courage and patience in typing the manuscript and Eric de Nie for his fine cover design. 


\section{Introduction}

Loss of appetite and body weight are common symptoms in cancer. Although there is a tendency to consider them as a result of advanced malignancy, they may occur as an early manifestation of the disease and be present when the tumor is still small and localized.

More often though, anorexia appears as the malignant neoplasm grows or spreads and it is always a major contributant to the cachectic state of the terminal cancer patient. Except for the disease itself, anorexia may be caused by other factors. The psychosocial and emotional status of patients suffering from cancer may be responsible for this lack of appetite while iatrogenic effects also may worsen the impaired appetite in these patients. In any stage of the malignant disease, the cancer itself may be the main cause of anorexia as it tends to disappear after curative therapy.

The impact of anorexia upon the nutritional status of the cancer patient may be significant and when superimposed upon a high energy requirement, may enhance cancer cachexia.

The progressive depletion of body stores of a patient harbouring a growing malignancy is an all too common clinical problem.

Not only may therapeutic possibilities for the cachextic patient be limited or their application delayed, the state of malnutrition also leads to an associated decrease in host resistance as is often reflected by a decreased cellular and humoral immunity. This may favor malignant growth and leave the patient susceptible to opportunist infection.

This growing awareness of the nutritional impact of the malignant tumor upon its host now has led to a policy of vigorously hyperalimenting the depleted patient via enteral of parenteral route, requiring prolonged hospitalization, acceptance of a certain rate of complications and often causing great discomfort to the patients and their relatives.

Although hyperalimentation has been proven successful in cancer patients, it clearly is not the solution to the problem. Better understanding of the mechanisms involved in cancer anorexia ultimately may render this problem accessible to treatment.

Many hypotheses have been advanced to explain the anorexia of malignant disease, but its pathogenesis remains unclear. This is mainly due to the fact that at present time, normal physiology of feeding still is poorly understood. Although significant progress has been made in the understanding of the genesis of hunger and satiety, the precise signals triggering these aspects of feeding have not yet been elucidated.

It still remains unclear what specific event provides the initial stimulus that leads to food ingestion, from what site this event originates, and how it is communicated to the brain. 
The hypothalamus is considered to contain the centers for feeding and satiety. The ventromedial nuclei - or more precisely the noradrenergic ventral bundle - supposedly form a satiety center exerting an inhibitory action within the hypothalamic regulatory feeding system.

The lateral hypothalamus is also involved in the control of energy balance by playing a critical role in the initiation of food seeking behaviour.

It is a facilitory center and when bilaterally lesioned, it causes aphagia while the lesioning of the ventromedial hypothalamus results in hyperphagia. Other brain centers which belong to phylogenetically younger systems, located in the neocortex and the limbic system, may exert modifying influences upon feeding behaviour.

A variety of studies on other central neurogenic and humoral systems have been published, but also strict peripheral influences on feeding behaviour such as glucostatic, aminostatic, lipostatic and the thermostatic

(hypothetic) systems, have been demonstrated.

It has been suggested that one of these systems may be malfunctioning in cancer and consequently may cause anorexia. Evidence for this is lacking. It becomes more apparent that anorexia is an expression of a more general vegetative decline, and it is tempting to suggest that central systems will be involved rather than peripheral ones.

One characteristic of all hypotheses and theories on the central regulation systems of feeding seems to be the difficulty in defining the 'afferent side' of the centers involved.

This thesis tries to focus upon the aspect of how activity in a regulatory system is linked to parameters derived from the consumption of food and how such an interaction might be affected by the presence of a malignant tumor. It is suggested in this study that a serotoninergic system may be involved in controlling food intake in general and, particularly, that derangements of this system may be responsible for tumor induced anorexia.

The framework of this thesis is as follows: an extended literature study, mentioning all current data and hypotheses on systems that may be involved in animal and human feeding behaviour (chapter 1) and how these systems eventually may be affected by cancer (chapter 2), will precede the author's report of his experimental work in the Laboratory of Surgical Physiology of the Massachusetts General Hospital and Harvard Medical School in Boston. Massachusetts, U.S.A. (chief: Prof. Dr. J.E. Fischer; at present Professor in Surgery and Director of the Surgical Department at the University of Cincinnati College of Medicine in Cincinnati, Ohio, U.S.A.). 
In this second part, chapter 3 reports the study of amino acid profiles in plasma and brains of Walker-256 tumor bearing animals and how these relate to tumor growth and malnutrition. Brain tryptophan (TRP) concentration is introduced and discussed with respect to its possible role in the mechanism of cancer anorexia. Chapter 4 deals with the determination of the factors which account for brain concentrations of TRP in normal animals and in the animal tumor model studied. In chapter 5, the relationship between brain TRP and brain serotonin/5-HIAA is focused upon and in a brief discussion, the hypothesis on a central mechanism for anorexia in cancer involving serotonin as the key neurotransmitter is fully expressed.

In chapter 6, evidence to support the role of serotonin in feeding behaviour in cancer is collected and discussed.

A brief final discussion will conclude this thesis. 


\section{PART I:}

Literature and Hypotheses. 


\section{Chapter 1}

\section{Literature study on the control of normal feeding behaviour}

\subsection{Central mechanisms}

\subsubsection{Anatomical Approach}

The classic statement that two regions of the hypothalamus guide our eating behaviour is at present generally considered to be too simplistic a view, as other brain regions that influence feeding have been demonstrated. The ventral diencephalic area had been suspected to dominate feeding behaviour and body weight balance long before Hetherington and Ranson (1939)(121) presented their results of lesioning the ventromedial hypothalamus in producing obesity secondary to hyperphagia as pointed out later by Brobeck (1943) (42).

Ever since attention has focused on the properties of the different components of the thalamus and their specific role in feeding behaviour.

The hypothalamus is divided into two halves by the third ventricle.

Several midline nuclei are located immediately adjacent to the third ventricle; they can be subdivided into anterior, medial and posterior nuclei; the ventromedial (V.M.) nucleus occupies a prominent position in the medial hypothalamus. Lesioning the larger part of the anterior ventromedial nucleus together with some of the tissue directly lateral to it, the caudal ends of the ventromedial nucleus including the premammillary region and a small part of the adjacent lateral hypothalamus and the area dorsal and lateral of the mammillary body all induce hyperphagia, while this is not the case when the anterior hypotholamus, fornix, the greater part of the rnammillary body, ventral septum system or olfactory tubercle are lesioned (117).

Recently, is has been suggested that, rather than the ventromedial nucleus itself, a ventral bundle containing noradrenergic fibres is more essential in the regulation of food intake. The bundle ascends from midbrain and has terminals close to the ventromedial hypothalamus. Its destruction results in hyperhagia $(103,192)$.

In contrast to the ventromedial hypothalamic regions as described above, the lateral nuclei are less clearly defined. It has been repeatedly demonstrated however, that destruction of the lateral hypothalamus creates hypophagia in all species studied. Adipsia is superimposed upon aphagia when both the lateral and the extreme lateral hypothalamus are destructed. Connections between the lateral and medial hypothalamus do exist although they are difficult to demonstrate. 
Bilateral interruption of these connections results in hyperphagia as observed in lesioning of the ventromedial nuclei. The connecting fibres mainly travel with the bundle of Schutz to the lateral hypothalamus. Destructive lesions of other parts of the brain have been shown to alter food intake. Animals in which the corpora amygdaloidea were lesioned, increased their food intake, an effect potentiated by simultaneously lesioning the ventromedial hypothalamus (193). Hyperphagia is also seen as a result of frontal lobotomy (110). Extra-hypothalamic brain regions causing a decrease in food intake when lesioned are the globus pallidus, nucleus caudatus and tegmentum, as reviewed by Grossman (1972)(110). As far as the anatomical approach is concerned, other techniques currently are used to investigate central control of food intake i.e. electrical stimulation, chemically induced stimuli via micro injections and exclusion of centers using local anesthetics (e.g. procaine). Electrical stimulation of the ventromedial hypothalamus as a rule, has effects opposite to those obtained with ablations and results in decreased food (5). Similar results have been noticed after electrical stimulation of the globus pallidus, nucleus caudates and the laterobasal part of the corpora amygdaloidea (93). Conversely, electrical, stimulation of lateral hypothalamus, septum, thalamus, tegmentum and to a certain extent the angulate gyrus will provoke hyperphagia as does chemical stimulation by direct injection of noradrenaline into the anatomical structures mentioned above (109).

Grossman reported in 1962 (117) that hypothalamic injections of noradrenaline can produce hyperphagia even in satiated rats. The same response has been found in other species $(14,243)$. Also adrenaline has been shown to produce similar effects when injected into the hypothalamus with perhaps a greater potency than nor-adrenaline (153). The most effective site to elicit a feeding response, even at doses as low as $4 \mathrm{ng}$ (nor-) adrenaline, is the paraventricular nucleus at the anterior hypothalamic level. In other experiments however, it has been shown that injection of (nor-) adrenaline in the hypothalamus may in some instances decrease food intake instead (169). This contradictory phenomenon may be explained by preliminary results of experimental work done by Leibowitz (152). She suggested that suppression of feeding occurs more readily with injections into the lateral hypothalamus, in contrast to injections into the medial hypothalamus, where stimulation with (nor-) adrenaline increases feeding, a situation which is opposite to the effects seen with electrical stimulation. It is surprising that stimulation of a particular brain center would result in the same effect as its destruction. Evidently, the stimulating agent acts only on structures sensible to that agent. This will be discussed in the section dealing with the physiological approach to central control of feeding behaviour (chap. 1.1.2.) 
Several studies on (nor-) adrenergic stimulation of other brain regions like the thalamus, globus pallidus and cingulate gyrus also reported increased food intake. Injection of procaine, a local anesthetic, into the medial hypothalamus resulted in increased food intake. Conversely, anaesthetizing the lateral hypothalamus depressed feeding activity (76)

Hodontological work-up based upon the data obtained from previously described anatomical studies has added much to the understanding of pathways involved in the regulation of feeding. Knife cuts which isolate the entire hypothalamus produce hyperphagia in monkeys as is achieved by transection of fibers lateral to the ventromedical nucleus, producing less weight gain however than is caused by lesioning of the ventromedial nucleus (3). Dissections anterior to the ventromedial nucleus produced a slightly increased food intake in female rats but left males unaffected. Posterior knife cuts had no influence on feeding at all. As mentioned earlier, transsection of the ventral nor-adrenergic bundle resulted in hyperphagia. Parasagittal cuts in the hypothalamic region appeared to be particularly effective at the level of the paraventricular region $(102,217$. 241). Coronal cuts in the perifornical area also caused overeating while more rostral to the paraventricular nuclei evidently no such effect was noticed $(3,156,242)$. Knife cuts in the lateral hypothalamus inhibited feeding response similar to the effects of electrolyte lesions. The anatomic lesioning and stimulation studies roughly determined which brain areas may be involved in the regulation of feeding. but they do not provide details on the actual mechanisms.

The data are conclusive in certain aspects, i.e. that the hypothalamus plays an important role in feeding activities: the lateral part of it having a facilitating action while the medical component has a more inhibitory effect on food intake. It also appears from these data and from those obtained by comparing the effects of destruction and stimulation in hungry and satiated animals, that the ventro-medial hypothalamus is predominantly active when the animal is in a "satiated" state while the lateral hypothalamus is active in a "hunger" state. The hodontologic studies combined with data obtained from (nor-) adrenergic stimulation allowed a more precise characterisation of the function of the structures involved. It also gave to the recognition of (nor-) adrenergic systems within the hypothalamus and adjacent regions playing an important role in initiating or depressing feeding activity. 


\subsubsection{Physiological approach}

The dual center theory, based upon the reciprocal function of lateral and medial hypothalamus as proposed by Anand and Brobeck (4) has provided a fruitful basis for a great number of experimental studies on the function of these centers under physiological conditions.

It has been demonstrated that the neuronal firing rate of units localized in the ventromedial hypothalamus of starved experimental rats is slower than of units in the lateral hypothalamus. This situation was reversed after glucose was administered (6).

Olds and co-workers $(168,207)$ reported the first experiments describing self-stimulation as a method to study feeding behaviour: electrodes are implanted in specific brain areas and a bar is made available for the experimental animal in such a way that pressing this bar introduces an electrical current through the implanted electrodes.

When such stimulation by means of pressing a lever is repeated by the animal itself, the stimulus is called rewarding. When electrodes are placed in the lateral hypothalamus for two weeks and then tested, rats will depress the bar that elicits food intake. The rate of self-stimulation in the lateral hypothalamus is increased with food deprivation or insulin administration and decreased following forced feeding of glucose or glucagon administration. This demonstrated tha: plasma glucose levels could affect feeding behaviour by influencing lateral hypothalamic "reward". When the electrodes were placed such that bar-pressing resulted in simultaneous stimulation of the medial and lateral

hypothalamus, both feeding and the rate of self-stimulation decreased (124).

When the ventromedial hypothalamus was stimulated asynchronously with self-stimulation of the lateral hypothalamus, this did not cause cessation of self-stimulation. Exclusion of the ventromedial hypothalamus by way of ablation or local anaesthesia with procaine, increased lateral hypothalamic self-stimulation or restored the rate of self-stimulation of a fed animal to its pre-feeding level. These experiments showed a close relationship between feeding behaviour and motivation to self-stimulate the lateral hypothalamus. It also supports the statement that the ventromedial hypothalamus is active when the animal is "satiated" while the lateral hypothalamus acts as the 'feeding' center. As mentioned earlier, there is convincing evidence that catecholinergic pathways are involved in the hypothalamic regulation of feeding. Especially the nigrostriatal dopaminergic pathway, which originates in the substantia nigra region of the midbrain and descends through the lateral hypothalamus to innervate the striatum, appears to be involved (156). 6-Hydroxydopamine is a neurotoxic analogue of dopamine, which selectively destroys dopaminecontaining neurons. Intracerebral or intraventricular injection of this agent 
produced a state of aphagia and adipsia. Animals with these lesions however are somnolent and may eat only when vigorously aroused, suggesting that loss of consciousness may in part be associated with the aphagic syndrome (277). Also neuronal systems acting via the neurotransmitter noradrenaline currently are thought bo be involved in the hypothalamic control system of feeding behaviour (154). Apparently, there are two central catecholamine-mediated mechanisms in the hypothalamus for food control: an alpha-receptor-mediated hunger and betareceptor-mediated satiety area. This is based on the following experimental data $(154,155)$ : the injection of nor-adrenaline into the ventromedial nucleus of a fed rat enhances feeding, an effect which can be antagonized by phentolamine, an alpha-blocking agent, but remains unaffected by a beta blocker (e.g. propranolol). Thus, the ventromedial hypothalamus and more precisely the paraventricular nucleus has an alpha-adrenergic receptor. Injection of drugs such as isoproterenol into anterolateral hypothalamus of a hungry rat inhibits feeding activity. This effect can only be blocked by a beta-blocking drug (propranolol); alpha blockers are ineffective here. The catecholaminergic neuronal system belongs to the ascending reticular activating system. These catecholaminergic neurons arise from discrete cell bodies in the pons and mesencephalon, traverse the ventral diencephallon in the lateral hypothalamus and internal capsule and finally project to the limbic forebrain, basal ganglia and neocortex (253). It is a central nervous system that is known not to be restricted to feeding but also mediates components of arousal and motor function common to all voluntary behaviours and thus participates in the control of feeding activity. Normal feeding patterns have been compared with those exhibited after hypothalamic adrenergic stimulation in rats. As with the eating response induced by central adrenergic stimulation, the eating of a normal meal by rats occurs vigorously and continuously over a period of 5 to 15 minutes. The average rat takes six to ten meals a day and the size of each meal in both cases generally varies between two and three grams. Similar behaviour of drinking in relation with the meals has been noticed after adrenergic stimulation, when compared with normal rats. Similar to the drinking behaviour observed under normal conditions, water ingestion after non-adrenaline injection appeared to be positively correlated with the size of the corresponding meal. The similarities between natural and adrenergically elicited ingestive behaviour have been considered to furnish strong support for an endogenous adrenergic system to be involved in the physiologic control of food intake. The origin of the stimuli which probably may trigger this system has not been unreveled. Also, data which provide evidence for alteration of the activity of nor-adrenergic neurons in fed compared with hungry animals are lacking. 


\subsubsection{Central neurotransmitters}

It has long been noted by neuro-pharmacologists that correlations existed between the behavioural and physiologic effects of drugs and the changes these agents produce in the brain concentrations of particular neurotransmitters. They suggested that, in general, the neurons containing the transmitter affected by the drug, contribute to the brain function altered by that drug $(87,90)$.

The administration of drugs, known to stimulate or suppress central catecholamine activity, has been observed to exert effects upon food intake and appetite. This finding has been interpreted as supporting a role for catecholaminergic neurons in regulating feeding behaviour (156). Another assumption is, that the amount of neurotransmitter present within the brain, reflects the quantity which is contained within the nerve endings to be released when the neurons depolarize. Presumably, such variations in the amounts of neurotransmitters that are released will proportionally alter the quantity of information flowing across the synapses and consequently cause alterations in the net impulse traffic through brain networks containing the affected neurons. This may ultimately be reflected as changes in behavioural or physiologic brain outputs. In addition to drugs, other substances equally affect neurotransmitter concentrations in the brain. Several years ago, Wurtman and his group noticed that the neurotransmitter serotonin was synthetized at a higher rate after eating a meal rich in carbohydrates $(85,86)$. Serotonin is one of the six compounds which have a reasonably well established chance as neurotransmitters in mammalian brains (246). The others are acetylcholine, gamma aminobutyric acid, adrenaline, nor-adrenaline and dopamine (246). An even larger amount of compounds are under investigation with regard to their possible establishement as a neurotransmitter, e.g. histamine, glutamine and some other amino acids (246, $215,224)$. It should be noticed, that some consider serotonin more a neuromodulator instead to be a neurotransmitter (183), as it does not fulfill all five the criteria. It has been demonstrated by the same group, that besides carbohydrates, also protein intake and fat consumption influence serotonin-synthesis rate, mainly attributable to large fluctuations in uptake of tryptophan into the brain. Tryptophan is one of the essential amino acids which, in the brain can be rapidly converted into the neurotransmitter serotonin. A similar but less responsive relationship exists between brain tyrosine, the precursor amino acid for catecholamines or for choline, the precursor of acetylcholine. The best correlation between precursor levels and rate of neurotransmitter synthesis has been established with tyrosine and catecholamine synthesis rate. The reason for his is, that tyrosine hydroxylase which catabolyzes the rate limiting step in this reaction, responds strongly to end-product inhibition and the flux of nerve impulses 
through catecholamine neurons. This means that there exists no obvious relation between the tyrosine-catecholamine axis and a possible regulatory role in feeding behaviour, whereas such a role for the acetylcholinergic system has never been claimed in literature. The serotoninergic system, however, appears to stand as a fair candidate. Electrophysiologic and neuropharmacologic studies have not only suggested a direct effect of serotonin agonists and antagonists upon feeding behaviour, but also serotoninergic and noradrenergic neurons in the brain reciprocally inhibit one another. The role of serotonin, as suggested in these numerous studies $(18,40,48,53,95,96,107,134,135,150,203,233)$. can be summarized as follows: increased serotoninergic activity, as measured by its metabolic product 5-HIAA, causes anorexia while decreased activity appears to initiate hyperphagia. Recently, specific destruction of central serotoninergic fibres by stereotactical injections of the neurotoxin, 5.7 dihydroxy-tryptamine into the brain of rats has become a novel procedure to induce hyperphagia (234).

Intercellular transmission of neurochemical information may also be influenced by other agents. The calcium ion may constitute an important component within the neurotransmission of feeding stimuli. Increasing the concentration of calcium in the lateral cerebral ventricles from $2.5 \mathrm{mM}$ to the rather unphysiologic level of $151.2 \mathrm{mM}$ made satiated rats start eating again in the experiments carried out by Myers et al (1972) (197). while other ions e.g. magnesium or sodium had not such an effect. This action of calcium could be slightly influenced by $\alpha$ and $\beta$ adrenergic blockade. Panksepp (1974) proposed a mechanism in which catecholamines modify feeding behaviour by regulating transmembrane ionic concentrations of calcium (212). It is still not conclusive whether one or more central neurotransmitters have a key function in the regulation of food intake. As the synthesis of some neurotransmitters (i.e. serotonin, the catecholamines and to a lesser extent acetylcholine) is dependent on dietary precursors, they become potent candidates for such a function because they could link dietary intake directly to neurochemical information. Further data which support this are forthcoming.

\subsubsection{Special senses: taste}

Normal laboratory animals will maintain relatively stable body weights, even when the availability or caloric density of their diet is varied over a wide range. Increasing the palatability of the meals however, may increase food intake in these animals. This hyperphagic response may induce overt obesity, while decreasing the pleasant taste of the food offered will cause loss of the gained body weight at any time, suggesting that taste also is a determinant in feeding behaviour, involving gustatory 
and olfactory stimuli (157). In the rat, sweet taste and greasiness are qualities which greatly increase the palatability of experimental meals. The hungry rat however, reacts differently to altered palatability than satiated. freely feeding animals. The experiments of Jacobs and Sharma (1969) demonstrated that starved rats would eat more of a sweetened meal than freely feeding animals. The food deprived rats however would eat much less of food to which quinine was added than controls (130). Although the mechanism is unclear, the relation of caloric density and taste of the diet has been stated by the investigators as follows: ". . an animal eats for calories when it does not need them and eats for taste when it needs calories". Diets containing large amounts of fat are preferred to dry chow by laboratory animals both in normal rats and rats with ventromedial hypothalamus lesions. The latter group however, tended to react differently to sensory qualities of the diet. For example, food made less tasty through addition of quinine reduced food intake more than that of normal rats $(45,186,190)$.

Also Levison et al (1973) found that palatability of the diet is easier to modify in ventromedial hypothalamic lesioned animals (161). It has not been established yet in how far this effect is based upon altered taste appreciation secondary to the ventromedial hypothalamic lesion or on the laziness and finickiness which is part of the ventromedial hypothalamic lesion syndrome. The phenomenon does not occur in genetically obese rats whereas it does occur in rats of the same strain, subjected to lesioning of the ventromedial hypothalamus (38).

Taste appreciation of the diet has been shown to be dependent on plasma zinc concentrations. Mc Connell and Henkin (1974) demonstrated that zinc depleted rats could not distinguish well between the normally avoided solutions (e.g. hydrochloric acid or quinine sulfate) and water. They concluded from these observations that subsequent to the onset of zinc deficiency, these animals exhibited loss of taste acuity (178). This phenomenon has also been demonstrated in humans with L-histidine induced hypozincemia. L-histidine supposedly strips off zinc from plasma albumin, its common carrier in the plasma, thus causing zinc to appear in the urine in quantities, proportional to the administered amount of histidine (118). When zinc gradually disappears from the plasma, hypogeusia and hyposmia become more pronounced until distortion of taste and smell perception becomes evident. It is suggested in these studies that brain concentrations of zinc decrease proportionally with plasma concentrations, as zinc crosses readily the blood-brain barrier and that normal central zinc levels are essential for optimal taste and smell perception (118). Other factors evidently determine palatability of the diet as well. It is known, that omitting a single but essential amino acid from the diet is enough to make a rat refuse his meals. This animal stops eating and will even die when the missing amino acid is not administered $(29,116$, 
218). When the missing amino acid is injected into the carotid artery, food intake is restored to normal, while injection in the jugular vein has not this effect. Where exactly this amino acid deficiency is recorded has not been established yet. It seems unlikely that the ventromedial hypothalamus is involved because lesioned animals show the same hypophagic response to the withdrawal of essential amino acids (116).

Amphetamines also have an influence on taste perception and cause taste aversion. The conditioned taste aversion effect induced by repeated administration of amphetamines, suppresses food intake more than the direct pharmacologic anorectic activity of the drug (44). In humans, it is well documented that physiological factors may strongly affect the appreciation of food. Recently, this fact gave rise to the proposal of the institution of a branch of nutritional science, called "Nutrition Physiology" (Workshop Appetite and Food Intake, Berlin, December 1975). The effect of gustatory and olfactory stimuli upon appreciation of food is well established in different species. The regulating role of taste on food intake itself however, has not been demonstrated. There also is a considerable difference between species in the appreciation of palatability of a meal. This makes it difficult to determine the control mechanism, if present. There is evidence however that the plasma concentration of zinc, and (mostly) essential amino acids do influence taste appreciation in several species. Psychological factors as well may affect appetite but these factors usually do not affect food intake over a longer time.

Interestingly, Cabanac (1971) postulated that a given gustatory or olfactory stimulus can either induce a pleasant or an unpleasant sensation. depending on the subject's internal state. This phenomenon was called alliesthesia and proposed to provide adequate motivation for behaviour such as food intake (43).

\subsection{Alimentary tract factors.}

Mechanisms exist which directly involve the gastro-intestinal tract in the regulation of feeding: i.e. feeding initiating mechanisms and mechanisms that terminate feeding.

The senses: sight, taste and smell as well as temperature and propriocepsis in the oral cavity are involved in the encounter with food and they trigger many physiologic effects conductive to food intake. The stimulation of receptors within the oral cavity is essential for the initiation of swallowing (74). Positively appreciated taste stimuli result in the flow of saliva, an increase in gastric secretion and even alterations in the respiratory quotient and blood glucose $(139,200)$. Although eating for calories is well regulated, is has been shown in several species that 
separate intragastric feeding does not reduce oral intake by an equivalent amount $(26,46)$. These studies also indicated that gastric distention plays a role in terminating feeding. The ingestion of food may serve to inhibit feeding by means of distention of the gastro-intestinal tract by activating neural pathways to the central nervous system, as suggested by Carlson as early as $1912(46)$. Distention of the stomach increases the firing rate of the vagal nerve and this might be the afferent stimulus for the central nervous system as there is a concomitant increase in the unit activity in the ventromedial hypothalamus $(210,244)$. Stimulation of the lateral hypothalamus inhibited gastric motility when the stomach was alive, but increased this when the stomach was quiescent (98). Another possibility to provide signals from the gastro-intestinal tract which ultimately might stop food intake is the release of gastro-intestinal hormones secondary to food intake. Evidence for such a mechanism may be derived from the finding that cross transfusion of blood from satiated rats into food deprived rats depressed food ingestion in the latter. Flemming (1969) showed that when one rat of a parabiotic pair ate one hour before the other, the food intake of the second one was suppressed (92). Parameswaran et al (1977) stimulated the lateral hypothalamus of one rat of a parabiotic pair inducing hyperphagia in that rat while inhibiting food intake of the other animal up to a point where it stopped eating, lost weight and clearly showed aversion to food (214). These experiments suggest that a substance is transmitted from the fed or overfed rat to the food deprived partner. It has been suggested recently that cholecystokinin might be one of these humoral factors: rats which had gastric fistulas were trained to consume a liquid formula diet. If the gastric cannula were open, the ingested liquid drained out and the animals ate large amounts without stopping, however when the gastric carnula was closed, food intake dropped to normal. Injection of small, nearly physiologic dosages of cholecystokinin in animals with open fistulas inhibited food intake as would closing the fistula (97). Dafny et al (1975) noticed similar effects of cholecystokinin and also proposed the concept that a gastro-intestinal hormone released during feeding induces satiety by altering central nervous electrical activity. They furnished evidence for their suggestion by measuring the electrical activity in the ventromedial and lateral hypothalamus. Pentagastrin or secretin did not have any effect upon food intake (59). These data provide evidence for a humoral mechanism which inhibits food intake. Data on the action of other gastro-intestinal hormones are not available. A last mechanism influencing feeding directly from the gastro-intestinal tract is the signal evoked by early absorption of nutrients. After digestion, the nutrients enter the portal circulation and subsequently are directed towards the liver and the general circulation. Nutrient-dependent mechanisms influencing food intake are well studied for glucose. There is sufficient evidence that there are glucosensitive receptors at three different levels: 
1. gastro-duodenal; 2 . hepatic and 3. brain (hypothalamus). Gastroduodenal gluco-receptors have been demonstrated by Novin (1975). He found that intraluminal infusion of glucose in the duodenum depressed feeding more than when this glucose was given straight into the portal vein, an effect which is abolished by vagotomy (205). The vagal nerve also plays a major role in conducting information from the liver to the central nervous system. Niijima (1969) noted that the firing state of the vagal nerve from the liver was lower as the glucose concentration in the portal vein was increased (201). The effect of liver mediated response of glucose on food intake has been studied with glucose as well as with the glucose analogue: 2-deoxyglucose, which can be phosphorylated but cannot finish the pentose phosphate pathway. 2-Deoxyglucose competes with glucose for the hexokinase substrate and may contribute to a progressive failure of hexokinase, owing to depletion of ATP $(265,272)$. It is functionally a glucose antagonist. Russek (1970) demonstrated that glucosensitive mechanisms were involved in the effect of glucose upon food intake (232), while Novin et al (1973) found that the injection of 2-deoxyglucose into the portal vein of rabbits produced the onset of feeding more rapidly than if injected into a peripheral vein. This effect was significantly delayed when the vagal nerves were transsected (204). Although neuronal information from peripheral glucosensitive areas ultimately is carried to the central nervous system by route of the vagal nerves, there are several threads of evidence for the presence of glucosensitive centers in the hypothalamus itself (177). Hypothalamic glucoreceptors have an increased firing rate after putting glucose directly onto hypothalamic neurons (209) or after injecting glucose into the carotid artery (172). Balagura (1970) (16) demonstrated that 2-deoxyglucose depresses food intake when given into the ventro-medial hypothalamus, whereas glucose in the same nucleus increased food intake. He also found that the administration of 2-deoxy glucose via cannulae into the lateral hypothalamus significantly increased food intake. Implanting glucose into this nucleus also increased feeding, but to a lesser extent as 2-deoxyglucose. Balagura hypothesized that, at least in the lateral hypothalamic area there are two functionally different types of cells. One type is part of a neural system in charge of controlling eating behaviour (effector) and another type is composed of glucosensitive cells (receptor). The receptor cells modulate the activity of the effector cells. Oomura however demonstrated the presence of glucosensitive neurons in the lateral hypothalamus and insulin-sensitive areas in the medial hypothalamus (209). The stimulation of receptors in the oral cavity is important for the initiation of feeding. Is seems unlikely, that a major regulatory function is primarily carried out by altering initiating stimuli. There are four mechanisms which can terminate feeding, i.e. gastric distention by food, the release of gastro-intestinal hormones as a consequence of eating, signals evoked during early absorption of food. 
mediated by either peripheral or central gluco-receptors and appreciation changes of taste and smell caused by state changes of the body (43). A direct influence upon feeding behaviour exerted by nutrients has been suggested for amino acids $(184,185)$ and body lipids (141). These findings have resulted in a series of theories on the control of body calories by means of peripheral signals, which will be discussed later.

\subsection{Hormonal systems}

As intermediators between central and peripheral factors, the hormonal regulation of food intake deserves some attention. The stimulating effect of insulin upon feeding activity has been established, but other hormones have also been reported to influence food intake. Even hormones, which do not have a primary metabolic function can have an impact on appetite. Injection of small quantities of insulin causes a short lasting increase of food intake, while prolonged administration causes hyperphagia and weight gain $(108,125)$. Insulin may act through peripheral hypoglycemia or through an effect on the central nervous system.

A glucose preload of the lateral hypothalamus inhibits the increased food intake which usually results from injections of insulin, suggesting an indirect role for insulin (36). Recently, brain receptors for insulin have been documented (209). When glucagon is injected, an effect which is opposite to that of insulin is obtained, i.e. hypophagia $(128,220)$.

The role of gonadal hormones in the control of feeding has been subject of numerous studies in experimental animals. The rat normally has four to five days between estrous cycles. On the day of estrous the animals shows increased running, decreased food intake and loss of body weight. In the nonestrus phase of the cycle, food intake and body weight rise again (260). Castration abolishes this cyclic pattern of food intake. The administration of estrogen or estrogen - like compounds results in a depression of food intake (256). The site of action of estrogen with respect to feeding behaviour is not fully established. When estradiol is implanted in the ventromedial nucleus of female rats, this will significantly reduce food intake (267). However, the same effect is seen when estradiol is administered to hyperhagic hypothalamic ventromedial nucleus - lesioned female rats. Since male rats, which do not have a substantial cyclic variation in food intake, and female animals respond differently, it has been suggested that estrogens act both on the ventromedial nucleus and on the anterior and lateral hypothalamus as well. In man, estrogens are known to affect appetite causing nausea and vomiting probably secondary to the derangement of sodium - water balance. Human chorionic gonadotrophin has been reported to influence feeding behaviour (9). Injection of this hormone has been claimed to decrease food intake without causing hunger or decreasing the feeling of well-being, and 
therefore, this procedure has been proposed as a mode of treatment for obesity (3). However, the efficacy of human chorionic gonadotrophin in decreasing food intake, has been challenged by others (123).

Growth hormone is another hormone which may be involved in the regulation of food intake. Administration of growth hormone is followed by an increased food intake and longitudinal growth of both human and experimental animals. Ablative procedures resulting in low concentrations of growth hormone usually result in decreased food intake and the cessation of growth (142). At present, the mechanism responsible for the decreased appetite in the absense of growth hormone is still unknown. In summary, insulin induces hyperphagia while glucagon exerts the contrary effects which both seem to be secondary to alterations in intermediary metabolism. The effects of gonadal hormones seem to be more complex and less consistent.

\subsection{Control mechanisms based on homeostasis}

A number of hypotheses have been advanced to account for the control of food intake and body calories. These include thermostatic, glucostatic, lipostatic, osmostatic, and aminostatic regulatory systems, which will be summarized next.

\subsubsection{Thermostatic control}

This mode of regulation of food intake has been proposed by Strominger and Brobeck (254). They suggested that heat production due to the specific dynamic action of food modulate daily food intake. This concept is supported by the observation that homeothermic animals eat more in cold than in hot environments. The control center for body temperature is located in the preoptic area of the anterior hypothalamus. Destruction of this area caused loss of temperature control and the animals lost adequate responsiveness to the thermic effects of food: overeating in the heat and undereating in the cold (113).

However, when local heat was applied to this hypothalamic area, food intake increased, and conversely, cooling this area induced hypophagia (248). These data are surprising as one would expect the reverse to happen. Moreover, different types of reactions to such stimuli between species have been reported (7).

Although not fully established, it seems that environmental temperature somehow affects feeding behaviour. It remains to be examined whether temperature influences feeding to preserve body temperature. 


\subsubsection{Glucostatic control}

The central nervous system is known to depend largely on glucose for its metabolic needs, yet its capacity to store glucose is negligible. Therefore, the brain is dependent on glucose supply by the blood. To guarantee a glucose supply to the brain, several control mechanisms are believed to be involved like a minimal production of 150 grams of glucose a day by the liver, thus providing the brain with $2580 \mathrm{~kJ}$ oule $/ 24 \mathrm{hrs}$. which actually represents the basal energy need of the central nervous system (161). Control of nutritional intake of glucose could be another way to achieve this purpose. In the brain, glucosensitive areas have been reported 1209 . 177). The ventromedial hypothalamic nucleus, however, seemed to be more responsive to changes in the rate of glucose utilization rather than the absolute levels of glucose in the blood (176). This has been determinated in both physiologic and pathologic conditions.

Steffens (1959) noticed that plasma insulin levels dropped just before the onset of a meal. Such a dropping insulin level supposedly is associated with a decreased glucose utilization and thus initiates eating, according to the glucostatic theory (250). A decreased utilization of glucose has been suggested to cause hyperphagia in diabetes mellitus despite the

hyperglycemia. Hyperglycemia, subsequent to the injection of glucose as well as secondary to diabetes causes a reduction of gold-thioglucose deposition in the ventromedial nucleus of the hypothalamus, where gold concentrations normally are highest after injection of gold-thioglucose $(60)$. Injection of other gold containing compound does not produce accumulation in the ventromedial hypothalamic nucleus, suggesting that glucose was the carrier to that area and that the cells of that nucleus can transport glucose $(60,61)$.

Blocking this transport with phloridzin injections in the ventromedial hypothalamus resulted in increased food intake (99). This suggests the need of glucose to be utilized in order to become detected. Quaade (1962) reports a modest correlation between capillary venous glucose differences and feelings of hunger (230). Conventionally infusion of glucose into hungry individuals is known to reduce the "feeling of hunger", a phenomenon described by Stunkard and Wolff (1956) and seen in everyday's clinical life, e.g. during parenteral nutrition (255). Steffens (1959) noticed, that plasma insulin levels dropped just before the onset of a meal. Such a dropping insulin level supposedly is associated with a decreased glucose utilization and thus initiate eating, according to the glucostatic theory (250). Other studies however challenge the statement that decreased glucose utilization is a critical feeding stimulus (252). 
Thus, the hypothalamus contains cells which can accumulate glucose readily and may be sensitive to insulin. These cells may function in the control of stored calories in the body, a statement which has recently been stressed by Rothwell (1978). She noticed that when a "nibbling" animal, such as the rat, is forced to consume the largest part of its daily intake in a few smaller meals, the total energy intake of these animals will be the same as in freely feeding rats, yet the forced-fed group will become obese (231). Although leaving us with a paradox, these findings bear some weight upon, among others, the theory of glucostatic control of food intake.

\subsubsection{Lipostatic control}

The lipostatic theory, as proposed by Kennedy, includes the suggestion that some metabolite of fat controls the body's fat stores (141). This hypothesis has been based upon studies in rats with injuries of the ventromedial hypothalamic nuclei. When these animals were allowed to overeat, they became obese, and when underfed, they became lean but when put on a free diet again, these animals did not become obese again but returned to their pre-experiment weight. This suggested a suppressable effect of hypothalamic lesioning.

The main metabolites released from adipose tissue are free fatty acids, glycerol and, to a minor extent, prostaglandins. Each of these metabolic products may evoke a control signal as its concentration in the blood changes. Free fatty acids are not generally considered to exert such a control function as the plasma levels show rapid alterations during the day but some authors claim, that the hypothalamus is sensitive to free fatty acid stimuli (208).

Glycerol, which is released from adipose tissue during hydrolysis of triglycerides, has to be transported to the liver in order to be converted to glucose because adipose tissue lacks glycerol-kinase, a key enzyme for the gluconeogenesis from glycerol. Therefore, the amount of glycerol which is released into the blood stream is proportional to the rate of hydrolysis of triglycerides and may perform a control function in lipolysis. The hypothalamus metabolizes glycerol more readily than do other parts of the brain although the permeability of the blood-brain barrier for glycerol is not different in the species investigated (105). Glycerol sensitive areas in the hypothalamus thus might exert a control function directly related glycerol concentration in the circulation. By increasing food intake when glycerol levels are relatively high, the total amount of body fat hardly gets a chance to decrease thus serving a lipostatic mechanism. However. as glycerol is transformed into glucose directly, this glucose might as well 
provide a signal to glucoreceptive systems so that we are basically dealing with a glucose-dependent system instead of a lipostatic one. Le Magnen (1973) introduced the gluco-lipostatic theory with this pathyway in mind, but also by its reverse: - glucose is converted into fat as soon as glucose intake outnumbers glucose consumption, during glucolysis or glycogenstorage (158). The filling of fat stores up to a certain level using glucose might seve lipid homeostasis.

Prostaglandins are metabolic products of arachidonic acid. It has been demonstrated by Martin et al (1973) that when one of the prostaglandins (11 $\alpha$, 15-dihydroxy-9-keto-prosta $(5-13)$ dienoic acid $=$ PGE) is injected into the hypothalamus of sheep, food intake decreased.

Whether this mechanism works under physiological conditions or ot has not been determined. Data on prostaglandin levels in the hypothalamic area during different metabolic circumstances are not available (174). Another approach to the lipostatic theory has been advenced by Hervey (1973) in which signal substances, dissolved in or produced by fat, are sensed by cerebral centers (119). As more fat is stored, the amount of circulating substance decreases. This fall in concentrations of physialogical tracer has been proprosed to decrease feeding activity. Some steroids have been advanced to act as a signal substance. It is known that e.g. progesterone increases fat deposition. This hormone has also a key position in steroid metabolism and has therefore been considered important in this context. Further data to support the theory are mandatory.

Thus, the lipostatic theory involves different aspects of fat metabolism and basically suggests that either metabolites of fat (free fatty acids, glycerol and prostaglandins) may regulate fat storage, or fat-dissolved and fatproduced substances may be detected by brain centers. Steroid hormones like progesterone may fulfill this role.

\subsubsection{Osmotic control}

Temporary withdrawal of water from various tissues and consequently the dehydration of these tissues which has been proposed to occur after a meal has been considered a cause for satiety and cessation of eating (114). There is substantial evidence however, that osmotic conditions are not significantly aitered, yet feeding activity fluctuates significantly. The control of food intake via osmostatic mechanisms alone therefore appears unlikely (43). 


\subsubsection{Aminostatic control}

A direct correlation between daily protein intake and daily total caloric intake has been demonstrated by Dole et al. as early as 1953 (72). Later, Mellinkoff (1956) observed an inverse relationship between levels of amino acids and food intake, suggesting that these nutrients might be important in regulating feeding behaviour: a rise in serum amino acids resulted in weaning of appetite while decreased levels stimulated appetite. He also observed, that appetite seemed more related to amino acid levels than to the blood glucose level (184). He subsequently concluded, that not only the total serum amino acid concentration but also the pattern of amino acids in plasma and extra-cellular fluids are important signals for food intake control (185). Experimental animals will reduce their food intake when their diet is low or devoid of a single amino acid, or when there is excess of one amino acid. This is especially true if one essential amino acid is missing in the diet $(116,29,218)$. Feeding imbalanced amino acid mixtures to experimental animals results in reduced food intake and negative nitrogen balance; these effects are supposedly secondary to relative deficiency as well as relative toxicity (235). When for example isoleucine was omitted from the diet, food intake of laboratory rats decreased to 75 per cent the first day. The plasma levels of amino acids tended to rise except for the deficient one, which fell (219). As $93 \%$ of amino acids are bound in protein in a fixed precoded manner, shortage of one amino acid may lead to a decreased protein synthesis. A diet lacking one essential amino acid may cause accumulation of all other amino acids. This hyperaminoacidemia is common in several metabolic disorders like hepatic insufficiency, renal failure, conditions which are associated with anorexia (P.B. Soeters, personal communication). Animals also eat different amounts of two diets, depending on their amino acid concentration, hence it appears, that some mechanisms exist whereby the amino acid or protein content of the diet can be detected. Although decreased palatability of the diet when manipulated to alter amino acid content might play an important role in the decline of appetite, there are sufficient data to offer strong support for a possible aminostatic control mechanism. Of special interest in this context is the finding of Ziparo et al (1979) that diets containing only branched-chain amino acids are readily consumed by experimental rats, at least in short time experiments (286). Although speculative, it is tempting to suggest that the brain does not recognize any "shortage" as this organ can metabolize branched-chain amino acids as readily as it does glucose or ketone bodies. Brain mechanisms seem to mediate changes in feeding behaviour when animals are offered amino acid - imbalanced diets, except for the branched-chain amino acid diet, although data on long-term feeding with this diet are not 
available yet. Interestingly food intake in rats consuming diets containing deficient amounts of threonine or isoleucine, declined. Infusion of this amino acid in the carotid artery restored a normal feeding pattern, while infusion of this amino acid in the jugular vein did not (159).

The receptor system for detecting the deficiency of the amino acid is still ill defined, but appears to be situated in the ventromedial hypothalamic area, but also other areas do react upon amino acid imbalances e.g. medial septum, prepyriform cortical areas and lateral hypothalamus. When balanced amino acid solutions are injected directly into the lateral hypothalamic area, food intake is inhibited in hungry rats $(211,281)$. suggesting the presence of aminostatic sensors in this area. It became suggestive on the basis of these data that specific brain regions might contain aminostatic control systems for feeding that are sensitive to some. but not all diet-induced changes in plasma amino acid patterns. Of the brain regions examined thus far, however, no single area appears to have the capability of mediating all aminostatic responses. Moreover, aminostatic responses may still be overruled by other metabolic needs. The depression of food intake when the diet is deficient in one amino acid returns to normal when the animals are exposed to cold. Under these conditions, the animal increases its total diet and metabolizes the excess amino acids to provide heat (19). Another example is that although food consumption decreases when animals are first offered a high-protein diet, the daily food intake and growth rate return to near-normal levels within a few days. The adjustment to these dietary imbalances appears to correlate in time with several biochemical adaptive changes like altered activity and concentration of amino acid degradative enzymes. With these data in mind, it is suggestive that aminostatic mechanisms would become dominant only when the experimental animals are restricted to protein or amino acid imbalanced diets since most adult animals usually have sufficient access to a diet that contains balanced mixtures of proteins and amino acids. However, it is possible that diet-induced changes in plasma amino acids may directly intervene in functional activity of brain areas that mediate or initiate feeding activity. This reverts to the suggestion as proposed earlier in this chapter by Fernstrom an Wurtman and his group $(84,86,88,89,90,279,280)$ that diet-induced changes in plasma amino acids alter the concentration of putative brain neurotransmitters. The brain neurotransmitter serotonin is involved in the neuro-physiological control of feeding behaviour. Also from a dietary point of view, this neurotransmitter may play a key role as its synthesis in the brain depends on an adequate concentration of its precursor amino acid tryptophan. In mammals, tryptophan is an essential amino acid, hence its body concentration ultimately depends upon the presence of an adequate dietary concentration of tryptophan. It has been demonstrated that dietary intake of tryptophan correlated fairly well with brain serotonin concen- 
trations $(191,281)$. However, brain serotonin levels correlated best with brain tryptophan concentration, which is controlled by mechanisms involving blood-brain barrier properties, and plasma conditions responsible for the amount of free circulating tryptophan. It is of special interest, that these mechanisms may be individually influenced by the other keystones of the diet, carbohydrates and fats, thus subjecting the tryptophan-serotonin axis to dietary as well as metabolic influences: As will be shown later, these phenomena interact in a way, representing a highly sophisticated control mechanism for feeding behaviour. This can be summarized as follows, that the quality of the diet alters the plasma amino acid pattern and thus the amount of tryptophan available for transport through the blood-brain barrier, which then changes brain serotonin turnover; the changes in brain serotoninergic neurons then feed - forward subsequent feeding behaviour.

The aminostatic theory has been built upon early observations of appetite being correlated with plasma amino acid concentrations. This correlation however, was not always consistent. Only recently, a possible explanation emerged from data. suggesting that plasma amino acid profiles rather than actual concentrations were correlated to food intake. Plasma amino acid profiles are, among other factors, important determinants for brain levels of certain amino acids. Some amino acids seem to be detected by receptive brain centers. Plasma amino acid patterns are also highly dependant on the diet, thus linking dietary intake to perception of nutritional status. The mechanisms for control of feeding behaviour listed and briefly discussed in this chapter, are mainly studied in experimental animals. Whether these systems also function in humans has not been fully established yet because detailed studies on this process in man are small in number, compared with those reviewed above. However, it appears that at least the neuro-anatomical structures involved in the control of food intake and neuro-pharmacological reactions to manipulation of the serotoninergic system appear to be the same in man $(18,39$. 203). 


\section{Chapter 2}

\section{The impact of cancer on feeding control}

Anorexia is a common symptom in cancer and contributes to a large extent to the cachectic state which so many cancer patients exhibit. Many hypotheses have been advanced to explain the inappropriately low food intake of these patients and although significant progress has been made in our understanding of the genesis of hunger and satiety as reviewed in chapter 1 , the signals that initiate and the mechanisms that control food intake not been fully elucidated. This review of theories concerning the control of hunger and satiety might serve as a basis for the discussion of the potential abnormalities of the control mechanisms of food intake in the cancer patient.

\subsection{Central control sytem}

Theoretically lesioning of hypothalamic areas known to affect feeding behaviour by primary or metastatic tumors should have concomitant effects on appetite, although no such observations have been reported in literature. Hyperphagia or hypophagia does occur as a part of brain tumor syndromes but probably extremely seldom in its isolated form. A dysfunction of brain centers as the cause of anorexia in cancer has not been detected. Baillie (1965) reported that when a Walker-256 tumor was transplanted into rats, which were previously rendered hyperphagic by distruction of the ventromedial hypothalamus, the food intake started to decline 15 days after the transplantation and eventually reached very low levels. From this, it seems unlikely that the decreased voluntary food intake in the intact tumor bearing host is mediated only via the ventromedial hypothalamus (15).

The derangement in central neurotransmission has not been investigated previously. Therefore, data on this aspect will be presented and discussed fully in the remaining chapters of this thesis. Instead, gustatory and olfactory senses received a great deal of attention in cancer anorexia. Recent studies in cancer patients have delineated changes in taste sensation and smell sensation which would result in blunting of the normal excitatory stimuli for food intake. De Wijs noticed an altered taste sensation for sucrose and urea in cancer patients. In his studies, there seemed to be a correlation between the taste anomaly and the extent of malignant disease $(66,67,68)$. Williams $(1978)$ reported changes in taste threshold for sour, not for bitter, sweet nor salt (273). Other investigators reported altered gustatory appreciation of food in cancer bearing subjects, but there is a lack of consistency and apparently taste alteration is rather 
unspecific. Decreased taste sensation was always associated with loss of appetite and it remains doubtful whether loss of taste perception is only a concomitant effect of decreased appetite (or satiety) in general or actually the cause of a decrease in appetite. Studies, which discriminate between these alternatives, are still lacking.

\subsection{Alimentary tract factors}

Local infiltration or extended growth of malignant tissues in the upper gastro-intestinal tract will influence food intake merely because of subnausea or "early fullness" secondary to anatomical obstruction. Effects exerted by a distant tumor upon the alimentary tract do exist however. It has been postulated that toxic polypeptides released by the tumor induce significant mitotic depression of gastro-intestinal mucosal cells, thus causing anorexia, but experimental evidence for this hypothesis has not
been presented (257).

\subsection{Hormonal systems}

Neoplasms of various endocrine glands give rise to arrays of biochemical effects which are appropriately related to the hormones secreted by these glands. In addition, during the last two decades substantial information has been collected showing that conventional hormones may be produced by neoplasms arising from a variety of non-endrocrine tissues, conditions which have been termed "ectopic humoral synuromes" or paraneoplastic syndromes. Current evidence indicates that tumors may produce any of the following different ectopic hormones: adrenocorticotropic hormone (A.C.T.H.), melanocyte stimulating hormone, parathyroid hormone, leuteinizing hormone, follicle stimulating hormone, antidiuretic hormone. human chorionic gonadotrophin, chorionic somatomammotropin, gastrin, VIP, erythropoetin, a thyroid stimulating factor, insulin, glucagon and numerous hormone-like polypeptides. As mentioned in the previous chapter under 1.2., some hormones do influence appetite. Glucagon, estrogen, human chorionic gonadotrophin have been reported to decrease food intake. The systemic influences of the high levels of these hormones in the serum of patients suffering from such an endocrine or paraneoplastic tumor may however degrade the assoclated hypophagia to a minor symptom. On the other hand, it has been repeatedly observed in cancer
patients and tumor bearing animals, that the production of A.C.T.H. and
adrenal corticosteroids is increased

adrenal corticosteroids is increased $(20,21,22,55)$.
Since these hormones induced hyperphagia rather than hypophagia, it
seems unlikely that these hormones will be responsible for the and seems unlikely that these hormones will be responsible for the anorexia in cancer conditions, although they change at any rate the state of the
organism and could cause alliesthesia (43). 


\subsection{Mechanisms based upon homeostasis}

\subsubsection{Thermostatic control}

According to the suggestion advanced by Strominger et al (1953), that the specific dynamic action of food controls daily food intake one would expect tumor bearing organisms to increase their food intake as the tumorbearing host exhibits an increased energy requirement secondary to an increased expenditure $(82,269)$.

In vitro experiments have shown that substances, present in serum of sarcoma bearing rats or extracted from tumor tissues are able to uncouple oxidative phosphorylation of normal liver mitochondria $(64,198)$. There is no evidence, however, of an in vivo alteration in the coupling mechanism of the tumor bearing host. If uncoupling with its resultant increased heat liberation would occur, this could explain the decreased voluntary food intake in cancer according to the thermostatic control hypothesis. Anorectic tumor bearing rats will temporarily increase food intake when placed in a cold room but subsequently anorexia will reappear (251). This signifies that the mechanism for heat homeostasis is basically preserved in tumor bearing rats but that mechanisms causing anorexia in these animals overrule thermostasis.

\subsubsection{Glucostatic control}

Altered carbohydrate metabolism in cancer has been reported repeatedly since the initial observation of Freund (1885). This alteration is reflected in a decreased glucose tolerance and in elevated concentrations of fasting blood glucose. Decreased glucose tolerance or "diabetic" glucose tolerance tests have been noted in $37 \%$ of one series of 628 patients with all types of cancer (100). in $62 \%$ of 31 hospitalized cancer patients (271) and $56 \%$ of 75 patients with endometrial carcinoma (24).

The decreased glucose tolerance in patients with cancer has been subject to some study. Levine et al (1970) have reviewed carbohydrate homeostatic mechanisms normally operative (160). The secretion of insulin is increased in response to the presence of glucose in the duodenum or to the occurrence of an elevated blood sugar. The stimulus evoked by the presence of duodenal glucose appears to be mediated via a local "hormone" probably G.I.P. in the duodenum which, in turn, may stimulate release of insulin from the pancreas. The elevated blood glucose is a more direct stimulus. Insulin is likely to be located in two pools in a compartment of the beta cell, one of which releases the insulin rapidly and a second pool in which slower, but continous release, is coupled with synthesis. Decreased glucose tolerance may reflect either diminished secretion of, or a diminished responsiveness to, endogenous insulin, due 
for instance to increased levels of counter regulatory hormones (e.g. glucagon, secretin, VIP). Such endogenous responses may be determined by the measurement of insulin in serum, but sensitive techniques for such determination have been available only since the early $1960^{\prime}$ s and no insulin measurements were performed in cancer patients who were tested with oral or intravenous glucose loads. However, earlier studies with exogenous insulin intravenously administered at a dose of $0.1 \mathrm{unit} / \mathrm{kg}$ body weight 75 minutes after intravenous glucose administration showed that the rate of decline in blood glucose concentration was slower in patients with neoplastic disease than in normal individuals (170). Basal glucose kinetics cannot however be determined reliably from intravenous glucose tolerance tests (276). Altered glucose tolerance has also been reported in other serious diseases and, as Brennan (1977) stated, there is quite a resemblance in altered carbohydrate metabolism of cancer patients and patients with severe trauma or sepsis (14). So, the "diabetic" glucose curve in cancer patients might, as in sepsis, be secondary to the increased, insuppressible hepatic gluconeogenesis and altered peripheral glucose utilization (i.e. changed rate of glucose extraction from plasma and changed metabolic fate of glucose in the tissues) (275). This implies that actual measurement of insulin levels may not provide conclusive information concerning the fact that blood glucose levels are slightly higher in cancer patients. According to the hypothesis of glucostatic control, these higher glucose concentrations secondary to an increased endogenous production might suppress food intake. If, however, the increased blood glucose levels were due to defective clearance of glucose from the blood as a consequence of decreased insulin availability or responsiveness, like for instance in subclinical diabetes, one would expect an increased appetite, as in diabetes mellitus. Higher insulin, however, enhances TRP entry into the brain which is of importance for the present research $(62,165,182)$.

\subsubsection{Lipostatic control}

As stated in the previous chapter, the principal metabolites released from adipose tissue are free fatty acids, and glycerol, with prostaglandins representing quantitatively a minor product. Free fatty acids have not been considered suitable to fulfill a regulatory function in food intake because of frequent changes in circulating concentrations during the day and their response to variations in metabolic state. One of the conclusions of this thesis is, that free fatty acid concentrations in the plasma may be important in a mechanism of anorexia in cancer. Besides this, glycerol and also prostaglandins may be involved, but data on the levels and fate in malignant disease are not yet available. A thorough study on plasma lipid components was carried out by Müller et al (1961). In 30 normal subjects, 
the mean value for the concentration of these components was $0.35 \pm$ 0.12 (SD) $\mathrm{mEq} / \mathrm{liter}$ as compared with a value of $0.58 \pm 0.30(\mathrm{SD}) \mathrm{mEq} / \mathrm{liter}$ for a group of 41 patients with cancer in various stages of the disease (195). Rapid turn-over of free fatty acids, which is relatively uninfluenced by previous diet, has also been reported by Waterhouse et al (1964) as being a typical phenomenon in malignant disease (270). The level of free fatty acids in the serum is one the determinants of free tryptophan concentrations in the blood. Therefore, the role of FFA will be dealt with in the chapters on the specific role of tryptophan in the control hypothesis which is the subject of this thesis. Neoplasms can synthetize steroids (106, 245). According to Hervey (119), steroids may behave as physiological tracers serving as a measure for the amount of total body fat, using a method similar to the dilution principle. The steroids which usually are mentioned with respect to appetite control (e.g. progesterone), are not regular products of neoplastic tissues. Whether other steroids, synthetized by the tumor, influence the regulation of food intake remains speculative.

\subsubsection{Osmotic control}

The control of food intake by way of osmostatic mechanisms is still dubious and, as stated in the previous chapter, awaits further investigation. According to the hypothesis, dehydration of tissues subsequent to food intake, causes satiety. In cancer, the water content of various tissues of the tumor bearing host is significantly increased (239). One would therefore expect weaker satiety signals to originate from the overhydrated tissue and increased appetite to occur in patients with cancer.

\subsubsection{Aminostatic control}

Mellinkoff (1956) was the first to postulate a reciprocal relationship between serum amino acid concentrations and appetite (184). In more recent literature, this observation received more support, since Fernstrom suggested that diet-induced changes in plasma amino acids alter the concentration of brain neurotransmitters $(90)$. It has been suggested in the pervious chapter that the brain neurotransmitter, serotonin, is involved in neurophysiological control of feeding behaviour and that the synthesis of this neurotransmitter in the brain ultimately depends upon the availability of its precursor amino acid tryptophan. Brain levels of tryptophan in turn depend on plasma concentrations of free tryptophan, but also on plasma concentrations of amino acids which compete with tryptophan for transport across the blood-brain barrier. In tumor-bearing animals, plasma concentrations of amino nitrogen and of various amino acids were altered 
(51, 148). This has also been reported in patients with various types of malignant disease $(37,281)$. The alterations of the free amino acid patterns in the blood and tissues of tumor bearing organisms are most likely primary effects of cancer and only in part secondary to malnutrition (147, 148).

The abnormalities of the plasma amino acid patterns and their consequences for metabolism and synthesis of brain neurotransmitters may be major contributory factors to anorexia in cancer.

\subsection{Other hypotheses on anorexia in cancer}

Mider (1954) demonstrated that the inclusion of Iyophilized Walker-256 carcinomas in the diet of the tumor-bearing rat resulted in an improvement of appetite, a resumption of eating and weight gain. He postulated, that the tumor might have an excessive demand for a certain substance, thus causing a deficit of this substance for the host, and that this deficit induces anorexia (188).

Similar observations have been reported by Millar (1957) with other experimental tumors (189). Chemical analysis of malignant tissues has not shown any unusual concentration of specific nutrients in the tumor, while metabolic studies have not clearly demonstrated any excessive utilization of any particular substance, except giucose and possibly tryptophan (148, 262). Substances causing anorexia, which presumably were produced by the tumor itself, have been isolated from the urine of patients with cancer. Convincing evidence for such a simple cause for tumor-anorexia however has never been presented (49).

In order to explain the pathogenesis of anorexia and cachexia in the patient with cancer. Theologides introduced the following hypothesis $(261,262,263,264)$. The activity of various enzymes can be modified by different kinds of small molecules such as peptides and nucleotides. The tumor produces these metabolites as a result of the depression of several genomes. These metabolites may induce allosteric activation or inactivation of various enzymes of the host, resulting in alterations in the metabolic patterns of the host and changes in metabolic balance. Theologides postulates, that the malignant tumor creates a metabolic chaos: biochemical reactions are inactivated or activated needlessly and randomly. Metabolites, released as a consequence of such reactions, enter metabolic pathways of the host, and are trapped by the tumor, which is geared mainly to growth. As the tumor has limited its biochemical reactions mainly to those essential for multiplication, it is less vulnerable 
and less affected by the small molecules it produces. Subsequently, it is proposed by Theologides, that such alterations in metabolic patterns, equilibria and concentrations of various metabolites in the tissues and the blood of the tumor bearing host are responsible for the generation of signals and messages which reach the brain and may be interpreted as representing a physiologic state of satiety. Suppression of food intake then even occurs in the presence of an increased energy expenditure because of the derangement of normal metabolic balance, thus causing cachexia. 


\section{PART II:}

The experiments 


\section{Chapter 3}

\section{Plasma and brain amino acids in Walker 256 carcinoma bearing rats.}

\subsection{Introduction}

After reviewing literature concerning control mechanisms of feeding and the possible derangement of these systems by a malignant tumor, we opted for an aminostatic or amino acid dependent system.

This is because it was felt, that such a system linked the intake of nutrients to the synthesis of brain neurotransmitters, which ultimately can influence feeding behaviour, as suggested from recent neuro-pharmacologic and neuro-physiologic studies. The following study was performed to investigate plasma and brain amino acids in tumor bearing animals for two reasons. First, to obtain data on brain levels of precursors of brain neurotransmitters and how they are related to the plasma concentrations; secondly, to obtain an impression about the impact of the malignant growth on the amino acid pattern in plasma and brain of experimental animals carrying a tumor burden.

There is considerable evidence that protein metabolism is altered in growing malignant tissue, in that both the rate and pattern of protein synthesis are different in tumor cells $(11,52,104,180,264,268)$.

Synthesis of structural proteins is increased while the capacity to produce specialized proteins is often impaired or entirely lost. Host protein synthesis is aiso influenced by the tumor. Higher rates of tumor protein synthesis demand increased quantities of amino acids for incorporation into protein, the major part of which is supplied by the free plasma amino acid pool. The content of the plasma free amino acid pool is determined by the balance between dietary intake, protein synthesis, protein degradation and intermediary metabolism within the liver, muscle, kidney and perhaps fat.

It is believed that amino acids from tumor protein breakdown may also be used as precursors for the synthesis of new protein in tumor cells. Tumor cells have the ability to concentrate amino acids from the plasma amino acid pool in a more efficient way than normal cells thus enabling them to compete succesfully with the tissues of their host for available amino acids (104). During periods of reduced dietary intake, resulting from anorexia, this competition may lead to depletion of the host. A similair type of competition exists in the metabolism of carbohydrates and fat, so that a rapidly growing malignant neoplasm may induce in the host a state of combined nitrogen and energy deficiency similar to that seen in malnutrition. When such quantitative changes in free plasma amino acids are superimposed upon tumor related qualitative derangements of the normal plasma amino acid profile, the resulting amino acid pattern of the 
plasma in malignant disease may be expected to differ from that of malnutrition alone.

Reports of plasma amino acid patterns in tumor bearing humans and animals are largely anecdotal and do not usually include complete amino acid profiles. Furthermore, adequate control suffering from malnutrition alone have not usually been included $(10,80,140,173,199,229,237$, $274,278,285)$.

in this study, we report experiments in which tumor bearing rats have been compared not only with normal rats, but also animals without tumors, but with the same degree of malnutrition as the tumor bearing group, a situation achieved by careful pair-feeding.

This experimental design was deliberately chosen to distinguish the effect of the tumor upon amino acid pattern from the effect of malnutrition alone. In addition to studying plasma amino acid profiles, we have measured the concentration of amino acids within the brain. This aspect, which has not been studies before, was included because of recent suggestions that changes in brain amino acid concentrations might influence feeding behaviour by way of altered neurotransmitter synthesis $(88,90,147,282)$.

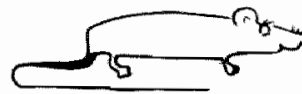

+ SHAM
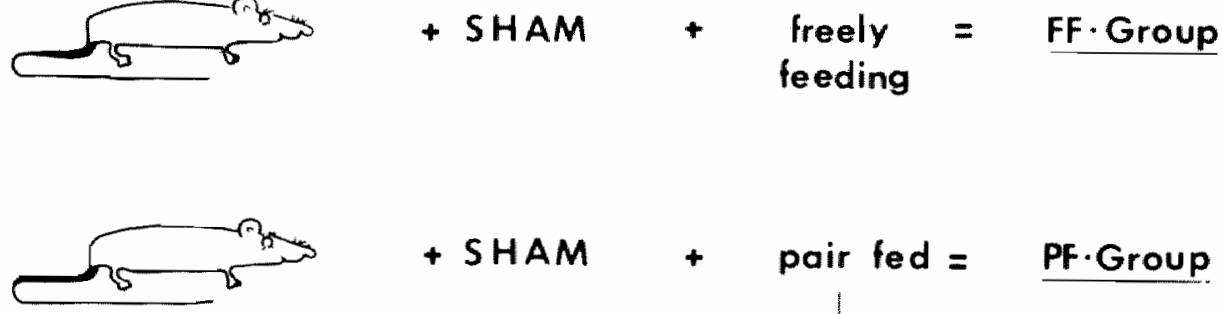

+ SHAM

$+\quad$ pair fed $=$

PF. Group

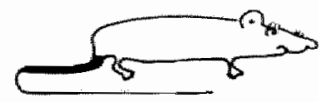

+ TUMOR

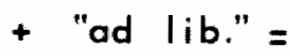

TB.Group

Legend to figure 1:

Scheme of groups of experimental rats as used in all experiments mentioned in chapter 3, 4 and 5 . 
3.2. Materials and methods (figure 1).

Young fémale Sprague-Dawley rats (80-100 g) were kept individually in wire-bottom cages at $20^{\circ}$ C. A 12 hour dark-light schedule was maintained. After determining baseline values for daily food intake and growth for three consecutive days, groups of six animals were injected with $10^{6}$ Walker-256 carcinoma cells in the right thigh and permitted free access to rat chow (Purina Lab Chow) and water (TB: tumor bearing group). Two control groups of the same strain, sex and weight were injected with saline: one group (FF: freely feeding) was fed ad libitum while another group (PF: pair-fed) received only the amount of diet consumed the previous day by its pared TB rat, each animal in the PF group being carefully matched for weight and age with a TB rat. Food intake and body weight was estimated every day at the same hour. Ten days after injection, when food intake of TB rats had fallen significantly behind that of FF rats for several days (table 1) all rats were stunned and decapitated. Blood was collected from the cervical wound into chilled, herparinized beakers and plasma separated by centrifugation at $4^{\circ} \mathrm{C}$.

Brains were rapidly removed and frozen on dry ice, and plasma and brain stored at $-70^{\circ} \mathrm{C}$ until analysis. The tumors were excised in toto and weighed. Plasma total tryptophan was assayed fluorometrically by the method of Dencla and Dewey (65) as revised by Bloxam and Warren (30). Plasma amino acid analysis was carried out on a supernatant of plasma rendered protein-free by $5 \%$ sulfosalicylic acid precipitation.

The brains were hemisected sagitally in two equal parts. In one hemisphere of the brain tryptophan was determined while the remaining part was processed for amino acid determination. For amino acid determinations, $0.5 \mathrm{ml}$ of plasma was deproteinized by addition of $1.5 \mathrm{ml}$ of a sulution of $5 \%$ sulfsalicylic acid (SSA) previously adjusted to $\mathrm{pH} 1.8$ with $20 \% \mathrm{LiOH}$. Brains were weighed and homogenized in 3 volumes of the same deproteinizing solution. After protein precipitation, samples were centrifuged $\left(10.000 \mathrm{rpm}, 25 \mathrm{~min}, 4^{\circ} \mathrm{C}\right)$ and the supernatants frozen at $-70^{\circ} \mathrm{C}$ until analysis. Immediately before analysis, each sample was passed through a Millipore filter (.45 micron, pore size) to remove particulate material. Amino acids were determined on 50 ul of each sample by a Beckman 121-MB automated amino acid analyzer using the fivebuffer, single column, lithium citrate system. In order to minimize analysis variability, plasma and brain samples from each animal were run alternatively at the same recorder range setting of 0.5 O.D. Amino acid concentrations were reported as $\mathrm{nmol} / \mathrm{ml}$ of plasma or $\mathrm{nmol} / \mathrm{g}$ - wet weight of brain. All values were statistically analyzed by Student's t-test. 


\section{Legend to table 1:}

Daily food intake in tumor-bearing rats and in freely feeding control pats.

Food intake was calculated by dividing weight of consumed food by weight of rat at the time food was presented.

Statistical significance was determined by Student's $T$ test.

TABLE 1. DALLY FOOD INTAKE IN TUMOR - BEARING RATS AND IN FREELY FEEDING CONTROL RATS.

AVERAGE DAILY FOOD INTAKE

$(\mathrm{g} / 100 \mathrm{~g}-\mathrm{RAT} ; \mathrm{MEAN} \pm$ S.D.)

\begin{tabular}{|c|ccc|}
\cline { 2 - 3 } $\begin{array}{c}\text { DAYS AFTER TUMOR } \\
\text { TRANSPLANT }\end{array}$ & CONTROL (FF) & TUMOR (TB) & $\%$ DIFF. \\
\hline DAYS $1-3$ & $12.0 \pm 0.7$ & $11.4 \pm 0.4$ & -5.0 (n.5.) \\
DAYS 4-6 & $12.7 \pm 1.5$ & $10.2 \pm 0.6$ & $-19.7 * *$ \\
DAYS 7-9 & $11.9 \pm 1.6$ & $8.6 \pm 0.4$ & $-27.7 * *$ \\
\hline
\end{tabular}

\subsection{Results}

All animals injected with Walker-256 carcinoma cells developed tumors which were of similar weight $(9.7 \pm 0.5 \mathrm{~g}$, mean $\pm \mathrm{SD})$. None of the animals showed any evidence of bacterial infection.

Food intake in the TB animals (and hence in the PF group) was significantly less than in the FF controls (table 1, figure 2a). After several days, the TB and $P F$ rats gained less weight than those in the FF group (figure $2 b$ ).

Plasma amino acids (table 2, figure 3):

A comparison of the plasma amino acid patterns of the FF and PF rats shows that only significant differences which can be related to a reduced food intake are a higher concentration of plasma tyrosine and a lower concentration of plasma tryptophan. Similar changes were noted in the TB rats, suggesting that these were also of dietary origin. 

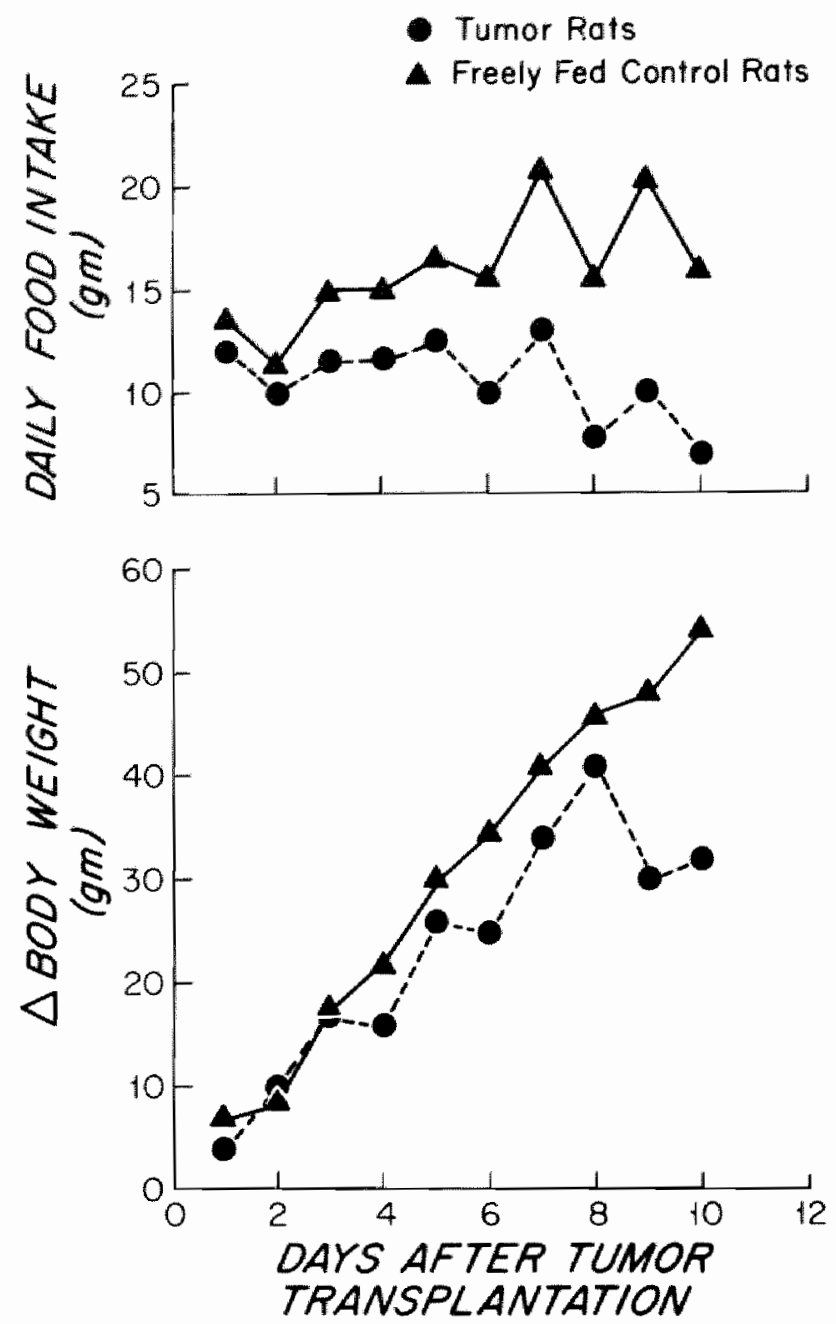

Legend to figures $2 A+B$ :

A. Mean daly food intake (g) for tumor-bearing and freely feeding rats;

B. Daily changes in body weight (g).

Note that young animals were used for the experiments.

The freely feeding control animals show a linear growth curve which is in concordance with the age of the rats.

- = Tumor rats

$\boldsymbol{\Delta}=$ Freely fod contral rats 


\section{PLASMA}

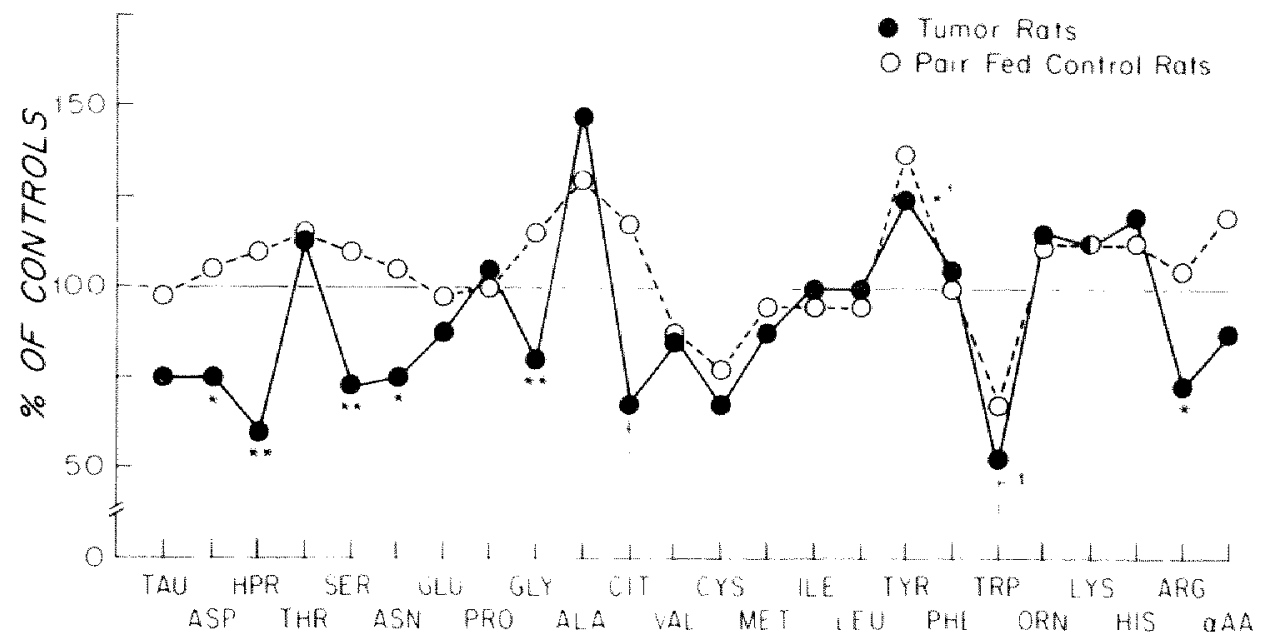

\section{Legend to figure 3 :}

Mean values of individual plasma amino acid concentrations in tumor-bearing and pair-fed rats expressed as percentages of freely fed control animals.

Statistical significance: ${ }^{*}, p<0.05 ;{ }^{*}, p<0.02$;

,$+ p<0.01$ (Significance of differences between tumor-bearing and pair-fed rats based on $T$-test for paired datal.

Note: 1.

Significance of differences between tumor-bearing or pair-fed rats with freely feeding animals: indicated only when of relevance to the text (data not paired).

$\alpha$ AA, $\alpha$-amino adipic acid.

Plasma concentration of alanine was raised in TB and PF rats compared with the FF group but the differences did not attain statistical significance. The TB rats also showed a plasma amino acid pattern which differed significantly from that of the PF group and was therefore presumably tumor related. Table 2 shows that the TB rats differed from their PF controls in having significantly reduced plasma concentrations of aspartate $(-28 \pm$ $7 \%, \mathrm{p}<0.02)$, hydroxyproline $(-44+7 \%, \mathrm{p}<0.02)$, asparagine $(-28 \pm$ $8 \%, p<0.05)$, glycine $(-30 \pm 7 \%, p<0.02)$, citrulline $(-43+4 \%$, $\mathrm{p}<0.01)$ and arginine $(-35 \pm 8 \%, \mathrm{p}<0.02)$. 


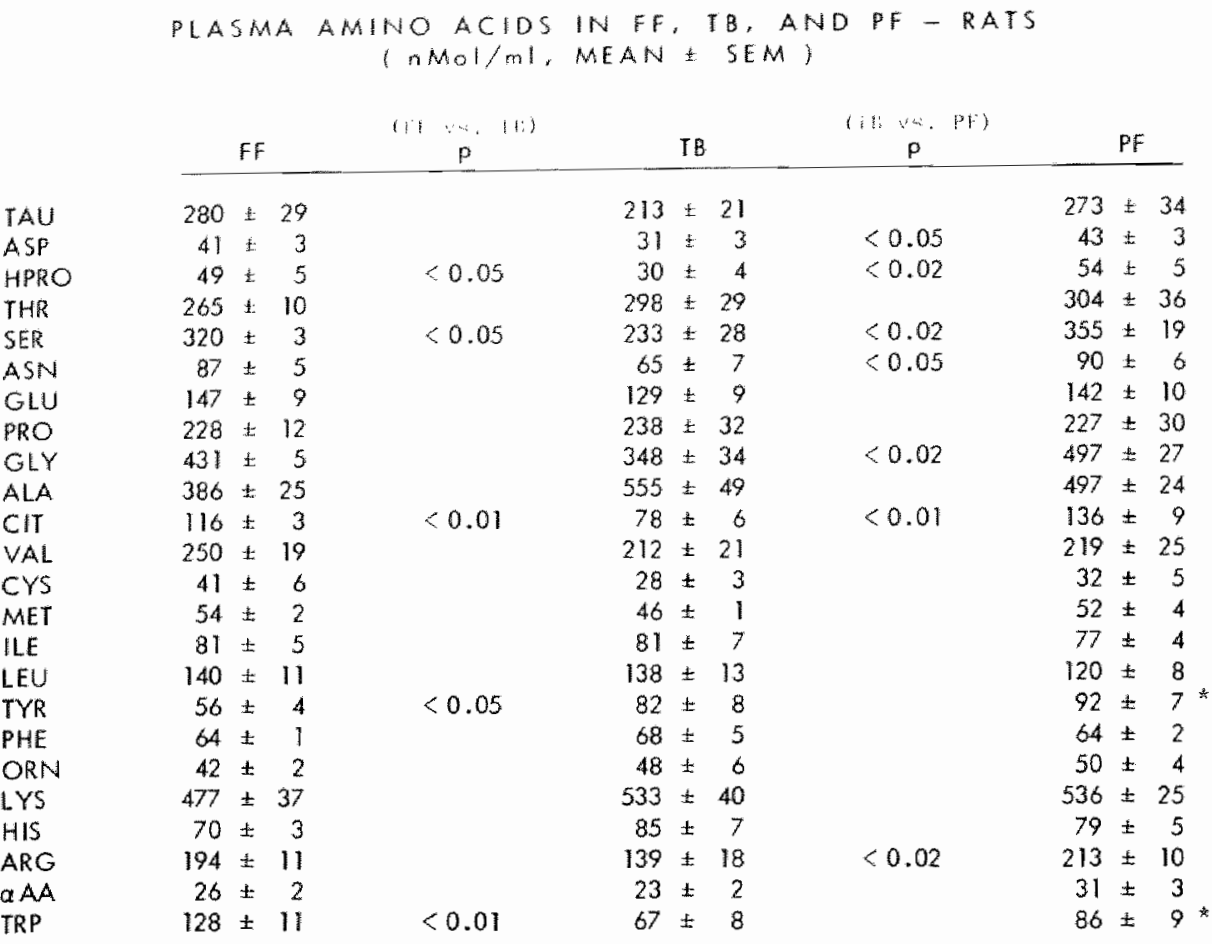

\section{Legend to table 2:}

Plasma amino actds in freely feeding. tumor-bearing. and pair-fed rats.

Statistics on tumor-bearing and pair-fed rats are based on $T$ test for pared data, while significances of differences between tumor-bearing and freely feeding animals are based on $T$ test for 2 means because the data with freely feeding rats were not paired.

For each group, $N=6$. 
BRAIN AMINO ACIDS IN FF, IB, AND PF - RATS
(MEAN SEM)

\begin{tabular}{|c|c|c|c|c|c|c|c|c|c|}
\hline \multirow[b]{2}{*}{ TAU } & \multicolumn{2}{|r|}{$F F$} & \multicolumn{2}{|c|}{ 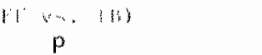 } & TB & \multicolumn{2}{|c|}{ 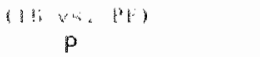 } & \multicolumn{2}{|c|}{$\mathrm{PF}$} \\
\hline & 5758 & +134 & $<0.02$ & 5076 & 4. 118 & $<0.02$ & 5510 & $t$ & 104 \\
\hline$A S P$ & 1886 & \& 60 & & 1653 & $1 \quad 72$ & & 1670 & $x$ & 117 \\
\hline HPRO & 29 & $\pm \quad 2$ & & 23 & 2 & & 25 & 1 & 3 \\
\hline THR & 511 & 27 & $<0.05$ & 614 & 26 & & 565 & + & 36 \\
\hline SER & 950 & 37 & & 842 & 33 & & 930 & $t$ & 38 \\
\hline ASN & 67 & +4 & & 73 & 4 & & 80 & \pm & 2 \\
\hline GLU & 6389 & \pm 161 & & 6169 & $\pm \quad 105$ & & 6027 & 1 & 220 \\
\hline PRO & 100 & 15 & & 93 & $\pm \quad 19$ & & 88 & \pm & 4 \\
\hline GLY & 942 & $\pm \quad 61$ & & 850 & 40 & & 873 & 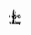 & 41 \\
\hline ALA & 832 & 70 & & 838 & 43 & & 786 & \pm & 46 \\
\hline $\mathrm{CIT}$ & 76 & 10 & $<0.05$ & 48 & \pm & $<0.05$ & 77 & \pm & 8 \\
\hline VAL & 122 & 20 & & 105 & \pm & & 98 & \pm & 8 \\
\hline CYS & 20 & \pm & & 20 & t. & & 18 & $t$ & 2 \\
\hline MET & 62 & \pm & & 52 & \pm & & 57 & \pm & 4 \\
\hline ILE & 43 & \pm & & 43 & \pm & & 39 & \pm & 3 \\
\hline LEU & 89 & $t$ & & 86 & \pm & $<0.05$ & 74 & \pm & $5 *$ \\
\hline TYR & 65 & 1 & & 92 & \pm & & 105 & \pm & $14^{34}$ \\
\hline PHE & 65 & $t$ & & 66 & \pm & & 62 & \pm & $b$ \\
\hline ORN & 22 & $t$ & $<0.01$ & 13 & \pm & $<0.01$ & 17 & \pm & 1 \\
\hline LYS & 425 & 46 & & 384 & 19 & & 393 & \pm & 34 \\
\hline HIS & 90 & 11 & & 101 & \pm & & 95 & \pm & 12 \\
\hline ARG & 178 & 17 & $<0.01$ & 104 & \pm & $<0.02$ & 150 & \pm & 1 \\
\hline$a A A$ & 53 & 1 & & 46 & \pm & & 47 & $t$ & 4 \\
\hline TRP & 21 & $t$ & & 19 & \pm & $<0.01$ & 14 & $t$ & 1 \\
\hline
\end{tabular}

\section{Legend to table 3 :}

Brain amino acids in freely feeding, tumor-bearing. and pair-fed rats.

Statistics on tumor-bearing versus par-fed rats are based on paired $T$ test, and statistics on umor-bearing versus freely feeding animals are according to $T$ test for 2 means. 
Brain amino acids (table 3 , figure 4 ):

Concentrations of amino acids in the brains of PF an FF rats differed significantly only with respect to increased concentrations of leucine and tyrosine in the PF rats $(17 \pm 6 \%, p<0.05$ and $65 \pm 22 \%, p<0.05)$ respectively and a decreased concentration of Iryptophan $(33 \pm 5 \%$,

$p<0.011$. The increased brain concentration of tyrosine in the PF rats reflects a similar change in the plasma concentration of tyrosine in these animals, but this is not the case for leucine and tryptophan.

Furthermore, the TB rats which had even lower concentrations of plasma tryptophan, had relatively high brain concentrations of this amino acid. This apparently anomalous finding is explained by the fact that the TB rats had a threefold increase in plasma free tryptophan despite a decrease in the total tryptophan concentration. This may be due to a $250 \%$ increase in the concentration of plasma free fatty acids which compete with tryptophan for binding to albumin and to a $25 \%$ reduction in albumin concentration in the TB rats $(127)$.

When compared with their PF controls, the TB rats showed significantly reduced brain concentrations of taurine $(-8 \pm 2 \%, p<0.01)$, citrulline ($38 \pm 5 \%, p<0.05)$ ornithine $(-34 \pm 5 \%, p<$ $(-3) \pm 5 \%, p<0.02)$.

0.01 ) and arginine

\subsection{Discussion}

These experiments demonstrate that rats bearing Walker- 256 carcinomas have different amino acid patterns in both plasma and brain when compared with normal control rats. The use of a second control group whose dietary intake was matched to that of the tumor bearing group enables us to distinguish amino acid changes that are secondary to reduced food intake, from changes that are tumor related.

The actual mechanisms involved may be complex and include such factors as digestion, absorption, transport and subsequent metabolic handling. Some of these factors are outside the scope of this thesis, but others will be discussed.

The impact of protein and calorie deprivation upon plasma amino acid concentrations is wel documented $(12,13,75,129)$. Badger and Tumbleson $(12,13)$ showed that severe protein malnutrition in animals produced a reduction in plasma concentrations of threonine, phenylalanine, tyrosine and the branched-chain amino acids while concentrations of alanine and methionine were elevated. Energy deprivation produced similar but less marked changes with the exception of alanine which remained grossly elevated. In their experiments, the changes in plasma amino acids were also partially reflected in the free amino acid 


\section{BRAIN}

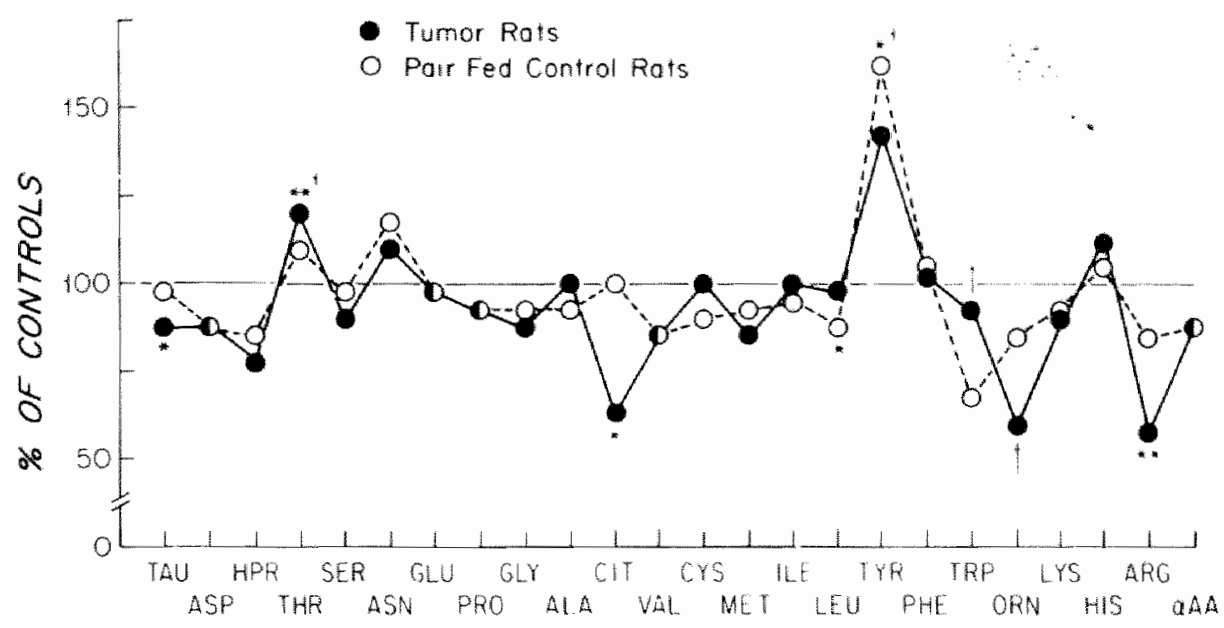

Legend to figure 4 :

Mean values of individual brain amino acids in tumor-bearing and pair-fed rats expressed as percentages of freely feeding control animals.

Statistical significance: ${ }^{*}, \mathrm{p}<0.05 ;{ }^{* *}, \mathrm{p}<0.02$;

$T, p<0.01$ (Significance of differences between tumor-bearing and pair-fed rats, based on T-test for paired datal.

1. Significance of differences between tumor-bearing or pair-fed rats with freely feeding animals; indicated only when of relevance to the text (data not paired).

$\alpha A A, \alpha$-amino adipic acid.

pool within the brain. Malnourished animals have lower plasma and brain concentrations of the amino acid tryptophan $(69,90)$.

In our experiments, the TB and PF rats consumed smaller amounts of a balanced diet than the FF controls. This presumably resulted in moderate protein and energy deprivation. Of the changes in plasma amino acid concentrations which we have observed in the TB rats, only the decreased tryptophan and increased alanine and possibly tyrosine (226) are explicable on the basis of malnutrition. Alanine is a preferential gluconeogenic amino acid $(81,227)$ and is synthetized in abundance when glycolysis is increased as in trauma (1), sepsis (163) or cancer(101). 
and also in the catabolic state associated with starvation $(81,175)$.

The tendency toward higher plasma concentrations of alanine in the TB rats may reflect the high rate of gluconeogenesis in malignant disease (227). Differences in plasma concentration of glycine and serine between TB and PF rats might reflect the known capacity of Walker-256 tumors to utilize these amino acids in vitro. Addition of glycine and serine to a standard medium increases the growth rate of the tumors (180).

Although speculative, the lower concentrations of arginine and aspartate in the TB rats may also be due to tumor consumption since those amino acids have been reported as being readily incorporated into growing malignant cells (104). Plasma concentrations of hydroxyproline were also significantly reduced in the TB rats. This amino acid is present in plasma in free forms: free, oligopeptide and protein bound and its only fate is incorporation into collagen. Approximately eighty per cent of total hydroxyproline is bound (34). At the present time, data on factors affecting this binding are not available. Since hydroxyproline is measured after precipitation of proteins, the actual amount of total hydroxyproline present in the plasma is undetermined.

Within the brain, concentrations of taurine, citrulline and arginine were also lower in the TB rats. This was probably due to secondary decreases in plasma concentrations of these amino acids. Although there was no difference in the plasma concentrations of ornithine in TB and PF animals, the brain concentration was significantly lower in TB rats. This remains unexplained. The relatively high brain concentrations of tryptophan in the TB rats are of particular interest.

This had occurred despite a reduction in the concentration of plasma total tryptophan, and this may be due to an increased concentration of that part of the total tryptophan not bound to albumin (147).

Transport of tryptophan across the blood-brain barrier is a matter of some controversy $(56,84,258)$. In addition to the role of plasma free tryptophan $(29,56,216)$, consideration must be given to the molar ratio of tryptophan to that of competing neutral amino acids (valine, leucine, isoleucine, phenylalanine, tyrosine and methionine) as they share a common carrier system $(84,132)$. In addition, local changes at the carrier site may influence brain tryptophan uptake as has been demonstrated by James, et al., in experimental hepatic failure (132). 


\subsection{Conclusions}

The results of this experiment allow the following conclusions:

1. Plasma and brain amino acid profiles of rats bearing a malignant tumor are different from normal control rats.

2. Some differences are produced by malnutrition and some are tumor related.

3. The relatively high plasma concentrations of alanine may reflect the high rate of gluconeogenesis in malignant disease.

4. The differences of some amino acids (glycine, serine) may reflect Walker-256 tumor specific properties to utilize amino acids.

5. The increased plasma concentration of tryptophan in the tumor bearing animals is only in part due to malnutrition as the pair-fed control rat had less decreased levels.

6. Despite the low plasma concentrations of tryptophan in both tumorbearing and pair-fed control rats, the brain levels of this amino acid were high in the TB animals but low in PF animals.

7. The role of elevated concentrations of brain tyrosine with respect to the effects upon catecholamine metabolism remains to be determined.

\subsection{Summary}

Decreased food intake (anorexia) and competition for nutrients by malignant tumors both may contribute to depletion of the tumor-bearing host. Superimposed upon the state of malnutrition, there are tumor induced changes in metabolic patterns of that host. In this chapter, amino acid metabolism was studied. Plasma amino acid profiles of anorectic Walker-256 carcino-sarcoma bearing rats, non-tumor bearing pair-fed rats and non-tumor bearing freely feeding control rats were investigated in an attempt to differentiate between tumor related changes in amino acid metabolism and the effects of malnutrition.

Elevated plasma concentrations of alanine and tyrosine and lowered plasma total tryptophan were noted in both TB and PF groups and were attributed to decreased food intake and malnutrition. Decreased plasma levels of serine, glycine, aspartate and hydroxyproline were found in TB rats only. This may be a reflection of increased consumption of these amino acids by the tumor. Brain amino acids were measured in all three groups. The brain concentrations of tryptophan were high in TB rats and low in PF animals. Elevated levels of brain tyrosine may have consequences for catecholamine metabolism. 


\section{Chapter 4}

What determines brain concentrations of tryptophan in the normal and the tumor-bearing animal?

\subsection{Introduction}

In chapter 3 , it has been demonstrated that significant difference existed between brain levels of tryptophan in tumor-bearing and normal control animals. The relatively high brain concentrations of tryptophan in the tumor-bearing rats were of particular interest because this occurred despite a reduction in the concentration of plasma total tryptophan (TRP). Tryptophan (TRP) is a constituent of numerous proteins and precursor of the indole neurotransmitter serotonin and is unique in its appearance in the plasma, and in its function within different metabolic systems.

In the plasma tryptophan is the only neutral amino acid that circulates largely bound to albumin, a binding which is influenced by competitive effects from non-esterified fatty acids or some psychotropic drugs and by various other plasma factors, e.g. plasma $\mathrm{pH}$ and albumen concentration. The plasma concentration of TRP (i.e. albumen bound tryptophan plus free circulating tryptophan) is subject to various influences. It has been well established, that nutritional state directly correlates with plasma levels of TRP $(16,90)$.

Malnutrition invariably is accompanied by low plasma TRP. Decreased plasma TRP levels are also found in some patients with carcinoids and may be caused by an excessively high consumption of TRP (80), secondary to a pathologically high systemic synthesis of serotonin.

Increased plasma levels may be found in acute fulminant hepatitis (91) and occasionally in congenital tryptophanuria, an inborn error of metabolism. Short time alterations of plasma tryptophan levels occur under influence of insulin, dietary carbohydrates, fat and proteins.

It has been demonstrated that both the bound and the free faction of plasma TRP are of importance in determining brain TRP levels. However, the transport of TRP across the blood-brain barrier is subject to some controversy.

At least, three mechanisms are involved:

1. The molar ratio of total TRP and the competing neutral amino acids.

2. The plasma concentrations of free TRP.

3. The brain uptake index for TRP, which reflects the ability of the transport system at the blood-brain barrier to carry TRP from plasma to brain. 
The mechanisms which determine brain TRP concentrations usually operate conjointly but it appears that under certain conditions, the relative influence of one mechanism may increase (83). It is important to define these mechanisms because alterations of brain TRP concentrations are immediately reflected by altered synthesis of the brain neurotransmitter serotonin which in turn may affect neurological, behavioural and metabolic systems. This study has focussed on these mechanisms and their interaction in cancer.

\subsection{Materials and methods}

Young female Sprague-Dawley rats $(80-100 \mathrm{~g})$ were kept individualy in wire-bottom cages at $20^{\circ} \mathrm{C}$. A 12 hour dark-light schedule was maintained. After determining baseline values for daily food intake and growth during three consecutive days, groups of six animals were injected with $10^{6}$ Walker-256 tumor cells in the right thigh and permitted free access to rat chow (Purina $\mathrm{R}$ Lab Chow) and water. Two control groups of the same strain, sex and weight were injected with saline: one group FF rats was fed ad libitum while another PF group received only the amount of diet consumed the previous day by its paired TB rat, each animal in the PF group being carefully matched for weight and age with a TB rat. Food intake and body weight were measured daily at the same hour. Nine days after injection, when food intake of TB rats had fallen significantly behind of FF rats for several days, all rats were decapitated. Blood was collected from the cervical wound into chilled, heparinized beakers and plasma separated by centrifugation at $4^{\circ} \mathrm{C}$. For $\mathrm{pH}$ measurements, blood was immediately collected in heparinized and chilled syringes sealed to prevent air contact. Measurements were carried out by means of the Corning Automatic pH-Bloodgas System (Medford, Massachusetts,

U.S.A.). Brains were rapidly removed and frozen on dry ice, and plasma and brain were stored at $-70^{\circ}$ until analysis. The tumors were excised in toto and weighed. Plasma free TRP was determined in $50 \mu$ l of an ultrafiltrate prepared by centrifugation of $1.0 \mathrm{ml}$ plasma $(\mathrm{pH}$ adjusted to $7.4 \pm .05$ with $\left.100 \% \mathrm{CO}_{2}\right)\left(100 \times 9,25 \mathrm{~min} .20^{\circ} \mathrm{C}\right)$ in a CF 50 Diaflo membrane cone (Amicon Corp. Lexington, Mass.). Free and total tryptophan were assayed fluorometrically by the method of Dencla and Dewey as revised by Bloxam and Warren $(65,30)$. Albumin was measured using the bromcresol green method as described by Doumas et al. (73). Free fatty acids in plasma were determined colorimetrically (78).

Blood-brain transport activity was estimated by determining the brain uptake index measurement (BUI) for tryptophan as described by Oldendorf 
(206). The principles of this technique are as follows: following the rapid injection of a labelled substance into the carotid artery, the uptake index is measured against the permeation of ${ }^{3} \mathrm{H}_{2} \mathrm{O}$, to which the blood-brain barrier is freely permeable. A rapid forceful injection of material into the carotid artery. clears the artery of blood and eliminates concern for concentration of the unlabelled material in the carotid artery. Rats were anesthetized with pentobarbital $(45 \mathrm{mg} / \mathrm{kg}$, i.p.) and the right common artery was exposed and cannulated using a 27-gauge butterfly needle. Injections of $0.2 \mathrm{ml}$. of a mixture containing $1.0 \mu \mathrm{Ci} 3 \mathrm{H}_{2} \mathrm{O}$ and $0.2 \mu \mathrm{Ci}$ of ${ }^{14} \mathrm{C}$-test substance in Krebs-Ringer's buffer adjusted to $\mathrm{pH} 7.4$ with $7 \mathrm{mM}$ HEPES were given into the common carotid, without occluding blood flow. Since injections were completed in less than 0.3 seconds and the artery blanched briefly during the injection, it was assumed that minimal mixing of the injected solution with the blood occurred. Exactly 15 seconds after injection, the rats were decapitated, and brain cortex ipsi-lateral to the injection and rostral to the midbrain was removed. Brain tissue was extruded through a 20 gauge needle into $\mathrm{ml}$ NCS tissue solubilizer and heated at $50^{\circ} \mathrm{C}$ for approximately 1 hour with repeated vortexing. The solubilized tissue was then added to $1.0 \mathrm{ml}$ of toluene-based scintillation fluid and $3 \mathrm{H}$ and ${ }^{14} \mathrm{C}$ content determined by conventional double-label counting techniques using internal standards. A $5 \mu 1$ aliquot of the injection solution was also counted. The BUI, as defined by Oldendorf is calculated according to the following formula:

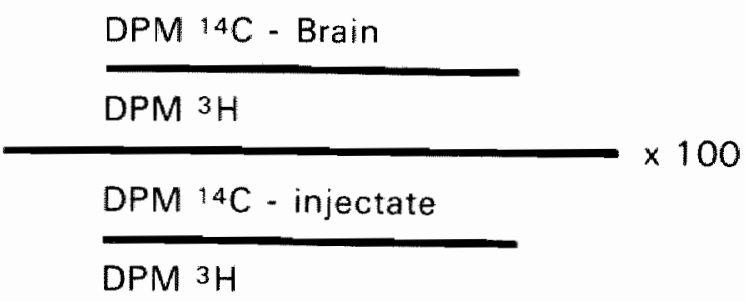

Because many analyses were to be performed on relatively small animals, we performed 4 different sets of experiments following indentical protocols. The data were collected according to a scheme which allowed overlap of data such that key analyses were repeated where possible while additional information was gathered from individual experiments. Thus, data on food intake, body weight and tumor weight are given for all animals $(n=72)$. All other data were obtained as explained in the legends.

\subsection{Results}

In alle sets of experiments, TB rats ate significantly less than FF controls (table 1 and figure 2). Also, in all the experiments, brain tryptophan levels of TB rats were significantly increased (about $25 \%$ ) as compared to PF rats (table 4). 


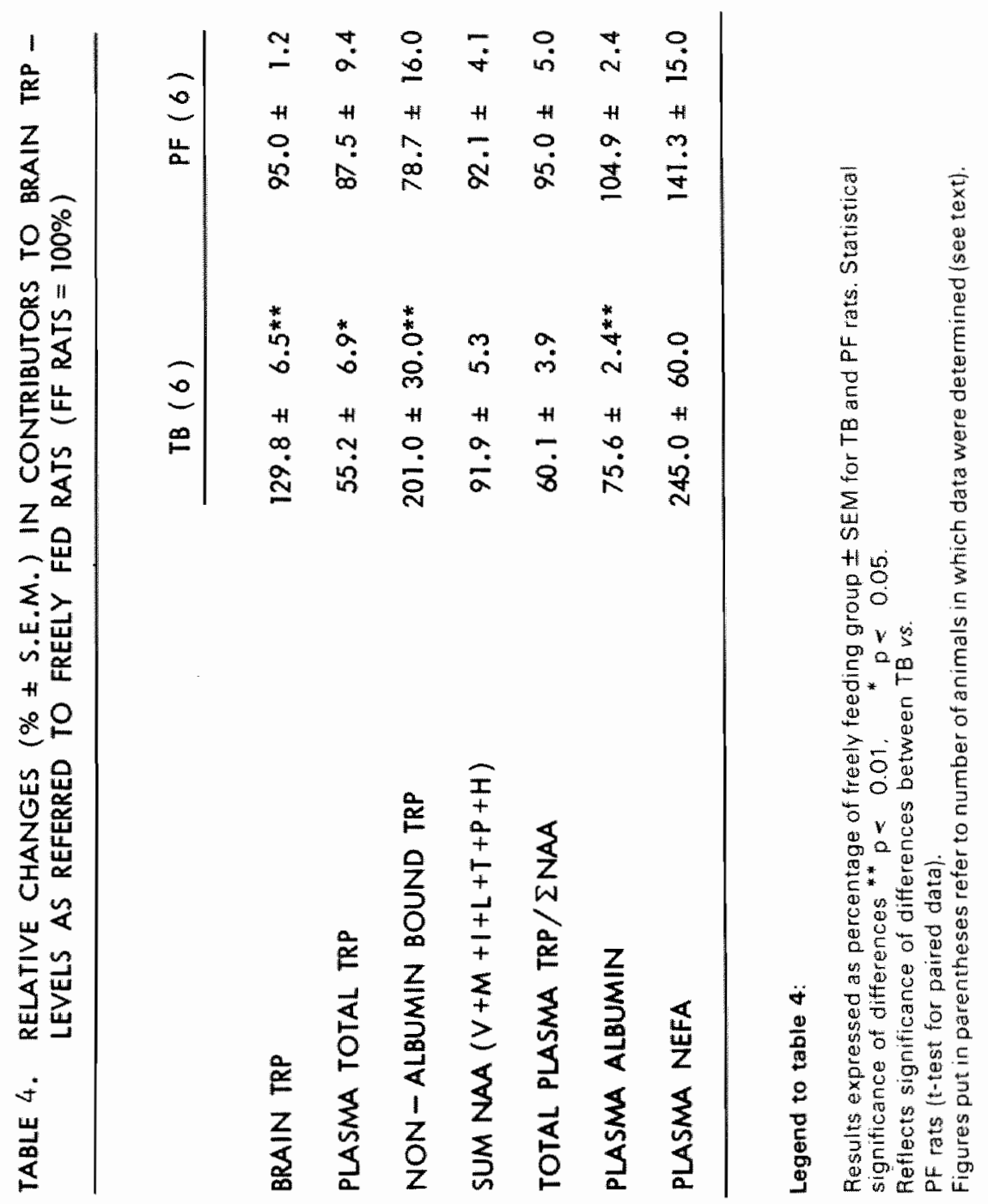


No significant difference was observed between brain tyrosine of TB and $P F$ rats although $T B$ rats had significantly higher brain tyrosine than FF rats. Brain phenylalanine was similar in all groups. Plasma tryptophan (total) was significantly lower in TB rats than in FF rats (table 4.5). Plasma tyrosine of TB and PF rats was higher than in FF rats, however this difference did not reach statistical significance $10.05<p<0.01$ (table 2). Plasma - free tryptophan was found to be much higher in TB rats than in PF or FF rats and constituted a much higher percentage of total tryptophan in TB rats than in either PF or FF rats (table 4). No significant difference was found in the sum of the other neutral amino acids, which compete with tryptophan for transport across the blood-brain barrier (table 4.5). TB rats had significantly lower plasma albumin with respect to PF and FF animals Plasma free fatty acids in TB rats was raised both in PF and FF rats, though only significantly in the latter group (table 5, figure 5). In order to exclude activity changes of the blood-brain neutral amino acid transport system, responsible for tryptophan elevation, we compared brain uptake of tryptophan (BUI-TRP) of TB rats with non-tumor bearing, saline injected FF control animals; no difference was found (TB: $28.86 \pm 8.52$ and FF: 28.66 $\pm 6.04, n=6$, results expressed as mean \pm SEM). Plasma $\mathrm{pH}$ did not differ in the groups at the time of decapitation but after storage of the plasma there was a difference. All stored samples had $\mathrm{pH}=8,0 \pm 0.3$ (S.D.). To adjust the $\mathrm{pH}$ of the samples to $\mathrm{pH}=7.4$ prior to determination of free tryptophan, more $\mathrm{CO}_{2}$ was needed to lower the $\mathrm{pH}$ of samples belonging to the non-tumor bearing group as compared to the tumor-bearing animals.

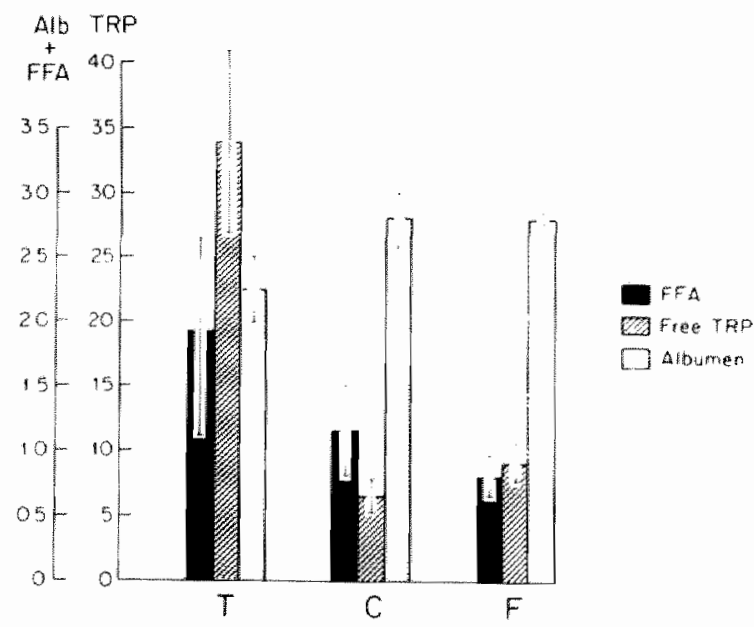

Legend to figure 5

Changes in plasma concentrations of FFA, free TRP and albumine, in tumor bearing rats (T), pair-fed control rats (C) and freely feeding control animals (F). (I SEM) 
BRAIN AND PLASMA NEUTRAL ANINO ACIDS IN TUMOR - BEARING RATS AND IN PAIR - FED FREELY FEEDING CONTROL RATS

RAIN CONCENTRATION ( $\mathrm{nMOI} / \mathrm{g})$ (MEAN \pm S.E.M.)

\begin{tabular}{|c|c|c|c|}
\hline AMINO ACIO & TB $(8)$ & $P F(6)$ & FF (4) \\
\hline TRYPTOPHAN & $19 \pm 1 *$ & $15 \pm 1 *$ & $21 \pm 2$ \\
\hline TrROSINE & $92 \div 7$ & $105 \pm 15$ & $65 * 8^{*}$ \\
\hline \multirow[t]{2}{*}{ PHENYLALANINE } & $66 \pm 4$ & $62 \pm 6$ & $64 \pm 7$ \\
\hline & & \multicolumn{2}{|c|}{$\begin{array}{l}\text { PLASMA CONCENTRATION }(\mathrm{nMol} / \mathrm{ml}) \\
(\text { MEAN } \pm \text { S.E.M. })\end{array}$} \\
\hline VALINE (V) & $212 \pm 21$ & $219 \div 25$ & $250 \pm 19$ \\
\hline METHIONINE (M) & $49 \pm 4$ & $52 \div 4$ & $54 \pm 1$ \\
\hline ISOLEUCINE (1) & $81 \pm 6$ & $77 \pm 4$ & $81 \pm 5$ \\
\hline LEUCINE (L) & $138 \pm 13$ & $120+8$ & $140 \pm 11$ \\
\hline TYROSINE (T) & $84 \pm 7$ & $92 \pm 7$ & $56 * 4$ \\
\hline PHENYLALANINE (P) & $63+5$ & $64 \pm 2$ & $04 \pm 1$ \\
\hline HISTIDINE (H) & $85 \pm 6$ & $79 \pm 5$ & $70 \div 3$ \\
\hline $\begin{array}{l}\text { TRYPTOPHAN } \\
\text { (IOTAL) }\end{array}$ & $86 \pm 8$ & $84 * 9 * *$ & $127 \pm 6^{* * *}$ \\
\hline $\begin{array}{l}\operatorname{SUM}(V+M+1 \\
+L+T+P+H)\end{array}$ & $712 \pm 56$ & $701 \pm 45$ & $715 \pm 32$ \\
\hline
\end{tabular}

\section{Leaend to table 5:}

Statistical significance. ** $p<0.01$. $t^{*} p<0.05$, when indicated in column haaded TB, represents significance of differences between TB $v s$.

$P F$ rats ( $t$-test for paired data) when indicated for values in column PF, represents differences between PF vs.

FF rats (data not paired), and when indicated for values in column FF represents differences between FF vs. TB rats (data not paired). 


\subsection{Discussion}

Studies performed with the Walker-256 tumor implanted in SpragueDawley rats of $200 \mathrm{~g}$ or more usually report that hypophagia does not occur until 15 to 18 days after implantation (15). However, we used weanling rats $(80-100 \mathrm{~g})$ because such animals show a highly reproducible pattern of tumor growth and die within 15 days after tumor implantation (data obtained from A.D. Little Inc., Boston, Mass.). We noted that these animals also react uniformly in developing anorexia, when the tumor is injected intramuscularly (161).

In our studies, rats bearing the Walker-256 tumor consumed less food than tumor-free rats. Nevertheless, they have higher brain TRP than tumorfree rats consuming the same quantity of food. Tryptophan is the only neutral amino acid bound to albumin. Madras (1974) suggested that both bound and free tryptophan compete for brain transport sites because the affinity of tryptophan to albumin approximates that of the brain transport system (166). Under normal circumstances, $80-90 \%$ of plasma tryptophan is bound albumin. The brain uptake index for C-labelled tryptophan in the presence of dialyzed rat serum is depressed by only 15 percent, which means that only this percentage of bound tryptophan is stripped off albumin at the blood-brain barrier. Dialyzed serum had no effect upon BUl of ${ }^{14} \mathrm{C}$-leucine or ${ }^{14} \mathrm{C}$-methionine, which is consistent with the lack of protein binding of these amino acids Yuwiler et al (1977) have shown that, depending on the amount of free fatty acids in the plasma, as much as 50 - 90\% of bound tryptophan may be loosened from albumin during a single passage through the brain (284) The competitive effect of free fatty acids on albumin binding with tryptophan has been reported by other investigators $(56,77,166)$.

In our experiments, the tumor-bearing rats had high plasma levels of free fatty acids. Waterhouse already mentioned increased plasma concentration of fatty acids in malignant disease (270). Little data on lipid metabolism and its disorders in cancer are available.

Hilf et al (1970) reported a $250 \%$ increase of free fatty acids in human breast cancer tissue; however, the study did not provide data on plasma levels (122). Muller et al. (1961) reports increased plasma concentrations of unesterified fatty acids (196).

The binding of tryptophan to albumin is dependent on other factors in plasma. There are a few reports available on decreased binding in the presence of drugs, usually psychotropic drugs $(23,213,259)$ because they compete with tryptophan for binding to albumin. Plasma $\mathrm{pH}$ strongly influences the binding tendency of tryptophan to albumin.

We studieg this phenomenon in human plasma (figures 6.7). 


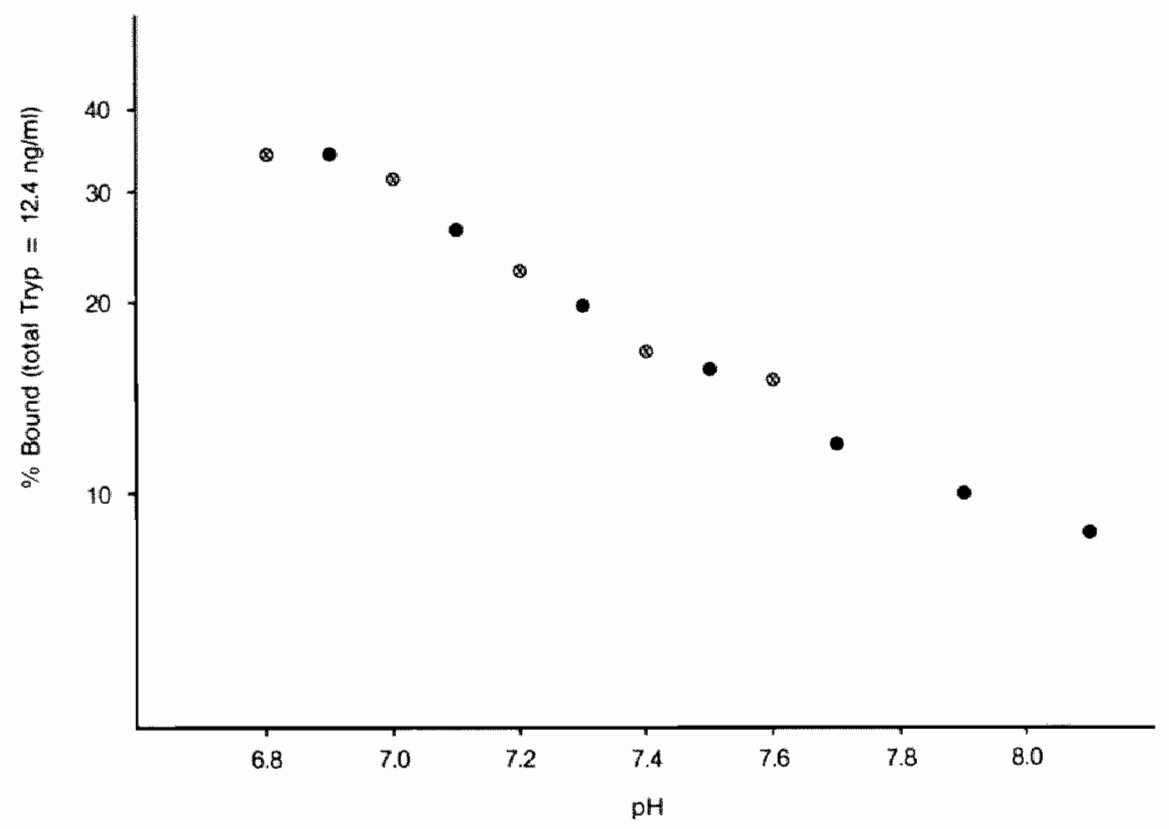

Legend to figure 6

Effect of $\mathrm{pH}$ on TRP-albumin binding in pooled human plasma.

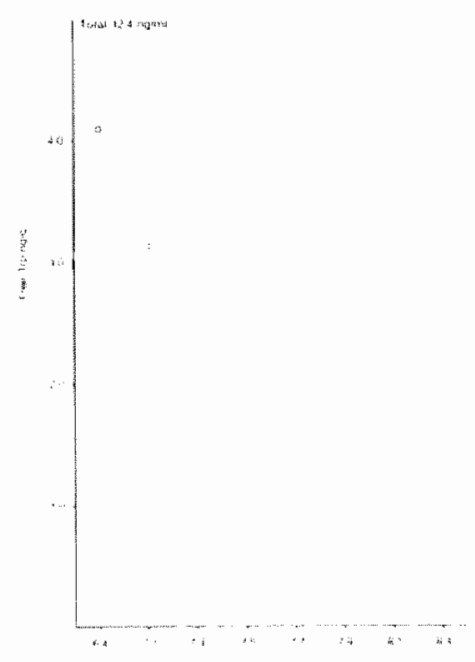

Legend to figure 7

Free TRP concentration in human plasma at different $\mathrm{pH}$-values. 
The decreased binding tendency as $\mathrm{pH}$ moves from 6.8 to 8.3 was consistent with data reported from other investigators (284). In our study in tumor-bearing animals, we noticed that the stored plasma samples had higher $\mathrm{pH}$-values but there was no significant difference between the groups.

Prior to the determination of tryptophan, the samples were adjusted to $\mathrm{pH}$ $=7.4$ with $\mathrm{CO}_{2}$. More $\mathrm{CO}_{2}$ was needed to obtain a lower $\mathrm{pH}$ value in the normal control rats as compared to the tumor-bearing group.

This may be explained by a decreased buffer capacity of plasma in tumor animals. The actual concentration of albumin evidently also contributes to the available binding sites for tryptophan in the plasma (77).

Plasma albumin was significantly decreased in tumor-bearing rats as compared with both control groups. Hypoalbuminaemia is a well known early complication in cancer, yet its etiology is not fully understood.

Inadequate nutrition and some degree of malabsorption may account for this, but it has been well established that the major causes are a defective or inhibited synthesis and increased degradation $(228,258)$.

Hypoalbuminaemia inducing substances produced by the tumor itself have been suggested $(151,266)$. This is currently under investigation. Tryptophan is an essential amino acid whose plasma and tissue concentrations ultimately depend on dietary intake, the balance between protein synthesis and protein degradation and the rate at which the liver metabolizes the amino acid. Malnutrition invariably is accompanied by decreased plasma (and brain) concentrations of tryptophan $(60,90,137)$. In our studies, we observed low plasma total tryptophan levels in both tumor-bearing and pair-fed control animals, which was expected because they consumed significantly smaller amount of a balanced diet than the freely feeding control group. Besides this, we noticed that the tumorbearing rats had lower plasma total concentrations than their pair-fed controls. Although the difference was consistent, it did not reach significance. Nevertheless, we investigated this point as it could reflect increased tryptophan consumption by the tumor (figure 8 ). We did not find any indication of such an increased tryptophan consumption by the tumors, at least not in the model used.

In humans, it has been demonstrated that some carcinoid tumors may expose a very high demand for tryptophan that lower plasma concentrations of this amino acid resulted from it (80). Thus, it appears that the high plasma free tryptophan concentrations in the tumor-bearing rats were secondary to the $150 \%$ increase of plasma free fatty acids and the $25 \%$ decrease of plasma albumin in the animals.

Brain tryptophan concentrations of tryptophan were significantly higher in the tumor-bearing group as compared with the pair-fed rats. 
The plasma concentrations of free tryptophan has been considered the only molecular form in which tryptophan can cross the blood-brain barrier $(56,258)$.

Legend

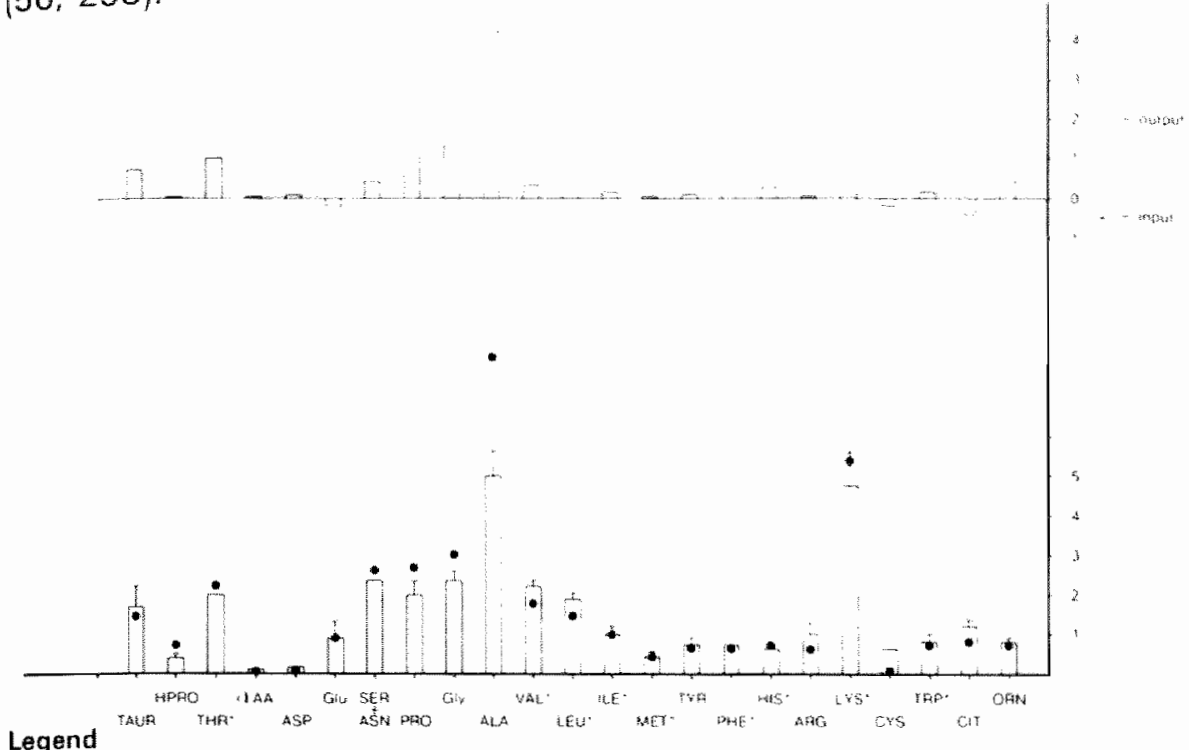

Ad. fig. 8

Pilot study to assess eventual tryptophan consumption by a Walker-256 tumor.

Female Sprague-Dawley rats $( \pm 100 \mathrm{~g}$ ) with a tumor implanted by intramuscular injection were used in this experiment. The tumor grew in the right thigh and had replaced most of the muscular mass. The control rats were of the same strain and sex, but did not have a tumor. A control rat was anaesthetized with ether and subsequently a laparotomy was performed followed by catheterization of the right common iliac artery at the level of its bifurcation. For this procedure, heparinized silastic tubing was used.

A tumor-bearing rat also anaesthetized with ether a laparotomy was performed. The iliac artery and vein on the side where the tumor was located were isolated and separated from each other. The common iliac artery was ligated at its origin and disected distally from the ligature. The circulation through the limb was restored by connecting the cut artery with the cathoter from the normal animal.

The common iliac vein of the tumor rat was also cannulated and connected to a sample tube which was kept on ice. The control rat was heparinized with an I.V. dosis of $0.1 \mathrm{co}$ thromboliquine. Thus, the tumor-bearing leg was perfused with blood from a live, non-tumor bearing donor. Venous blood from the tumor was collected in the tube until $3.4 \mathrm{cc}$ blood was obtained (i.e. venous sample).

Then, the arterialline was cut and the "donor" animal was bled into another testtube on ice (i.e. arterial sample).

Meanwhile, a new control animal was prepared and connected to the tumor rat via the arterial line. In this way, the tumor-bearing leg was kept perfused under physiologic conditions throughout the experiment. The perfusion was terminated when enough blood was sampled to perform amino acid and tryptophan analyses.

Top: arteriovenous differences tumor-free rat.

Bottom: arterial and venous concentrations in tumor bearing rats.

- = venous samples

open bar $=$ arterial samples \pm SEM 
66
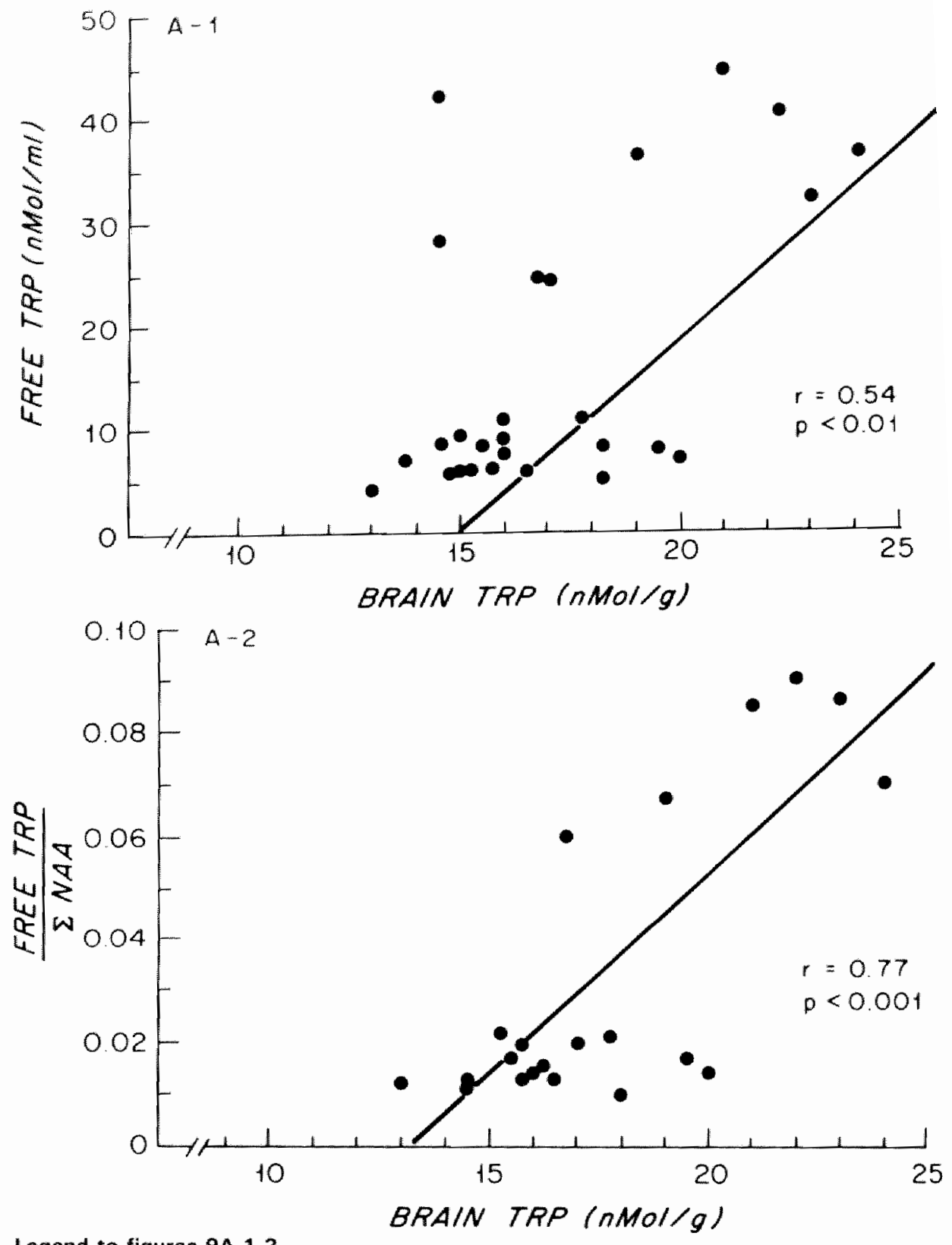

Legend to figures 9A $1-2$

Regression analysis to determine optimal relationship between brain TRP concentration and plasma free or bound TRP (see text). 

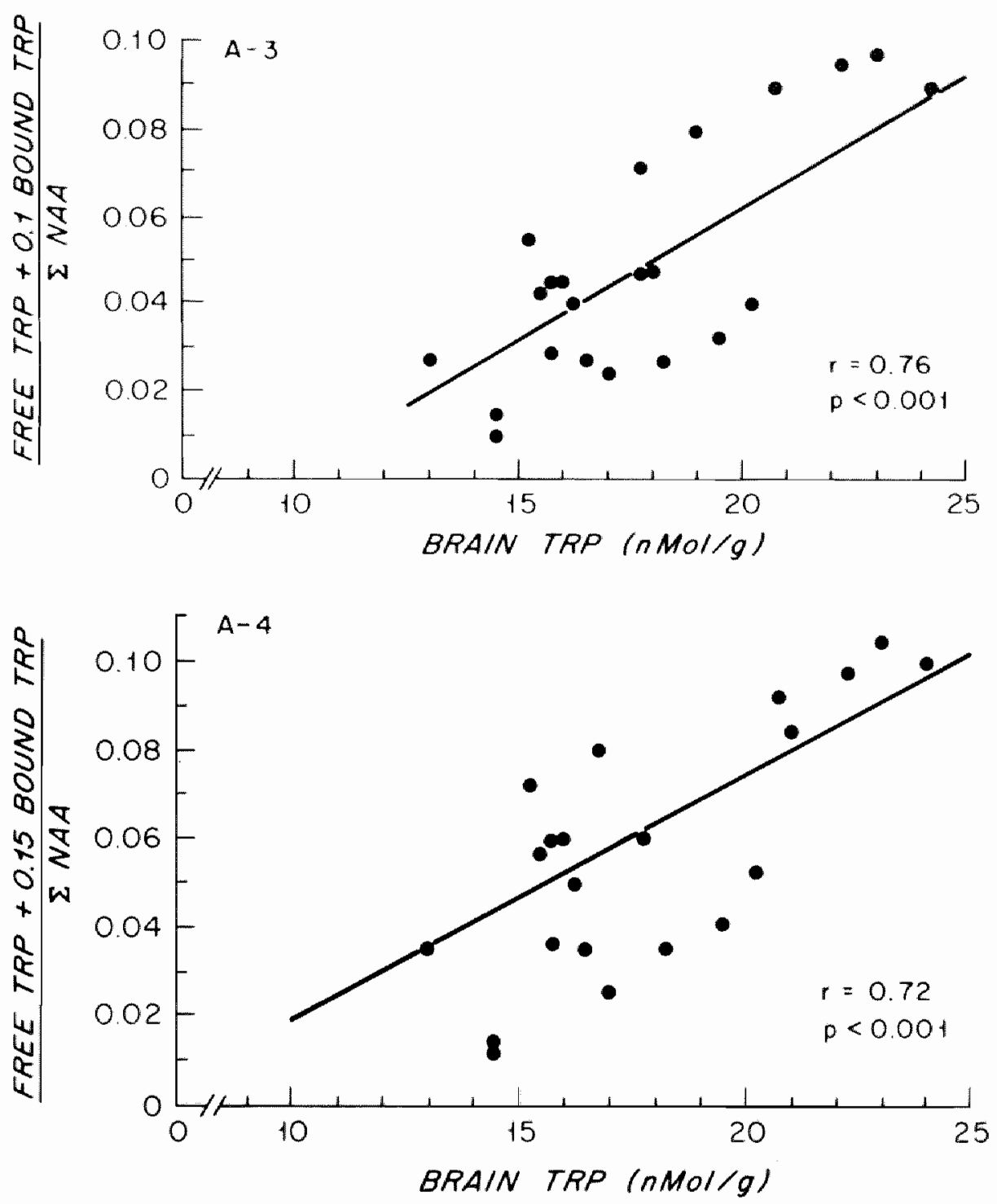

Legend to figures $9 A$ 3.4

Regression analysis to determine optimal relationship between brain TRP concentration and plasma free or bound TRP (see text). 

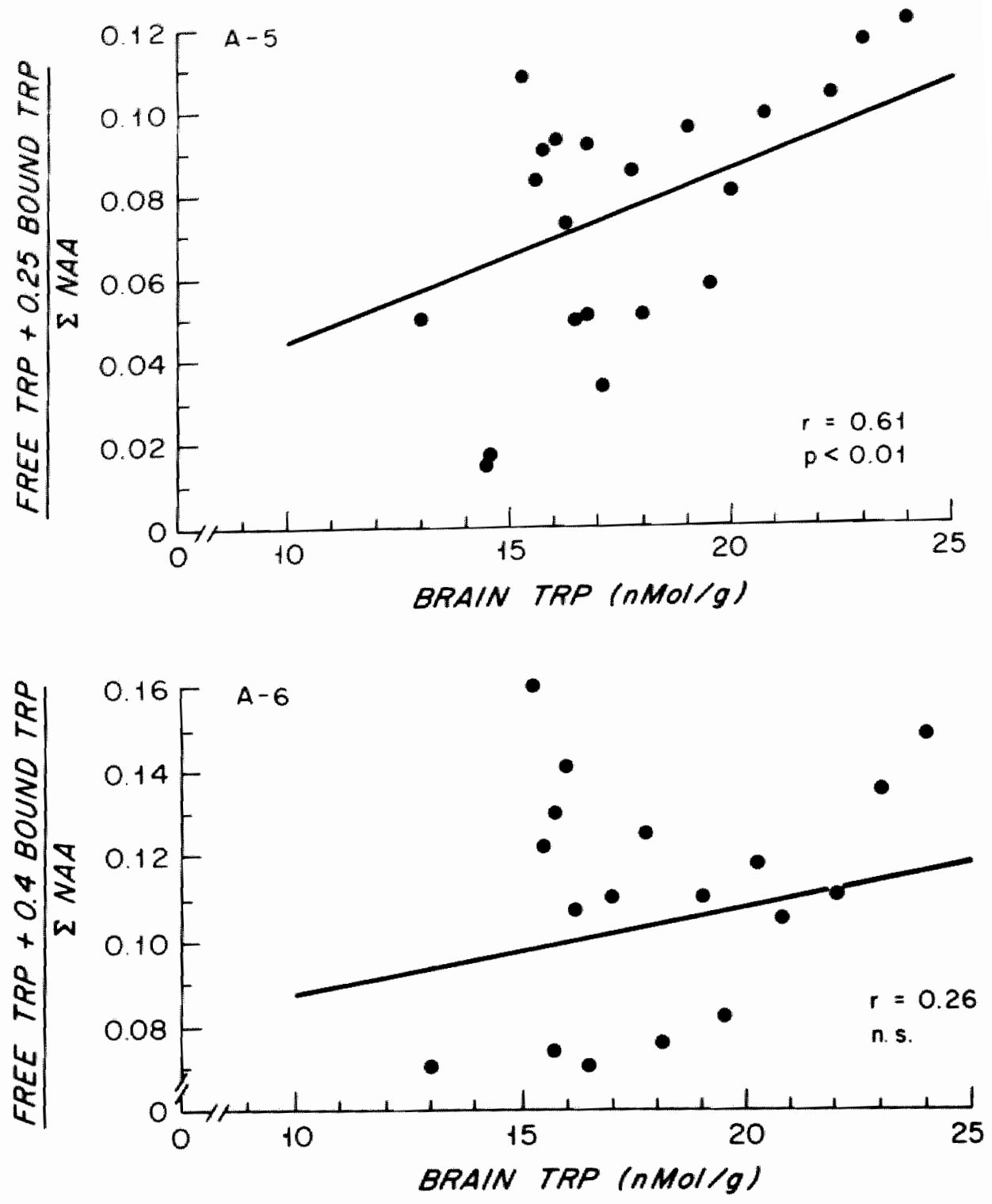

Legend to figures 9 A 5-6

Regression analysis to determine optimal relationship between bran TRP concentration and plasma free or bound TRP (see text). 

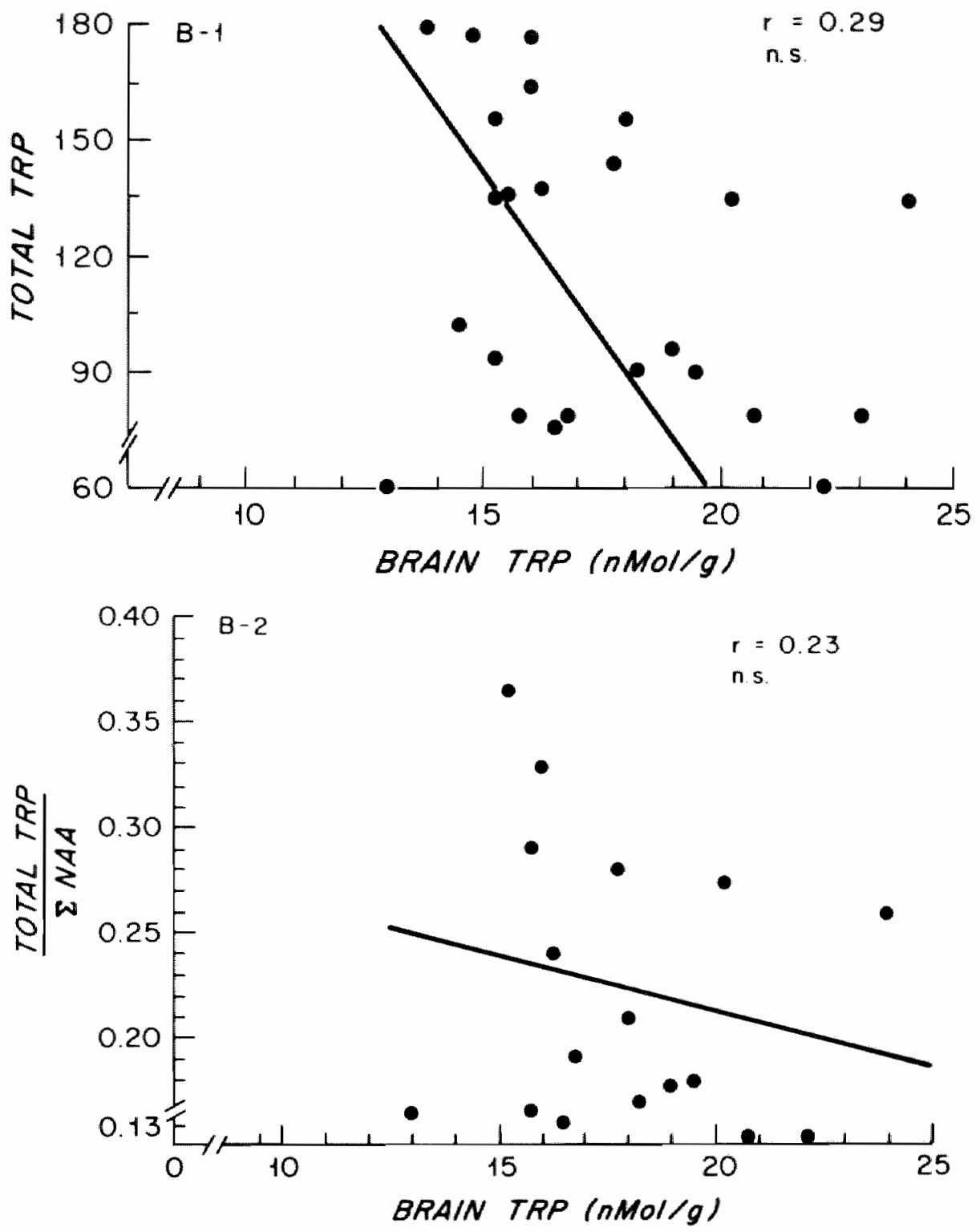

Legend to figures $9 B$ 1-2

Regression analysis to determine optimal relationship between brain TRP concentration and plasma free or bound TRP (see text). 
At first sight, our findings would be consistent with this assumption, but the competition by the remaining neutral amino acids and alterations of the carrier system at the blood-brain barrier itself still have to be considered. Brain levels of tryptophan decreased when another neutral amino acid was added to a tryptophan containing perfusate of rat brains. This was most markedly when the perfusion fluid contained albumin (284). According to the laws of competitive inhibition, the molar ratio of tryptophan to the sum of competing neutral aminoacids ( $\Sigma$ NAA) defines the apparent affinity of the blood-brain barrier transport system for tryptophan. The neutral amino acids that most effectively compete with tryptophan are: valine, leucine, isoleucine, tyrosine, phenylalanine and probably also methionine $(215,216)$.

Others propose that plasma free tryptophan versus $\Sigma$ NAA rather than total tryptophan versus $\Sigma$ NAA is crucial for the ultimate brain tryptophan concentration (221). From our experiments, it emerged that in the intramusculalry injected tumor-bearing rats. The sum of competitor amino acids was unchanged and therefore apparently could not inhibit tryptophan transport. The third factor involved the brain uptake index for tryptophan, was not altered either so that this factor could be disregarded. Several pathological conditions have been reported to induce local changes which might occur at the carrier site and consequently affect brain concentrations of tryptophan.

James et al. demonstrated increased blood-brain neutral amino acid transport activity in experimental hepatic failure (132). In this condition, the brain uptake index for tryptophan (BUI-trp) was increased (131).

Recently, Ziparo et al. demonstrated a similar phenomenon for experimental diabetes (286). Our results did not agree with the statement that plasma free tryptophan is the major determinant of brain tryptophan. as demonstrated with a regression analysis (figure 9).

The results of that analysis showed the best correlation in the ratio free $T R P+O .1$ bound tryptophan versus the sum of competing neutral amino acids

(free TRP +0.1 bound TRP) (figure $9-$ a3)

¿NAA

The ratio implies, that when $\Sigma$ NAA does not change, 10 per cent of bound tryptophan is stripped off albumin and added to the plasma free tryptophan during blood-brain transition. If, however 2 NAA changes significantly, a competition mechanism will limit the transport of tryptophan through the blood-brain barrier. We noticed greatly increased 
plasma $\Sigma$ NAA in rats which had received tumor cells by intraperitoneal injection instead of intramuscular. We do not have an explanation for this. but these animals had lower brain tryptophan concentrations, demonstrating that competition is involved.

Besides that, these animals ate more than the intramuscularly injected group. The numbers, however, were too small to attain significancy.

We suggest that in our experiments brain concentrations of tryptophan are determined by the ratio between the sum of plasma concentrations of free tryptophan and $10 \%$ of the fraction bound to albumin versus the sum of competing neutral amino acids.

\subsection{Conclusions}

From the data obtained in this experiment we may conclude that:

1. Free tryptophan concentrations in the plasma of Walker-256 tumorbearing rats are greatly increased secondary to raised plasma free fatty acid levels and decreased plasma albumin concentrations.

2. Brain tryptophan levels correlated best with the ratio

free tryptophan +0.1 bound tryptophan

¿NAA

\subsection{Summary}

Previous studies have shown differences in plasma and brain amino acid profiles of tumor-bearing rats as compared with normal controls. Brain tryptophan levels in tumor-bearing rats were relatively high compared to pair-fed control animals, while both groups had low plasma tryptophan concentrations. Apparently, the tumor-bearing rats had a facilitated bloodto-brain transition of tryptophan. The factors which are known to determine brain tryptophan concentrations were investigated and discussed in this study. It was found that plasma free tryptophan levels were greatly increased in tumor-bearing rats and that by means of simple regression analysis, the best correlation with brain tryptophan levels was obtained by the ratio free tryptophan +0.1 bound tryptophan/ $\Sigma$ NAA. 


\section{Chapter 5}

The impact of altered brain tryptophan concentrations on serotonin synthesis.

\subsection{Introduction}

From preceding studies we learned that anorectic Walker-256 tumorbearing rats had different amino acid patterns in their plasma and brains, some of which most likely are tumor associated rather than due to malnutrition. We found significantly higher brain tryptophan levels in these animals secondary to altered plasma factors which determine the concentration of plasma free tryptophan.

In the brain, tryptophan is hydroxylated by the enzyme tryptophan , hydroxylase to form 5-hydroxytryptophan (5-HTRP). The enzymology of tryptophan hydroxylase has not yet been worked out completely, but it is known to be the rate limiting enzyme in the conversion of tryptophan to serotonin (246) (figure 10).

At physiologic brain concentrations of tryptophan, the enzyme TRPhydroxylase is unsaturated and therefore alteration of brain tryptophan concentrations are directly reflected in altered serotonin metabolism 188 . 90). Since recent neuro-pharmacologic and neuro-physiologic data deliver evidence to implicate serotonin in feeding behaviour in a way that higher levels of brain serotonin are associated with hypophagia

(v.s. 1.1.3.) we start from the theory that increased brain serotonin concentrations in tumor-bearing rats as a consequence of raised brain tryptophan ultimately can explain the anorexia in these animals. This study was carried out to investigate the relationship between brain serotonin turn-over and precursor dynamics.

\subsection{Materials and methods}

Young female Sprague-Dawley rats $(80-100 \mathrm{~g})$ were kept individually in wire-bottom cages at $20^{\circ} \mathrm{C}$. A 12 hour dark-light schedule was maintained. After determining baseline values for daily food intake and growth for three consecutive days, groups of six animals were injected with $10^{6}$ Walker. 256 carcino-sarcoma cells in the right thigh and permitted free access to

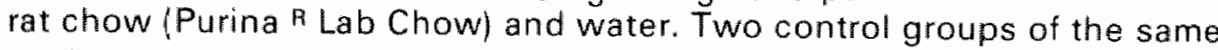
strain, sex and weight were injected with saline: one group (FF: freely feeding) was fed ad libitum while another group (PF: pair-fed) received only the amount of diet consumed the previous day by its paired TB rat. 
each animal in the PF group being carefully matched for weight and age with a TB rat. Food intake and body weight was estimated every day at the same hour. Ten days after injection, the animals were stunned and decapitated. The brains were rapidly removed and frozen on dry ice. The brains were hemisected sagitally. In one hemisphere of the brain. tryptophan was determined while the remaining part was processed for 5 HT and 5-HIAA estimation. For amino acid determinations, $0.5 \mathrm{ml}$ of plasma was deproteinized by addition of $1.5 \mathrm{ml}$ of a solution of $5 \%$ sulfosalicylic acid (SSA) which was previously adjusted to $\mathrm{pH} 1.8$ with $20 \%$ $\mathrm{LiOH}$. Brains were weighed and homogenized in 3 volumes ( $3 \times \mathrm{wgt}$ ) of the same deproteinizing solution. After protein precipitation, samples were centrifuged $\left(10.000 \mathrm{rpm} 25 \mathrm{~min} .4^{\circ} \mathrm{C}\right)$ and the supernatants frozen at $-70^{\circ}$ - until analysis. Tryptophan was assayed fluorometrically by the method of Dencla and Dewey as revised by Bloxam and Warren (65,30). 5-HIAA were measured as described by Curzon and Green (57). The extracts of 5-HT and 5-HIAA were complexed with OPT as previously described and measured fluorometrically on an Amino-Bowman fluorometer. Recoveries were determined by the addition of known amounts of 5-HT and 5-HIAA to homogenates.

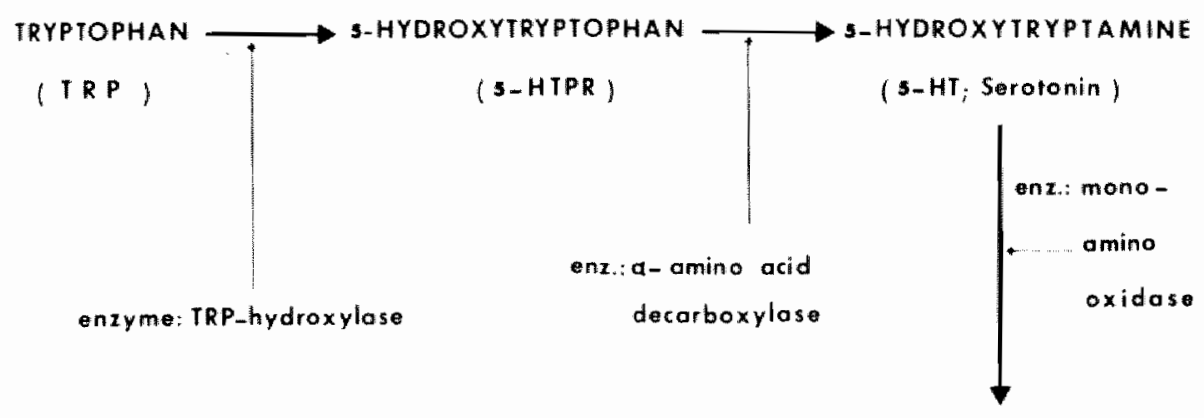

5-HYDROXYINDOIYLACETIC ACID

(3-HIAA)

Legend to figure 10

Schematic metabolic pathway of serotonine synthesis and degradation in the brain. 


\subsection{Results}

All tumor-bearing rats ate significantly less than freely feeding controls (table 1; figure 2). As in our previous experiments, brain tryptophan levels of $\mathrm{TB}$ rats were significantly higher by about $25 \%$ as compared to PF rats (table 2).

Table 6 shows that TB rats had significantly higher 5-HIAA levels as compared to PF rats. Brain serotonin was also higher in these animals but not significantly. Serotonin turn-over, as measured by 5-HIAA levels. correlated with brain TRP levels $(=0.54, p$ e 0.05$)$ (figure 11).

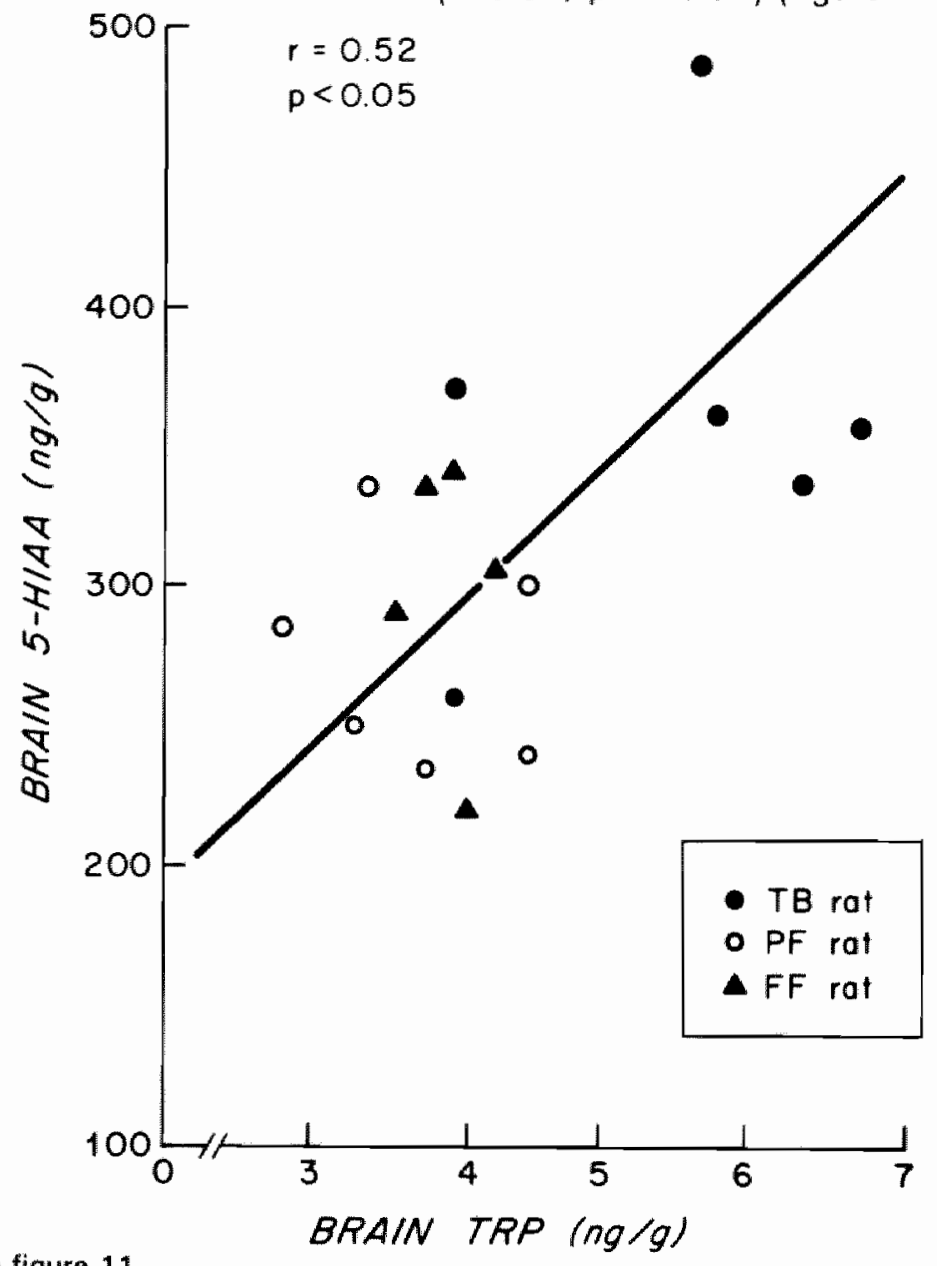

Legend to figure 11

Positive correlation between brain TRP values and brain 5-HIAA of each animal (17 animals total). Statistical significance $p<0.05$ determined by student's t-test. 


\subsection{Discussion}

It is generally accepted that serotonin turn-over in the brain is better reflected by 5 -HIAA content than by 5 -HT content itself $(58,146)$. In our experiments, a reasonable linear correlation between 5-HIAA and brain tryptophan levels was present. The correlation between brain tryptophan and 5-HIAA is more convincingly demonstrated in TB-rats in non-tumorbearing rats and the correlation with non-TB rats alone was not statistically significant.

However, when all animals were considered a significant linear correlation was obtained. This is consistent wiht results reported by others in which brain tryptophan levels correlated linearily with brain 5-HIAA concentrations $(90,146)$.

It has been suggested that changes in brain tryptophan fand hence in serotonin turn-over) following ingestion of food may convey information to the brain about the nutritional state of the organism $(84,90)$.

If this hypothesis is valid, then changes in any of the factors affecting blood-brain transport of tryptophan also may affect those centrally controlled activities, which depend upon nutritional information such as feeding behaviour.

In our experiment, tumor-bearing animals had a relatively high serotonin turn-over while in their pair-fed controls, this was relatively low.

Neuro-pharmacologic and neuro-physiologic studies gave evidence to implicate serotonin in feeding behaviour $(17,18,25,40,94,95,96,107$, $138,282,283)$. The results of these studies can be summarized: increased serotoninergic activity is associated with hypophagia while decreased activity induces hyperphagia. In view of the results from our experiments, this could imply that the tumor-bearing rats reduced their food intake because of an inadequately high serotonin turn-over while the pair-fed controls would behave hyperphagic if they were given the food.

We therefore hypothesize that the higher brain trytophan in tumorbearing rats may cause or at last contribute to tumor induced anorexia.

\subsection{Conclusions}

The following conclusions can be drawn from the data collected in this study. 
BRAIN TRP, 5-HIAA AND 5-HT VALUES IN THE THREE GROUPS (MEAN \pm SEM)

\begin{tabular}{|c|c|c|c|}
\cline { 2 - 4 } \multicolumn{1}{c|}{} & TB & PF & FF \\
\hline $\begin{array}{c}\text { BRAIN TRP } \\
\text { (n Mol/g) }\end{array}$ & $27.150 \pm 2.400^{* *}$ & $18.600 \pm 1.400$ & $19.800 \pm 0.550$ \\
\hline $\begin{array}{c}5-\mathrm{H} / \mathrm{AA} \\
(\mathrm{pMol} / \mathrm{g})\end{array}$ & $1.888 \pm 0.152^{* *}$ & $1.433 \pm 0.084$ & $1.553 \pm 0.110$ \\
\hline $\begin{array}{c}5-\mathrm{HT} \\
(\mathrm{pMO} / \mathrm{g})\end{array}$ & $3.019 \pm 0.136^{\text {ns }}$ & $2.747 \pm 0.159$ & $2.852 \pm 0.114$ \\
\hline
\end{tabular}

$* 0<0.01$

\section{Legend to table 6 :}

Results expressed as mean \pm SD for each group.

Statistical significance ** $p<0.01$ in column headed TB represents significance of differences between TB vs. PF rats (t-test for paired data). 
1. Brain concentrations of 5-HIAA, the principal metabolite from serotonin, were significantly higher in tumor-bearing rats than compared with their pair-fed controls $(p<0.01)$.

2. Brain concentrations of serotonin were also higher in tumor-bearing rats, but the difference did not reach statistical significance.

3. The tumor-bearing group of rats had increased serotonin turn-over while this was decreased in the pair-fed control rats, conditions which may be associated with hypophagia and potential hyperphagia respectively, considering that brain serotonin turnover is best reflected by the brain concentrations of 5-HIAA.

4. The results give support to the theory that elevated brain tryptophan levels and hence serotonin turn-over may induce or at least contribute to tumor associated anorexia.

\subsection{Summary}

This study is performed to test a theory regarding the relationship between brain tryptophan levels versus serotonin turn-over and the relation with the tumor anorexia.

In previous experiments, it has been demonstrated that tumor-bearing rats had high brain tryptophan when compared with a pair-fed control group. In this experiment, we showed that brain serotonin turn-over as measured by 5-HIAA correlated with brain tryptophan concentrations.

Anorectic, tumor-bearing rats had a higher serotonin turn-over than their semi-starved, pair-fed controls. Recent data from neuro-pharmacologic and neuro-physiologic studies are suggestive to implicate serotonin in feeding behaviour in a way that increased serotonin turn-over is accompanied by anorexia and a decreased activity is associated with hyperphagia. This study gives support to the theory that the elevated serotonin activity in TB rats may be responsible for the tumor induced anorexia. 


\section{Chapter 6}

Evidence to support the role of serotonin in feeding behaviour and cancer anorexia.

\subsection{General aspects of serotonin as central neurotransmitter.}

Like the catecholamines, norepinephrine and dopamine, the indoleamine, serotinin, is a putative neurotransmitter in certain neuronal tracts of the brain, but it is among the putative neurotransmitters a very likely one, although it does not fulfill all criteria necessary for the strict definition of a neurotransmittor (183).

A great deal of information about catecholamines and serotonin had accumulated prior to knowledge of which neuronal tracts contained them or even whether they were localized in neurons at all.

The cell bodies of serotonin containing neurons are localized in a series of nuclei in the lower midbrain and upper pons and medulla that are called raphe nuclei. These are a group of phylogenetically old structures, whose function was pbscure, until it was discovered, that they did contain serotonin. Serotonin is so highly concentrated in these raphe nuclei that probably all of its cells are serotoninergic.

Serotoninergic axons ascend primarily in the medial forebrain bundle and give off terminals to all brain regions and the spinal cord with the major proportion in the hypothalamus and the least in the cerebellum and cerebral cortex $(32,63,245)$.

A detailed study in serotonin distribution has been presented by Saavedra (1977). The medial forebrain bundle contains the highest amount of serotonin, $30 \mathrm{ng} / \mathrm{mg}$ protein, followed by the hypothalamus, $18,8 \mathrm{ng} / \mathrm{mg}$ protein. In the brain stem, but more precisely in the raphe nuclei, the highest serotonin concentrations were measured. In these nuclei, the highest concentrations of the enzyme tryptophan hydroxylase were measured (233). As shown in figure 10, tryptophan is hydroxylated by this enzyme to form 5-hydroxytryptophan and this enzyme is ratelimiting in the conversion of tryptophan to serotonin (figure 10) (246).

There is some evidence that synthesis of this enzyme is influenced by altered activity of nerves, containing serotonin (70). It is an established fact however, that tryptophan hydroxylase is unsaturated at physiologic brain tryptophan levels and that alteration of brain tryptophan concentrations are reflected in altered serotonin synthesis rate $(88,90)$.

It has been demonstrated by Mandell et all (1977) that a dynamic barrier exists between total brain levels of tryptophan and intra-neuronal 
tryptophan hydroxylase by way of the presence of two uptake systems in serotoninergic synaptosomes, with high and low affinity for radioactive tryptophan respectively. Changes in the high affinity uptake are reflected by comparable changes in the conversion of tryptophan by synaptosomes. This system might exert a regulatory role as demonstrated by influencing the high affinity system with drugs (e.g. lithium), such that as intraneuronal tryptophan increases, the concentration of tryptophan hydroxylase decreases, apparently in compensation, suggesting a buffer mechanism (167). However, this mechanism does not seem to be operative under physiological conditions, as serotonin turn-over rate appears to correlate with tryptophan concentration until the concentration was reached at which tryptophan hydroxylase was fully saturated (88). The further steps in serotonin synthesis are simple: 5-hydroxytryptophan is decarboxylated by an, aspecific, aromatic amino acid decarboxylase to form 5-hydroxytryptamin or serotonin. 5-Hydroxytryptophan decarboxylase, like DOPA-decarboxylase is able to decarboxylate all aromatic amino acids.

Serotonin breakdown is initiated by one enzyme, mono amino oxidase (MAO). Serotonin is not established as a significant neurotransmitter in peripheral nerves. Similar to other central neurotransmitters, serotonin accumulates in serotoninergic nerves via a highly specific uptake system operating at the level of the neuronal membrane (246). The synaptosomal membrane is involved in the release and re-uptake of serotonin. Storage of the biogenic amines at the presynaptic nerve terminal appears to occur in vesicles, the vesicular membrane playing a major role in the maintenance of the stores. The transport across this membrance can be active. involving different ATP-ases, requires sodium, is saturable, and obeys Michaelis-Menten kinetics, while it can be blocked by reserpine.

Uptake blockade in the synaptic vesicles is never complete as diffusion remains possible (112). Complete blockade cannot be achieved with tricyclic antidepressants. They block (re-) uptake from both catecholamines (CA) and indolamines (IA) at the membrance of the nerve terminal. The ratio CA/IA - uptake inhibition differs with the drug used. The availability of the neurotransmitter serotonin at this level is regulated by (re)-uptake, storage and release of the biogenic amine (112). Like other neurotransmitters, which have been investigated, the action can be terminated by reuptake into the nerve terminals that had released the neurotransmitter (245). The uptake 'pump' in the serotoninergic neuron differs from the pump in norepinephrine or other monoamine containing neurons in substrate specificity and susceptibility to inhibitors. A specific re-uptake blocking agent for serotonin is Fluoxetin (Lilli 110140). which induces a prolonged post-synaptic action of serotonin. Serotonin synthesis rate declines in these cases, may be by way of a compensatory mechanism in response to an enhanced action on serotoninergic receptors (94). 
There are two types of serotoninergic receptors in the brain, exitatory and inhibitory receptors (94). Inhibitory serotonin receptors can be presynaptic and localized in serotonin containing neurons in the dorsal raphe nucleus, or post-synaptic in neurons that have been documented to receive serotonin input. Serotonin antagonists do counteract all excitatory effects of serotonin but apparently do not antagonize inhibitory effects as readily (111). Serotonin antagonism can be achieved by 5 -HT reducing drugs or by synaptic blockade. Drugs that cause a marked reduction in serotonin in brain can be grouped into three categories in relation to their mechanisms of action: drugs that release the vesicular stores of serotonin such as reserpine: drugs that inhibit synthesis by competitive inhibition of enzymes such as $p$-chlorophenylalaline ( $p$-CPA) and drugs that have a cytotoxic effect on serotoninergic neurons such as 5,6- and 5,7-dihydroxytryptamine.

Some drugs have combined effects such as p-chloroamphetamin ( $p$-CA) of which the neurotoxicity might be responsible for its long lasting effect, i.e. a serotonin depletion of up to four months. The neuro-toxicity op p-CA seems to be limited to B-group cells of Dahlstrom and Fuxe, a group of mesencephalic cells which usually do not contribute much to serotonin levels. It is likely therefore, that areas are invoived, but these are not mapped out yet. The antagonistic action of $\mathrm{p}-\mathrm{CA}$ is limited to the serotoninergic system and does not affect the cathecholamines. $p$ Chlorophenylalanine (p-CPA) is a potent inhibitor or tryptophan hydroxylase with a less specific action.

The drug can compete with the transport mechanisms of tryptophan and the other neutral amino acids across the blood-brain barrier, it causes depletion of brain catecholamines and inhibitis the enzyme phenylalaline hydroxylase (50). The drug is decarboxylated in the brain to parachlorophenylethyl-amine which is a central stimulating agent 150 . 143,1441 .

Some of the advantages and disadvantages of cytotoxic drugs as 5,6 and 5,7-dihydroxy-triptamine have been extensively reviewed by Sanders-Busch (238). Post-synaptic acting serotonin blockers are e.g. cyproheptadine, methysergide and methiothepin.

The mechanism of serotoninergic neurotransmission has been described extensively by Aprison et al (8). They proposed a model of the serotoninergic synapse having a minium of three pools. In addition the to the released neurotransmitter pool, a larger amount of transmitter probably exists in two bound or storage forms within the nerve ending. Consequently, the total transmitter level may be composed of at least these three compartments or pools that are in equilibrium, a firmly bound pool, a labile bound pool, and a free pool.

An active transport mechanism operating in the pre-synaptic membrane permits transmitter from the free pool to be taken up by the nerve endings. 
The transmitter becomes part of the labile pool again or is rapidly metabolized. Hence, part of the 5-HT taken up into the pre-synaptic endings may diffuse directly to the site of MAO located in the mitochondria. It was suggested that the labile bound pool and the free pool represent a physiologically effective unit, and that in studies using concomitant measures of behavioural changes and changes in levels of neurochemical transmitter, the best correlation should be expected by measuring this physiological pool instead of total transmitter content in the brain, as usually occurs. However, evidence exists, that examination of turn-over rates of the serotonin can provide sufficient insight into neurochemical behavioural relationships $(8,225)$.

In summary: in the central nervous system, serotonin is a putative neurotransmitter, mainly localized in a phylogenetically old region of the brain, the raphe nuclei, which is in close connection with different higher brain-centers (e.g. the hypothalamus) and which are involved in different neurovegetative systems. The disposition of the neurotransmitter serotonin at the synaptic level is controlled by (re)-uptake, storage and release of it. Re-uptake terminates the action of the neurotransmitter. Different drugs, which promote or antagonize serotonin are discussed.

\subsection{Serotonin and behaviour}

Jouvet (1969) and other investigators presented studies on the relationship between brain serotonin and sleeping patterns $(136,246)$. Decreases in $5-H T$ coincide with hyposomnia, while the relationship between increased 5-HT and sleep is not clear, because in some situations increased 5-HT content dit not lead to increased sleep. Changes in behavioural patterns due to p-CPA induced serotonin depletion has been studied in several species. p-CPA gives in cats complete insomnia (136). in cats and rats excessively high sexual activity was noticed. In rats, only homosexual mounting was facilitated with no enhancement of the frequency of heterosexual interactions. Others have stated that serotonin inhibits and catecholamines stimulate sexual behaviour. Aggressive behaviour became more pronounced in rats but less in mice, when brain serotonin was decreased. Faster acquistition of conditioned avoidance response and facilitated learning was found in rats with low brain serotonin was decreased. Faster acquisition of conditioned avoidance administration of 5-hydroxy-tryptophan, thus bypassing the enzymeblockade to the synthesis of serotonin, which cannot cross the blood-brain barrier $(8,247,282)$. Serotonin also is involved in reaction upon painful stimuli. Depletion 5-HT can increase sensitivity to pain while increase in serotonin content in the brain decreases pain sensitivity.

Bogdanski et al (1958) reported pharmacological studies with large doses 
of the serotonin precursor 5-hydroxy-tryptophan in dogs, cats, rabbits, rats and mice and found depression of motor activity in all species concomitantly with increasing brain serotonin concentrations (35).

Serotonin apparently is also involved in the circadian rhythm, although it is not clear whether the diurnal variation in brain serotonin is secondary to circadian variations of tryptophan in serum (120).

Increased serotoninergic activity is also believed to lower body temperature and to be involved in gonadotrophin secretion, both functions which are disturbed in anorexia nervosa $(54,134)$.

Recently, Krieger et al (1976) presented evidence for serotonin being involved in the stimulation of ACTH-release (149).

It has been suggested that the serotoninergic system may be involved in psychiatric depression. Some relate high serotcnin to endogenous depressive state while others do not adhere to such a relationship $(2,29$. 202). Carrol (1977) interestingly suggests a treatment for Cushings disease with a serotonin antagonist (i.e. cyproheptadin), thus reducing the disturbance of the circadian rhythm and depressive condition, which goes along with this disease (47).

In summary: serotonin is related to sleep, sexual activity and aggressive and learning behaviour, but there is inconsistency in different species. Serotonin evidently is involved in the control of circadian rhythm, body temperature and the release of hormones (e.g. gonadotrophin, ACTH).

\subsection{Serotonin and feeding behaviour}

Although a voluminous literature exists on serotonin, the functional role of this indoleamine in the central nervous system and its relation to behavioural changes in animals and man are far from clear. The determination of an uneven distribution of serotonin in the hypothalamus with high 5-HT in nuclei associated with neuro-endocrine mechanisms, gives rise to the possibility that serotonin may be involved in the regulation of specific endocrine and neurovegetative function. Evidence to implicate serotonin in feeding emerges from a number of sources. That serotonin containing neurons may participate in systems, whereby the brain integrates information about metabolic state, has been suggested by Fernstrom et al. (1971) since they noticed that injection of insulin or carbohydrate in rats caused sequential increases in TRP concentration in plasma and brain with concomitant increase in brain serotonin turn-over (86). Serotonin given systemically is reported to cross the blood-brain barrier, although Koëlla has demonstrated that in the area postrema there may be a 'hole', where substances cannot enter the brain, but can 
penetrate into the paravascular tissue to a considerable degree. The area postrema could be the site of accumulation of perivasal serotonin receptors that could easily be reached by blood borne and CSF borne substances (145). When serotonin is injected into one of the brain ventricles, anorexia results, an effect which could be reversed by the serotonin antagonist, cyproheptadine.

Raising brain concentrations of serotonin by other means, equally resulted in decreased food intake. The currently popular anorectic drugs

Fenfluramine and Fluoxetine interact in the serotoninergic system, the first by releasing serotonin and blocking its re-uptake, the latter by blocking synaptic re-uptake alone $(94,138,236)$.

The anorectic action of these drugs is enhanced with pre-treatment with serotonin precursors (tryptophan and 5-hydroxy-tryptophan) had been instituted $(107,283)$. Antagonizing the serotoninergic system produces an opposite effect upon feeding behaviour.

Inhibition of serotonin synthesis by intraventricular administration of $p$ chlorophenylalanine caused hyperphagia and obesity of rats $(40)$. It should be noticed, that systemic administration of $p$-CPA by enteral or parenteral route may reduce food intake because it produces marked intestinal damage and causes severe discomfort in experimental animals $(41,95)$ although it appears to be tolerated better by humans. Two oiher drugs inducing hyperphagia should be discussed. The drugs are post-synaptic serotonin blockers and have been used initially for other purposes than increasing appetite. Cypropheptadine was meant to be an histamine antagonist, and methysergide was designed to be an anti-migraine drug, i.e. a peripheral anti-serotoninergic drug (28). Both drugs proved to have a common side effect: hyperphagia. Weight gain often was an unsollicited side effect of the used of these drugs. On the other hand, the hyperphagic effect of these drugs was soon employed for new indications.

Parallel to this development, these drugs proved to have a clear antiserotoninergic action and were used as such in neuro-psychiatric studies involving seretonin's role in schizophrenia or depression, for example. There is a fair amount of literature concerning the effect of serotonin's blocking agents and their indirect influence upon appetite in rodents, cats and humans $(18,25,48,96,126,127,236)$. These drugs also antagonized anorexia induced by serotonin releasing drugs $(17,95)$ or protected against drug induced anorexia when pretreated with a serotonin blocking agent (53).

Some studies on food intake and serotonin antagonists do not report hyperphagic effects. In these cases, however, the time period during which food intake actually was studied was only 2 hours, which might be too short because the duration of action of serotonin releasing or antagonizing drugs is much longer and interaction between these drugs have not been fully studied yet (31). Interestingly. Chakrabarty (1976) and 
his group reported alterations in activity on electroencephalographs taken from the lateral hypothalamic region after administration of cyproheptadine, but no changes were noticed in the ventromedial part of the hypothalamus. In these experiments, food intake was doubled after injection of cyproheptadine (48).

Our experiments with cyproheptadine and methysergide upon food intake in rats were rather discouraging. We noticed hypophagia almost invariably as shown in figure 12,13 both after intraperitoneal and oral

administration. We tried to explain this by proposing an action analogous to action of p-CPA, which causes profound nausea when given systemically, but hyperphagia when appropriately administered intra-cerebrally $(40,95)$. We therefore planned to test the drugs by intracisternal injection. For methysergide this appeared reasonable because the intracerebral level of this drug is only $13 \%$ of the expected calculated dosis, probably secondary to a very poor penetration of the blood-brain barrier $(27,150)$.

\section{Legend}

Fig. 12

Effect of cyproheptadine and methysergide on food intake in normal rats.

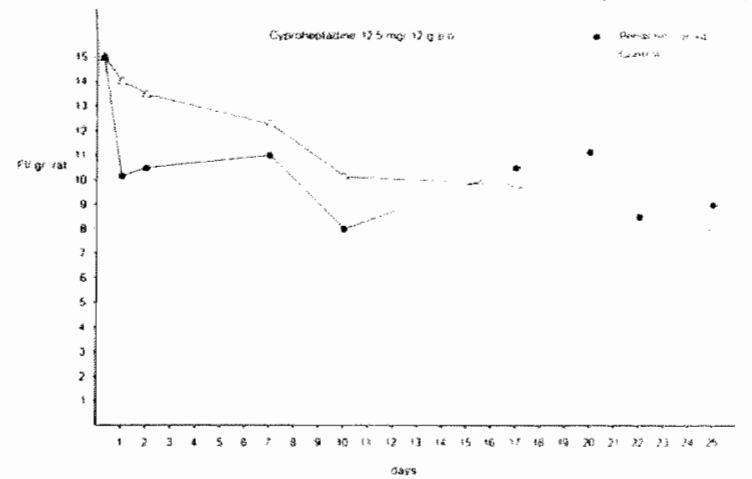

tars

\section{Legend}

Fig. 13

Effect of methysergide on food intake in nomal rats.

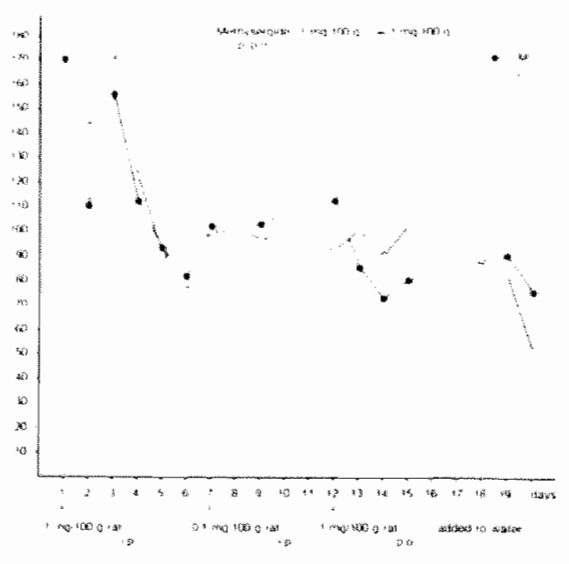




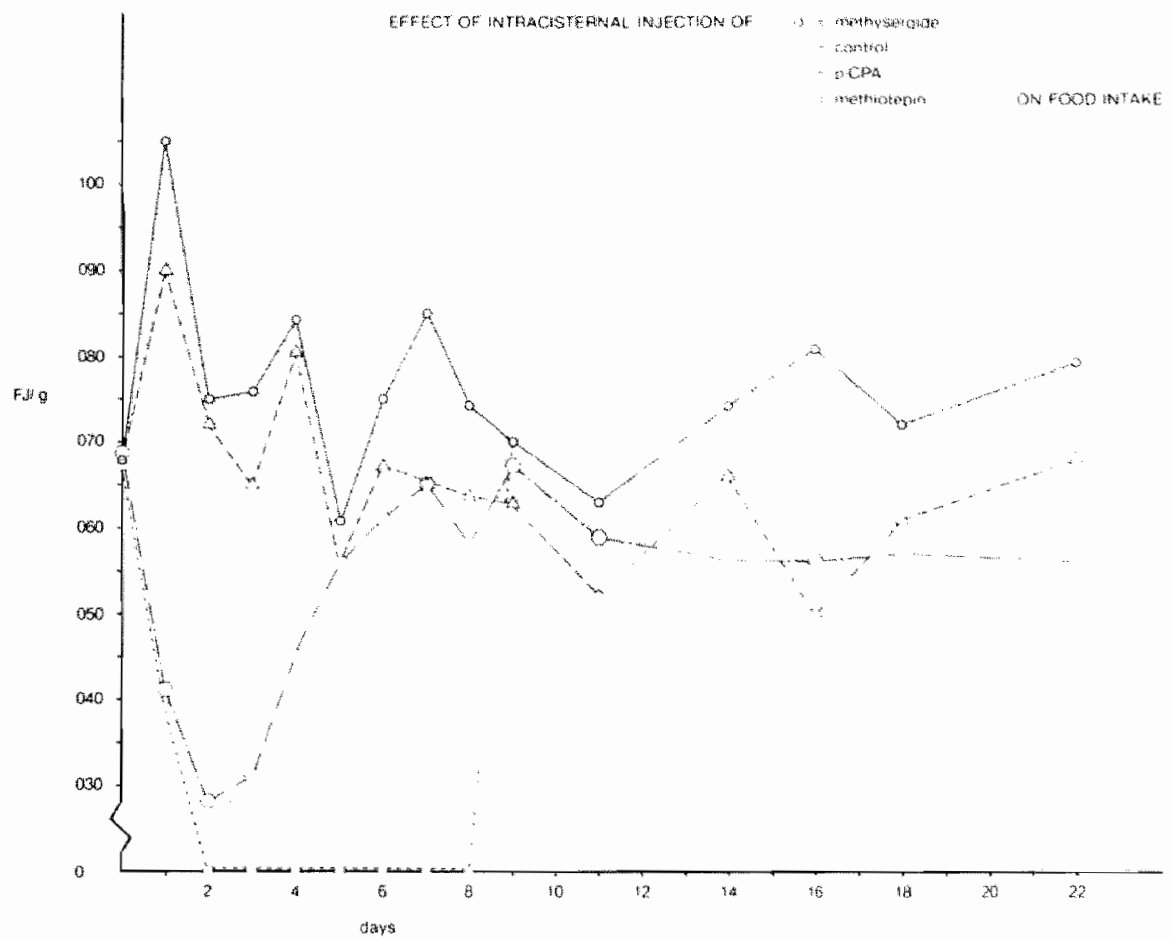

\section{Legend fig. 14}

Effect of intracisternal injections of methysergide on food intake of normal rats - a pilot study.

Female Sprague-Dawley rats $(200-250$ g) were housed individually in wire-bottom cages at $20^{\circ} \mathrm{C}$ and 12 hour dark-light schedule was maintained. One group $(n=6)$ received an intracisternal injection of $0.1 \mathrm{mg}$ Methysergide/100 $\mathrm{g}$ rat in $50 \mathrm{~A}$ artificial CSF (M.G.H. pharmacy). A control group ( $n=6)$, matched for strain, sex, body weight and food intake received intracisternal injections of the vehiculum only. The intracisternal injections were given under

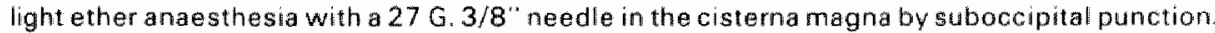
A third group ( $n=6$ ) of matched control rats was not injected and served as a "blanc" reference. Food intake and body weight were determined daily.

\section{Note:}

p. CPA and methiotepin have not been included in the discussion because the pilot study was only meant to determine which serotonine blocker was appropriate to induce hyperphagia by intracisternal injection. Much more data have to be collected to allow further conclusions. 
Unfortunately, we could not administer cyproheptadine by the intracisternal route because we could not dilute the drug to a concentration which was suitable for injection. We demonstrated, that an injection of $1 \mathrm{mg} / \mathrm{kg}$ of methysergide into the cisterna magna of rats results in a significant increase in food intake, an effect which lasts for about three weeks (figure 14). As discussed earlier, the prolonged action of p-CPA and p-chloroamphetamine supposedly is due to some degree of neuron toxicity (238). Whether this is the case with methysergide as well is currently under investigation.

In summary, it has been well established that central serotonin activity is involved in feeding behaviour. Evidence for this comes from number of sources. Currently used drugs against obesity like Fenfluramine and Fenoxetine act by increasing brain serotoninergic activity. Serotonin antagonists like p-CPA, cyproheptadine and methysergide cause hyperphagia or restore normal feeding when anorexia was instituted with serotoninergic drugs. We report the effect upon food intake as we observed it in our experiments. Some contradictory facts are discussed. We noticed that intracisternal injection of methysergide causes prolonged hyperphagia, a phenomenon which has been reported of $\mathrm{p}$-CA but not methysergide.

\subsection{Serotonin and cancer anorexia}

When rats were pre-treated with methysergide intracisternally and subsequently injected with $10^{6}$ Walker-256 cells (intramuscularly) we did not notice significant decrease in food intake as was observed in rats which were injected with Walker-256 cells only (figure 15). We expected however that the $30 \%$ increase in brain serotonin activity we measured in anorectic, tumor-bearing rats (147) would be reflected in a "decreased" antagonism" of methysergide.

Although these data do not permit conclusions at this stage, they do support the involvement of serotonin in anorexia of tumor-bearing organisms, like we hypothesized from data observed with our tumor model (147, 148, this thesis chapt. $4,5,6)$.

It is obviously difficult to obtain similar data from anorectic cancer patients. It is known, however, that in man brain tryptophan levels correlate well with serotonin activity (221). If the premise is accepted that plasma free tryptophan determines brain tryptophan levels in man as well as in the rat harbouring a tumor, then the finding of increased plasma free tryptophan levels may serve as indirect proof for increased serotonin activity. In fact, we have found that plasma free tryptophan was more than doubled in anorectic cancer patients, which was equally found in the animal study. In these patients, however, more factors may have contributed to alter free tryptophan concentrations. 
We were also interested in the other behavioural aspects of an altered serotoninergic state in our experiments with rats.

Of special interest in the study performed by Morisson (1974) in Walker256 carcinoma bearing Sprague-Dawley rats, in which he noticed that the normal high night/day - feeding ratio was depressed with the growth of Walker-256 carcinoma, and other tumors. He also noticed that changes in diurnal ratios preceded the decline in total daily food intake (194). As has been stated before, the circadian rhythm is triggered by serotoninergic mechanisms, thus the finding of altered diurnal pattern may be a reflection of changes in brain serotonin activity. In a pilot study, we also noticed alterations of diurnal activity patterns in tumor-bearing animals.

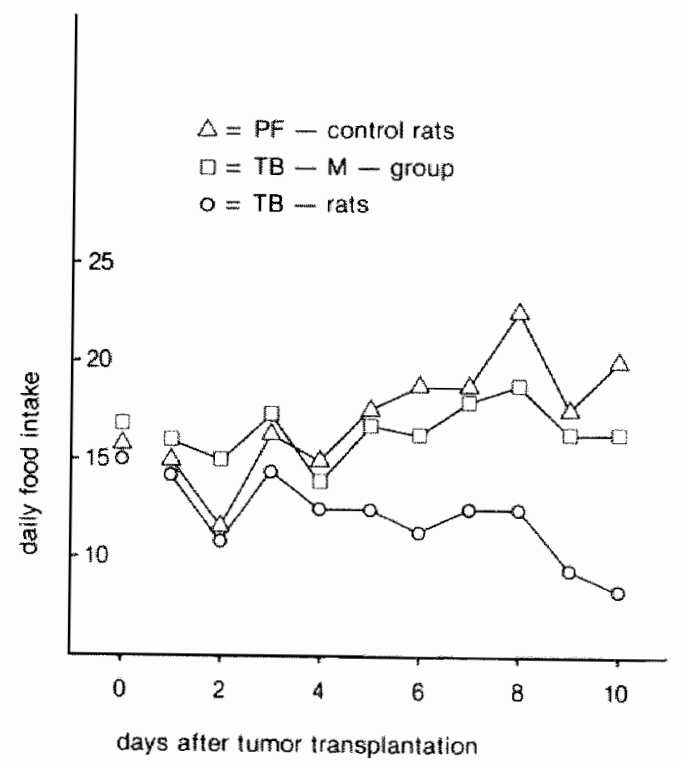

\section{Legend}

Fig. 15

The effect of intracisternal administration to methysergide on tumor associated anorexia A pilot study. 
We observed individually housed tumor-bearing rats in activity chambers which were equiped with electronic detectors of animal motor activity, and compared these animals with normal control rats of the same strain, sex. age and body weight. The normal high night-day activity ratio was depressed in tumor bearing rats: they were more active during day-time. This could be explained by the fact that the tumor burden may disable the tumor-bearing rats to a degree which makes it impossible to gather enough food during the night. We therefore introduced a sham-operated control group in which marbles were implanted into the thigh. which to the best of our judgement mimicked motor disability of the tumor condition fairly well. These animals did not show increased activity during the day. but seemed to be less active during the night without significantly decrease their food intake. It should be stressed, that this activity study was only a pilot study with too small a number of animals for statistical evaluation, but the preliminary results fitted well in the proposition of serotonin-induced alterations of several basic functions.

In patients, altered diumal patterns have not been reported. However, it was observed by Joanne Perri from the department of oncology at the New England Deaconess Hospital in Boston, Massachusetts, U.S.A., that cancer patients often were awake around midnight (222).

Other evidence, supporting for the concept of altered serotoninergic activity was derived from studies carried out by dr. Jimmie Holland and her group at the Memorial Sloan-Kettering Cancer Center in New York on the "vegatative depression" of cancer patients. She noticed, that depressive conditions in advanced cancer disease differed from the "psychiatric" depression in some essential points, e.g. there is no decreased self esteem in cancer associated depression and this depressive condition apparently does not improve with tri-cyclic antidepressive drugs, which owe their therapeutic activity to inhibition of the uptake of biogenic amines with resulting potentiation of amine release into synaptic cleft $(126,127,223,246)$. She moreover suggested that the anorexia in these patients was an expression of depressiveness and reported good effects of treatments with drugs like cannabis sativa and cyproheptadine.

We made an attempt to document cancer anorexia in relation with the supposed "vegetative depression" using a questionnaire (figure 16) and interviewed 31 anorectic patients with different types of malignancies, in whom the diagnosis had been proven through pathology but who were awaiting definitive treatment. One of the most striking results was that a greater number of patients simply were unaware of their anorexia. In these patients, the diet history proved the existence of anorexia and the patients were surprised to discover their decreased food intake. The anorexia was detected by others rather than by the patient himself. As for the type of anorexia, most patients who were conscious of their decreased appetite, complained of early satiety. To a minor extent, nausea was the 
1. Onset of Anorexia

Onset of weight loss

How detected

(5) Patient

(2) Family/triends

[0 Other

(c) a. do not know

(2) b. approximately

10. do not know

b. b. appoximately

\title{
2. Type of anorexia
}

weeks

months

weeks

months

(3) a aversion to certain food

[1] b. early satiety

c. nausea before and/or during meals

3) "selective appetite"

B e. unaware of decreased appetite

3. Diet prior to onset of anorexia

$\square$ Breakfast:

$\square$ in-between:

$\square$ Lunch:

$\square$ In-between:

$\square$ Supper:

[ Snacks:

[ Alcohol:

$\square$ Goodies/pastries:

4. Awareness of diagnosis

Hes [5 No

Changed appetite after diagnosis

(3) Yes [1 No [ Do not know

5. Other disorders to which anorexia can be attributed

\author{
7] Organic \\ (9) Pychiatric \\ [0] Drugs llist names \& dosel
}

6. Concomitant symptoms

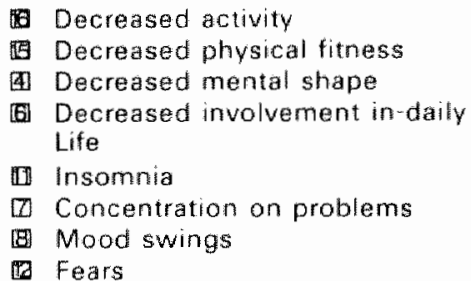

Legend to figure 16

Questionnaire on anorexia in cancer patients, results are reflected by the numbers in the squares. For details: see text. 
causative agent for decreased appetite, one patient already received chemotherapy for a stage 4 Hodgkin disease at the time of the interview. a second patient had $X$-ray therapy for inoperable breast cancer and the last patient was suffering from an adenocarcinoma of the bowel with bony metastases. With 'selective appetite" (figures 16-2d) it was meant to grossly uncover altered taste and consequent changes in preference for certain food. This was present in three cases, but there was new common preference. The extensive diet history was indispensible for the detection of anorexia. There was no common pattern in which food intake was decreased. Interestingly, some patients simply forgot to eat but would eat when someone else mentioned eating.

The question about the awareness of the patients diagnosis was put in to obtain some information about the psychological stress and consequent alteration of appetite. It become apparent that $25 \%$ of patients aware of being anorectic attributed their anorexia to their knowing to have a malignancy. It should be noticed that a relatively high score was obtained for concomitants symptoms. All the questions did concern the situation before the patient was hospitalized.

Although this investigation was only a brief orientation, is seems that the anorexia of cancer patients may be considered a part of a vegetative depressive state. We hypothesized that anorexia in cancer might be a serotonin dependent phenomenon in humans and found fairly good evidence for it in animal studies and it seems that serotoninergic systems being involved in the syndrome of vegetative depression of cancer. Extended investigation on this subject is mandatory.

If the hypothesis stands, cancer anorexia and the remaining symptoms of the vegetative depression syndrome in cancer will become a treatable problem.

In summary: the anorexia in tumor-bearing rats was reversed by intracisternally administered methysergide. Reports from the Memorial Sloan Kettering Cancer Institute in New York mentioned increased food intake in cancer patients with cyproheptadine. In anorectic cancer patients, plasma conditions which determine serotonin are identical to those in tumor-bearing animals suggesting an altered serotoninergic status in these patients. Other behavioural aspects of an increased brain serotonin are discussed. In the rats and maybe also in cancer patients. changes in circadian patterns are detectable. In patients other symptoms belonging to a "vegetative depression" state are discussed. 


\subsection{Conclusions}

The data obtained from literature and our own experiments which are gathered in this chapter, permit some conclusions:

1. Serotonin is a neurotransmitter whose relationship to some behavioural aspects, at least in part, has been worked out.

2. At physiological brain tryptophan concentrations the rate limiting enzyme tryptophan hydroxylase is unsaturated and alterations of brain tryptophan concentrations are reflected in altered serotonin synthesis rate.

3. Serotonin is involved in sleeping, sexual and aggresive behaviour, but the mode of reaction among different species to altered serotoninergic status is not uniform.

4. Serotonin probably is also involved in circadian rhythm and diumal patterns of central neuro-endocrine secretion.

5. There is a fair amount of evidence to implicate serotonin in feeding behaviour.

6. The altered serotoninergic status in tumor-bearing humans and animals may cause tumor associated anorexia.

7. Serotonin may also play a role in the "vegetative depression" of cancer patients. 


\section{Chapter 7}

\section{General discussion}

Anorexia in cancer with progressive depletion of body stores of a patient suffering from a malignancy is a common clinical problem.

The state of malnutrition or cachexia, which emerges from the inadequately low food intake in these patients, limits therapeutical possibilities or may delay adequate treatment but also the patient more vulnerable toward infections. Although there may be sufficient evidence that the energy requirements of cancer patients are increased, the cancer associated anorexia remains the main cause for host depletion in tumorbearing organisms.

Nutritional repletion of the cancer patient prior to definitive treatment has become a widely accepted way to achieve full benefit of cancer therapy. Despite the relatively good results of such a pre-treatment, this definitively is not the solution of the problem. It often is surprisingly difficult to bring cancer patients into positive nitrogen balance and hyperalimentation has its limits and its complications and requires prolonged hospitalization. In addition after specific cancer treatment, the cancer associated anorexia may start to deplete the patient again to a point where palliation becomes dubious. Recognition of the importance of the symptom anorexia was the basis of the studies presented in this thesis. However, the problem of discovering the mechanisms of anorexia in cancer cannot be solved by elucidating the role which the neoplasm might play in the genesis of anorexia, because the physiologic mechanisms regulating food intake as such are not fully established.

Many hypotheses have been advanced to explain hunger and satiety, some of which have been backed with a fair amount of evidence.

However, as shown in chapter 1 , there always remain contradictory facts and unanswered qeustions.

There is a fair amount of evidence suggesting that the hypothalamus is involved in regulating normal food intake. The ventro-medial part, or more precisely the nor-adrenergic ventral bundle, supposedly forms a satiety center and exerts an inhibitory action with in the hypothalamic regulatory feeding system. Bilateral lesioning of this part of the brain produces hyperphagia, while lesions of the lateral hypothalamic nuclei, which play a facilitory role in feeding activity, induce aphagia. More points in favour of hypothalamic regulation of feeding may be advanced but there is one characteristic, which all "central" theories on regulation systems of feeding have in common, i.e. the difficulty in defining the "afferent side" of the centers involved. Another point is, that at the present time, there is 
little evidence that the hypothalamus is involved in cancer anorexia, since it has been demonstrated that hyperphagia. induced by lesioning the ventromedial hypothalamus, turned into hypophagia when the experimental animal was transplanted with a malignant tumor.

All hypotheses on the physiology of feeding may be useful to some extent, but at the same time this variety of possibilities suggest another, more basic mechanism. Such a mechanism may influence all known systems and it ought to give an answer to the missing afferent side, as referred to earlier. In this study, we departed from the aspect of how activity in a regulatory system is linked to parameters derived from the consumption of food in general and how such an interaction might be affected by the presence of a malignant tumor.

The plasma amino acid tryptophan played a key role in our studies: it is a precursor of the putative brain neurotransmitter serotonin; it is an essential amino acid, yet the plasma and brain concentration vary with the nutritional intake of the amino acids, carbohydrates and fats in a sense that intake of either of these basic nutrients was reflected by increased serotonin turn-over. Recent neuro-pharmacologic data revealed the importance of serotoninergic systems infeeding: increasing brain serotonin either by the administration of precursors or by 'serotoninmimetic" drugs (fluoxetine, flenfluramin) resulted in anorexia while blocking the serotonin activity induced hyperphagia.

In rats, harbouring a Walker-256 tumor injected intramusculary we noticed decreased plasma total tryptophan, yet the brain levels were surprisingly high. When compared with pair-fed but non-tumor bearing control animals, the rats had about the same low plasma levels of total tryptophan. but brain tryptophan levels were low in the control rats. Brain serotonin however, as measured by brain 5-HIAA levels correlated with brain tryptophan levels. We therefore advanced the hypothesis that

serotoninergic systems may be involved in cancer anorexia: despite the lower food intake, the serotoninergic output in tumor rats is the same as in freely feeding, non-tumor bearing control animals. In other words, this state of serotoninergic activity can be achieved with less food intake by tumor bearing organisms than can non-tumor bearing organisms. The relatively high brain tryptophan concentrations of tumor rats was due to altered plasma factors regulating brain uptake of this amino acid. Plasma free tryptophan level was raised significantly in tumor rats due to early increases of free fatty acid concentrations in the plasma and decreased plasma albumin level. Still other factors may be involved in determining free tryptophan. This non-albumin bound fraction of total tryptophan was the major contributor to brain levels of this amino acid in the intramusculary injected tumor group, while competition of the remaining neutral amino acids or transport from plasma to brain did not play a significant role. 
In an attempt to test the validity of the newley introduced hypothesis, we investigated the effect of serotonin blocking agent on food intake of normal and tumor-bearing rats. Systemic administration of serotonin blockers did not provoke increased feeding activity. However, when methysergide had been injected intracisternally, prolonged hyperphagia, resistent to tumor induced anorexia was noticed. The mechanisms of this prolonged action of intracisternal injection of methysergide upon food intake is currently under investigation and neurotoxicity may be the major causative effect, since similar effects have been reported with para-chlorophenylalanine, both serotonin antagonizing drugs with prolonged hyperphagic effects.

Methysergide has been chosen because it does, unlike parachlorophenylalanine not affect the catecholamines.

Serotonin is a putative neurotransmitter whose localization within particular brain areas has been established and whose relationship with human and animal behaviour, at least in part, has been worked out.

The cell bodies of serotoninergic neurons are localized in the raphe nuclei, which are a part of a phylogenetically old brain system. Most of the serotoninergic neurons, which emerge from these nuclei, have endings in the hypothalamus, suggesting a close relationship between both centers. It is tempting to speculate upon the hypothalamus being triggered by the raphe nuclei in several basic vegetative functions since the

determinitation of an uneven distribution of serotonin within the hypothalamus, with high 5-HT concentration in nuclei associated with neuroendocrine mechanisms, give support to the possibility that serotonin may be involved in the regulation of specific endocrine and neurovegetative functions. We were able to find changes in diurnal activity patterns, which are well established to be serotonin dependent. A depression of the normall high night-day activity ratio was demonstrated in tumor-bearing animals. In rats, motor activity is mainly attributed to feeding, when the experimental animal is housed separately, so that it is difficult to distinguish between altered feeding behaviour and altered sleeping patterns.

In humans, this difference is much clearer and evidence has been presented that changes in diurnal activity patterns do occur in cancer patients. Although much remains to be done to elaborate the exact role of altered serotoninergic activity in cancer patients, it is tempting to suggest that the state of vegetative depression which so often accompanies malignant disease, may result from the altered serotoninergic status, with anorexia being only one symptom of a more voluminous syndrome. Long term studies will be needed to investigate the effect of adequate serotonin blocking agents upon appetite and possibly also upon the remaining symptoms of the hypothetized syndrome of "generalized vegetative depression in cancer. 


\section{Summary}

\section{Part I comprises a literature study on physiological and pathological aspects of appetite in general.}

In chapter 1, a review is given of current hypotheses concerning regulatory mechanisms of feeding behaviour. Because theories have been advanced from many different disciplines a more or less artificial subdivision is made.

In chapter 1.1. central mechanisms, the neuro-anatomic and neurophysiologic approaches are studied as they appear in the literature.

The hypothalamus traditionally plays a crucial role in this respect.

The ventro-medial nuclei - or more precisely the noradrenergic bundle are proposed by different authors to form a "satiety" center. These studies suggest an inhibitory action within the hypothalamic regulatory feeding system. Bilateral lesions in this area produce hyperphagia. The lateral hypothalamus is also involved in the control of energy balance and plays a critical role in the initiation of food seeking behaviour. The lateral hypothalamus plays a facilitory role and lesioning of this part of the brain induces aphagia. Electrical or chemical stimulation of these brain areas have reverse effects although contradictory phenomena do occur and extrathalamic structures may present the same properties as the hypothalamus itself.

From the neuro-physiologic point of view, the dual center theory also provided a basis for experimental studies. When the principle of selfstimulation was used in experiments with electrodes implanted in the different hypothalamic centers in animals revealed a close relationship between feeding behaviour and motivation to self-stimulation. There is also evidence that central catecholamine mediated mechanisms exist in the hypothalamus for food control: an $\alpha$-receptor-mediated "hunger" and $\beta$-receptor-mediated "satiety" area. Although there are similarities in natural and adrenergically elicited feeding behaviour, data providing evidence for alteration of the activity of nor-adrenergic neurons in fed compared to hungry animals are not presented.

The role of central neurotransmitters in food intake is extensively reported. Drugs which influence the synthesis of brain neurotransmitters are also known to influence behaviour. Especially serotonin has an action on feeding behaviour.

The synthesis of serotonin as well as catecholamines and acetylcholine is, at least, in part, dependent on precursor availability.

The precursor of serotonin is tryptophan. Tryptophan is an essential amino acid for most species studied, so that serotonin synthesis is closely linked to the dietary intake of its precursor amino acid. 
Moreover, plasma tryptophan concentrations experience influence from carbohydrates and fat in the diet. Because the rate limiting enzyme in the synthesis of serotonin is unsaturated at physiologic concentrations of tryptophan in the brain, alterations in precursor concentration are linearily correlated with neurotransmitter synthesis. This is much less the case with the catecholamines, which have tyrosine as precursor, while the key enzyme is subjected to influences such as end-product inhibition, which results in a much lower responsiveness to alterations in precursor concentrations. Choline, the precursor of acetylcholine is non-essential and no relation between acetylcholine synthesis and feeding behaviour seems to exist. Among the special senses, taste plays an important role in the appreciation and to a certain extent also the intake of nutrients.

The influence of taste on food intake is complex and varies greatly among species. A regulation mechanism relating taste to caloric intake on a longterm basis has not been reported, but the importance of dietary zinc upon taste perception is suggestive for a regulatory function. In these studies, it is suggested that brain concentrations of zinc vary proportionally with plasma concentrations as zinc crosses readily the blood-brain barrier and that normal central zinc levels are essential for optimal taste and smell perception. Alimentary tract factors are reported under 1.2. There is some evidence that gastric load has an important influence upon initiation and termination of feeding activities by increasing vagal nerve activity towards the ventro-medial hypothalamus. There are also indications that a circulation borne factor (e.g. a gastro-intestinal hormone) provides signals from the gastro-intestinal tract which may induce or stop feeding activity. Cholecystokinin has been suggested to have such properties, while (penta-) gastrin and secretine did not show any effects upon food intake. Signals evoked by early absorption of nutrients has been proposed as a third mechanism of gastro-intestinal tract regulation. Glucosensitive receptors in the gastro-duodenal area, in the liver and the brain do provide neuronal information resulting in altered feeding activity, restricted to the early absorptive state. Direct influence upon feeding behaviour exerted by nutrients has also been suggested for amino acids and free fatty acids. Hormonal mechanisms that may regulate feeding behaviour are reviewed in chapter 1.3. Prolonged administration of insulin causes hyperphagia while hypophagia is induced by glucagon.

The possible but more complex role of gonadal hormones and growth hormone is mentioned.

Regulatory mechanisms based upon homeostasis are extensively reviewed in chapter 1.4 .

There is some evidence that environmental temperature may effect feeding behaviour. However, there is a discongruent pattern of reaction to temperature among species and whether the reaction through altered feeding is to preserve body temperature remains to be settled. 
In the glucostatic theory, it is proposed that regulation of food intake is focussed upon constancy of glucose levels and availability. The lipostatic theory collects evidence for metabolic products of lipids in evoking control signals as their concentrations in the blood change. Glycerol appears more likely to do so than the other metabolites of fat. As glycerol is readily converted to glucose and vice versa, the gluco-lipostatic theory has been advanced. In this theory, it is suggested that excess of glucose is stored in adipose tissue, thus serving both glucostatic and lipostatic systems. Osmostatic mechanisms, suggesting that food intake is controlled by osmotic conditions in the body have been postulated, but these await more study. Aminostatic regulation has been hypothesized since an inverse relationship between plasma concentrations of amino acids and food intake was observed by Mellinkoff in 1956.

Especially, the amino acids which are precursors of brain neurotransmitters are discussed of which tryptophan, and to a lesser extent tyrosine and choline are good candidates for regulatory functions.

In chapter 2, these mechanisms are discussed in the light of potential abnormalities caused by cancer. There is some evidence that decreased food intake in the tumor-bearing host may be mediated via the ventromedial hypothalamus. Taste disorders in cancer are reported and may cause altered feeding behaviour but there is a lack consistency and taste alterations appear to be rather unspecific. Factors that cause anorexia originating from the alimentary tract are evident when local infiltration or extended growth of the malignant tumor prevents normal feeding. There may also be distant effects of the tumor upon the alimentary tract, but these are currently under investigation.

Tumors may produce a variety of hormones, conditions which are known as "ectopic humoral syndromes", but it seems that hormonal mechanisms are responsible for anorexia in cancer.

Potential disorders of homeostatic mechanisms are collected in chapter 2.4. There is evidence that the mechanisms for heat homeostasis is preserved but that mechanisms causing anorexia overrule thermostasis, at least in tumor-bearing rats. Decreased glucose tolerance or diabetic glucose tolerance tests are well established disorders in tumor-bearing hosts. This may be secondary to the increased gluconeogenesis in cancer. The extraordinarily high endogenous glucose production may suppress food intake according to the glucostatic theory on feeding regulation. Within the lipostatic mechanisms regulating food intake, no evidence of overt disorders due to cancer is reported. Steroids, which may act as physiological tracers for the amount of fat, apparently are not involved in cancer anorexia.

Osmotic alterations in malignant disease are reported, but these cannot account for the anorexia on the basis of osmostatic regulation. 
Abnormalities in aminostatic mechanisms may be involved in cancer anorexia. Disorders in amino acid metabolism in tumor-bearing animals and cancer patients have been reported. These reports are often incomplete or anecdotal, and therefore do not permit conclusions on a possible aminostatic explanation for cancer anorexia.

Other hypotheses on the mechanism of anorexia in malignant disease involve products, produced by the tumor which may affect enzyme systems, and thus institute a metabolic chaos with anorexia and cachexia as a result.

Part 11 of the thesis is a report of the experimental and clinical studies carried out by the author in the Surgical Physiological Laboratory and the Department of Surgery. Urology and Medicine of the Massachusetts General Hospital in Boston. Massachusetts, U.S.A.

In the studies, presented in chapters $3,4,5$ and 6 we opted for the amino acid dependent system for the regulation of food intake because such a system links the intake of nutrients to the synthesis of brain neurotransmitters which ultimately can influence feeding behaviour as suggested from the data in the literature.

In chapter 3, a report is given on the investigation of plasma and brain amino acids in tumor bearing rats in order to obtain data on brain levels of precursors of brain neurotransmitters and how they are related to the plasma concentrations, and also to receive an impression on the impact of the malignant growth on the amino acid pattern in plasma and brain of experimental animals carrying a tumor burden. In an attempt to differentiate between tumor related changes in amino acid metabolism and the effects of malnutrition, three groups of animals were used: anorectic Walker-256 tumor-bearing animals (TB), non-tumor bearing pair-fed (PF) rats and non-tumor bearing freely feeding control animals (FF). Plasma and brain amino acid profiles of tumor-bearing rats differed from normal control rats. Some, but not all differences were not produced by malnutrition and could be tumor-related. Some of the tumor-related differences reflected metabolic changes which are generally seen in malignant diseases (e.g. increased gluconeogenesis), while other probably were more bound to specific properties of Walker- 256 carcinoma (e.g. utilization of glycine and serine).

Plasma total tryptophan concentrations were low in both TB and PF group animals and therefore secondary malnutrition. Despite the low plasma total tryptophan, brain levels were significantly higher in the TB rats. This could have an effect upon brain serotonin turn-over and therefore justified subsequent experiments on the mechanism, responsible for this difference in brain tryptophan concentrations and neurotransmitter determination.

In chapter 4 , the factors which determine brain tryptophan levels are investigated in the three groups of experimental animals as mentioned in chapter 3. 
From the data obtained in this experimental set up, it was concluded that free tryptophan concentration in the plasma of Walker-256 carcinoma bearing rats were greatly increased secondary to raised plasma free fatty acid levels and decreased plasma albumin concentrations. In all groups, brain tryptophan levels correlated best with the ratio

\section{free TRP +0.1 bound TRP/ $\Sigma$ NAA}

(NAA = plasma neutral amino acids, which are known to compete with TRP for transport across the blood-brain barrier).

Chapter 5 contains a report of a study on the impact of altered brain TRP concentrations on serotonin synthesis in tumor bearing rats.

In this study, it was concluded that brain serotonin turn-over, as measured by its principal metabolite 5 hydroxyindole acetic acid (5-HIAA), was relatively high in TB rats and low in PF rats. These conditions could be related with the state of hypophagia and potential hyperphagia in TB and PF animals respectively. Our hypothesis, that the higher TRP levels and hence serotonin turn-over may induce or contribute to tumor associated anorexia was fully formulated here.

Evidence to support the involvement of serotoninergic systems in general and specially feeding behaviour and cancer anorexia was discussed in chapter 6 . In this chapter, serotonin was studied more closely with respect to its functions as a putative neurotransmitter. There is enough evidence to state, that serotonin is involved in several behavioural systems. Its relationship with circadian rhythm, diurnal patterns of neuro-endocrine secretion, sleep, sexual behaviour and aggressive behaviour has at least in part been worked out. Neuro-pharmacologic and neuro-physiologic data present a fair amount of evidence to implicate serotonin in feeding behaviour. The altered serotoninergic state of tumor bearing rats may cause tumor associated anorexia in these animals.

Antagonizing brain serotonin with intracisternal injections of methysergide (a specific serotonin antagonist with poor blood-brain transition) decreases the anorectic effect of malignant growth in Walker 256-tumor bearing rats. The parenteral or oral administration of serotonin antagonists to experimental rats did not show effects that allow any conclusions. It is tempting to suggest, that in humans too, the altered serotoninergic status may be responsible for tumor associated loss of appetite, since anorexia tends to respond well to oral doses of cyproheptadin in cancer patients. Cancer anorexia is briefly discussed in the light of its possible association with the "vegetative depression" of cancer patients, a condition in which altered serotoninergic state might alsu play a role. Much more remains to be done to elaborate the exact role of altered serotoninergic activity in cancer patients. Long term studies will be needed to assess the effect of adequate serotonin blocking agents upon cancer anorexia and possibly on the hypothesized "vegetative syndrome" in cancer. 


\section{SAMENVATTING}

In de inleiding wordt een kort overzicht gegeven van de problematiek veroorzaakt door de anorexie bij kanker. De oplossing van dit probleem wordt mede bemoeilijkt doordat de oorzaak van deze anorexia onbekend is. Uit de literatuur blijkt duidelijk, dat de normale fysiologie van de voedselinname nog niet geheel vaststaat, zodat een verklaring voor de anorexie als gevolg van kanker nog moeilijker te vinden is.

In dit proefschrift wordt een poging ondernomen enige duidelijkheid te brengen in de iiteratuur. In combinatie met uit eigen onderzoek verkregen gegevens, zal een hypothese geformuleerd worden, die ons iets verder naar de oplossing van het vraagstuk zal voeren.

In hoofdstuk 1 wordt een literatuuroverzicht gegeven van de bestaande hypothesen betreffende de mechanismen die de voedselinname reguleren. Daarbij worden de mechanismen beschreven die geconcentreerd zijn in het centraal zenuwstelsel. Hierbij speelt de hypothalamus de traditionele hoofdrol. Door verschillende auteurs worden de ventromediale hypothalamuskemen en, meer gepreciseerd, de noradrenerge bundel die deze kernen doorkruist, gezien als het 'verzadigingscentrum'. Bilaterale laesies van dit gebied veroorzaken hyperfagie.

De laterale hypothalamus speelt eveneens een belangrijke rol bij het effectueren van een evenwichtige energiebalans. Eén van de klassieke taken van de laterale hypothalamus is het fungeren als "hongercentrum" waar activiteiten in het organisme, die het innemen van voedsel tot gevolg hebben, in gang gezet worden. De laterale hypothalamus is op dit punt een faciliterend centrum en laesies ervan resulteren in afagie.

Het toedienen van elektrische of chemische stimuli aan de laterale hypothalamus daarentegen heeft doorgaans hyperfagie ten gevolge, alhoewel er contradictoire fenomenen beschreven worden en er extrathalamische structuren zijn met dezelfde eigenschappen ten aanzien van het voedingsgedrag als de hypothalamus zelf.

Vanuit neurofysiologisch standpunt vormt de 'twee-centra'-theorie de basis voor een schat aan experimenteel onderzoek.

Door het principe van auto-stimulatie toe te passen in experimenten waarbij elektroden in verschillende hypothalamische gebieden geimplanteerd werden, ontstond een duidelijke relatie tussen voedingsgedrag en motivatie tot auto-stimulatie.

Er worden in de literatuur ook aanwijzingen gevonden voor het bestaan van catecholaminerge mechanismen die in de hypothalamus gelocaliseerd zouden zijn: een via $\alpha$ - receptoren functionerend "honger"-centrum en via $\beta$-receptoren verlopend "verzadigings"-centrum.

Alhoewel er enige overeenkomst lijkt te bestaan tussen fysiologisch voorkomende en adrenerg opgewekte eetstimuli, zijn er geen duidelijke verschillen in noradrenerge activiteit van neuronen in gevoede en hongerige proefdieren aangetoond. 
Er wordt uitvoerig ingegaan op de rol van centrale neurotransmittoren bij de regulatie van de voedselinname. Vooral serotonine komt naarvoren als neurotransmittor waarvan de aanmaak in het centrale zenuwstelsel op minutieuze wijze gekoppeld is aan de aanvoer van het precursoraminozuur tryptofaan via de voeding.

Voor de meeste diersoorten die bestudeerd zijn, is tryptofaan een essentieel aminozuur. De concentratie ervan in het bloed is primair afhankelijk van de aanvoer van buitenaf. Bovendien blijkt de concentratie directe invloed te ondervinden van de koolhydraat- en vetinname.

Het enzym dat in de hersenen de omzetting van tryptofaan in serotonine bewerkstelligt, is onverzadigd bij fysiologische concentraties van tryptofaan in de hersenen, met als gevolg, dat veranderingen in precursor concentraties direkt weerspiegeld worden in de neurotransmittor-

synthese. Voor de catecholamines geldt dit in veel mindere mate. Daar is tyrosine het precursor-aminozuur en de activiteit van het sleutel-enzym in de omzetting naar catecholamines wordt sterk beinvloed door factoren als eindprodukt-inhibitie, waardoor een geringere gevoeligheid ontstaat voor schommelingen in precursorconcentraties.

Choline, de precursor voor acetylcholine is geen essentieel aminozuur en het is niet waarschijnlijk, dat er enige relatie bestaat tussen acetylcholine synthese en eetgedrag.

De smaak- en reukzin zijn van groot belang bij de waardering van het aangeboden voedsel en tot op zekere hoogte ook voor de consumptie ervan. De in het voedsel aanwezige hoeveelheid zink kan voor de smaakzin bepalend zijn en op grond daarvan deel uitmaken van een regulatie-systeem. Studies hieromtrent hebben uitgewezen dat de concentraties van zink in de hersenen afhankelijk zijn van de concentraties ervan in het bloed, omdat zink vlot de bloed-hersenbarriere kan passeren. Ook bleek dat normale concentraties van zink in de hersenen bepalend zijn voor een optimale smaak- en reukperceptie.

Vervolgens worden de regulatiesystemen, gelocaliseerd binnen de tractus digestivus, besproken. Er bestaan aanwijzingen dat de vullingstoestand van de maag van belang is voor het beginnen en beëindigen van eetactiviteiten en dat de informatie via de nervus vagus naar de ventromediale hypothalamus gevoerd wordt. Tevens worden systemen besproken, waarbij bepaalde stoffen (bv. gastro-intestinale hormonen) via de circulatie, signalen verstrekken aan de tractus digestivus waardoor zij de eetactiviteit kunnen bepalen.

Ook een ander regulatiesysteem van de tractus digestivus waarbij in de vroege post-prandiale fase neuronale informatie wordt verstrekt aan glucosensitieve receptoren in de regio van maag en duodenum, in de lever en in de hersenen wordt aan de orde gesteld. Aminozuren en vrije vetzuren uit de voeding zouden op zichzelf al invloed kunnen uitoefenen op het eetgedrag. 
Hormonaal werkende regulatie-systemen worden belicht in hoofdstuk 1.3. Geprotraheerde toediening van insuline veroorzaakt hyperfagie terwijl glucagon hypofagie geeft. De mogelijke, doch meer complexe invloed van geslachtshormonen en het groeihormoon worden ter sprake gebracht.

Aan de regulatiemechanismen die gebaseerd zijn op homeostase wordt uitgebreid aandacht besteed in het laatste hoofdstuk. Er bestaan aanwijzingen dat de omgevingstemperatuur het eetgedrag kan beinvloeden. Er valt hierbij een sterk wisselend patroon tussen de verschillende diersoorten waar te nemen en de vraag of de verandering in eetgedrag bedoeld is om de thermostasis te dienen, moet nog beantwoord worden. De glucostatische theorie gaat ervan uit, dat de regulatie van de voedselinname geënt is op het constant houden van de bloedglucosespiegel en de beschikbaarheid van deze glucose.

De lipostatische theorie is geënt op de mogelijkheid van het lichaam, concentratieveranderingen van bepaalde metabolieten uit de lipidenpool waar te nemen. Glycerol lijkt hiervoor eerder in aanmerking te komen dan de overige metabole produkten. Daar er een nauwe metabole relatie bestaat tussen glycerol en glucose en vice versa, wordt ook de glucolipostatische theorie naar voren gebracht. Deze theorie gaat ervan uit dat een surplus aan glucose opgeslagen wordt in vetweefsel en dat daarmee zowel de glucostasis als de lipostasis gediend kan worden.

Osmotische mechanismen, die de voedselinname afhankelijk stellen van post-prandiale osmotische veranderingen, worden in de literatuur slechts genoemd doch dienen nog nader bestudeerd te worden.

Aminostatische regulering van de voedselinname is gebaseerd op de waarneming van o.a. Mellinkoff in 1956, dat de voedselinname eerder correleerde met de aminozuursamenstelling van het bloed dan met de glucoseconcentratie.

In dit bestek wordt nog speciale aandacht besteed aan de aminozuren, die precursors zijn van hersenneurotransmittoren. De aminozuren tryptofaan, tyrosine en choline worden genoemd als potentiële kandidaten voor een regulerende functie.

In hoofdstuk 2 worden dezelfde mechanismen besproken maar dan in het licht van potentiële afwijkingen hierin, door kanker veroorzaakt.

Hoewel er enige aanwijzingen bestaan voor het feit, dat anorexie in kanker via de ventromediale hypothalamus kan verlopen, wordt dit toch niet waarschijnlijk geacht. De veranderde resu- en smaakzin die bij kanker beschreven wordt, zou de voedselinname kunnen beperken maar hieromtrent bestaan weinig overtuigende feiten; bovendien zijn de smaakveranderingen aspecifiek en in sommige gevallen therapie-gebonden. Dat anorexie kan ontstaan als gevolg van locale ingroei van de maligne 
tumor in de tractus digestivus is aannemelijk. Er zijn echter ook effecten op de tractus digestivus uitgaande van tumoren die er buiten gelegen zijn. Deze effecten zijn nog niet verklaard. Hoewel tumoren in staat zijn een uitgebreide scala van hormonen te produceren. lijkt het toch onwaarschijnlijk dat een hormonaal mechanisme verantwoordelijk is voor de anorexie in kanker.

Potentiële stoornissen in homeostatische regulatiesystemen komen aan de orde in het eerste deel van hoofdstuk 2. Bij het proefdier zijn aanwijzingen gevonden dat mechanismen die thermostasis bewerkstelligen, geëlimineerd kunnen worden door mechanismen die anorexie in kanker veroorzaken. Verminderde glucose-tolerantie of diabetische bloedsuikercurves worden frequent beschreven bij maligniteiten. Deze afwijkingen kunnen het gevolg zijn van een toegenomen gluconeogenese. Deze abundante endogene glucoseproduktie zou, volgens de glucostatische theorie de voedselinname kunnen verminderen. Er bestaan onvoldoende aanwijzingen om te veronderstellen dat deze anorexie verklaard zou kunnen worden door verstoring van lipostatische mechanismen.

Steroiden die genoemd worden als fysiologische "tracer" voor de hoeveelheid vet, kunnen niet ingepast worden in een anorexie-

mechanisme. Dit geldt tevens voor de osmotische plasmaveranderingen bij sommige maligniteiten die in de literatuur vermeld worden.

Stoornissen in aminostatische mechanismen kunnen een rol spelen in de genese van kankeranorexie.

De literatuur vermeldt afwijkingen in de aminozuurstofwisseling als gevolg van maligniteiten bij mens en dier. De gegevens hiervoor zijn vaak onvolledig en laten daarom geen duidelijke conclusies toe.

Tenslotte worden hypotheses besproken, die gebaseerd zijn op een min of meer direct anorexigeen effect van de tumor.

Het tweede deel van dit proefschrift rapporteert over het experimenteel en klinisch werk van de auteur in het Laboratorium voor Chirurgische Fysiologie en de afdelingen Heelkunde, Urologie en Interne Geneeskunde van het Massachusetts General Hospital in Boston, Massachusetts, U.S.A. In de studies, beschreven in hoofdstuk $3,4,5$ en 6 wordt uitgegaan van een aminozuur-afhankelijk regulatiesysteem, omdat een dergelijk systeem de inname van nutriënten direct koppelt aan de synthese van centrale neurotransmittoren. Hierbij kunnen de neurotransmittoren op hun beurt weer het voedingsgedrag beinvloeden, zoals uit de literatuurgegevens mocht blijken.

In hoofdstuk 3 wordt verslag gegeven van een onderzoek naar plasma en hersen-aminozuren van ratten met een maligne tumor met als doel, gegevens te verkrijgen omtrent de concentratie in de hersenen van sommige precursors van neurotransmittoren. Ook komt daarbij de vraag aan de orde hoe deze hersenconcentraties zich verhouden tot de 
plasmaconcentraties. Bovendien wordt in deze studie nagegaan hoe de maligniteit het aminozuurpatroon in bloed en hersenen kan beinvloeden in het proefdier met een maligne gezwel.

Teneinde tumor-specifieke veranderingen te kunnen scheiden van effecten die door ondervoeding teweeggebracht worden, werd gebruik gemaakt van drie groepen ratten: anorectische Walker-256 tumor , dragende dieren (TB), gepaard gevoede controledieren zonder tumor (PF) en vrij gevoede controledieren, eveneens zonder tumor (FF). Er worden verschillen in aminozuurpatronen in bloed en hersenen gevonden tussen de tumor-groep en de controlegroepen.

Deze verschillen zijn voor een deel toe te schrijven aan ondervoeding als gevolg van de anorexie, de overige afwijkingen kunnen met de tumorgroei in verband gebracht worden. Met name berusten enkele afwijkingen op metabole veranderingen die bij maligniteiten in het algemeen gezien kunnen worden (bv. toegenomen gluconeogenese), terwijl ook gewezen wordt op de mogelijkheid dat enige afwijkingen in aminozuurspectra specifiek behoren bij de Walker-256 tumor.

De plasma concentrations van totaal-tryptofaan zijn laag in zowel de TB als de PF groep en konden daarom toegeschreven worden aan ondervoeding. Ondanks deze lage plasmaconcentraties blijkt de tryptofaanconcentratie in de hersenen significant verhoogd te zijn in TB-ratten. Dit kan, zoals gebleken is uit de literatuurgegevens, een verandering in de centrale serotonine turn-over teweegbrengen, die past in een constructie waarmee de anorexie in deze dieren verklaard zou kunnen worden. Daarom werden meer experimenten uitgevoerd om dit fenomeen van inadekwaat verhoogde hersentryptofaanspiegels in TB ratten en de consequenties voor de synthese van serotonine nader te kunnen bestuderen.

In de literatuur bestaat onenigheid omtrent de faktoren die de hersenconcentratie van tryptopfaan bepalen.

In hoofdstuk 4 worden deze factoren in het rattenmodel onderzocht. Uit dit onderzoek blijkt dat de concentratie vrij-tryptofaan in ratten met een Walker-256 tumor sterk toegenomen is. Dit is het gevolg van sterk verhoogde plasmaspiegels voor vrije vetzuren en, hierop gesuperponeerd, een daling van de albumineconcentratie. De beste correlatie met hersentryptofaan concentraties werd gevonden in de ratio:

vrij-TRP + 0.1 gebonden-TRP

ENAZ

(NAZ = plasma neutrale aminozuren, die met TRP competitie aangaan voor transport door de bloed-hersenbarrière heen). 
In hoofdstuk 5 wordt onze hypothese geformuleerd, dat als gevolg van een inade kwaat hoge tryptofaanconcentratie in de hersenen van de ratten met een tumor en de daarbij horende toegenomen serotonine turn-over, de hypofagie van deze dieren verklaard zou kunnen worden. In dit verband wordt het effect van gewijzigde TRP-concentratie op de centrale serotonine turn-over beschreven.

Uit de experimenten blijkt dat de serotonine turn-over, gemeten aan de hersenconcentratie van diens belangrijkste metaboliet het 5-hydroxyindolyl-aceto-azijnzuur (5-HIAA) relatief hoog was in de TB-ratten en laag in de PF-groep. Zoals in de literatuur wordt vermeld past dit bij hypofagie (groep TB-ratten) en potentiële hyperfagie (honger) in groep PF.

In hoofdstuk 6 worden voor de gestelde hypothese mede vanuit de literatuur aanvullende argumenten gezocht.

Er is in de literatuur voldoende bewijs geleverd voor het feit, dat serotonine betrokken is bij verschillende gedragspatronen. Het verband, dat bestaat met het dag-nacht ritme, het diurnale patroon van neuro-endocriene secretie, slaap, sexueel en aggressief gedrag is reeds voor een belangrijk deel vast komen te staan.

Recente gegevens uit neurofarmacologische en neurofysiologische studies leveren eveneens voldoende bewijs, dat serotonine betrokken is bij het eetgedrag. De veranderde centrale serotoninerge status van de tumordragende ratten zou hun anorexie kunnen verklaren. Het intracisternaal injecteren met methysergide (een specifieke serotonineantagonist met slechte penetratie van de bloed-hersenbarrière) verminderde de anorexie bij de dieren met een tumor. De effecten van parenterale en enterale toediening van serotonine antagonisten aan proefdieren lieten echter geen conclusie toe. Bij anorectische kankerpatienten werden dezelfde plasma waarden voor vrij en gebonden tryptofaan, vrije vetzuren en albumine gevonden als in het proefdiermodel.

Tevens worden in de literatuur bij kankerpatienten met gebrekkige eetlust gunstige resultaten gemeld met cyproheptadine (eveneens een serotonine antagonist).

Er wordt een korte beschouwing gewijd aan de associatie van kankeranorexie met de "vegetatieve depressie" van kankerpatienten, waarbij de veranderde serotoninerge status als mede-oorzaak ter discussie gesteld wordt. Gecontroleerde prospectieve studies zullen nodig zijn om het effect van het op adekwate wijze blokkeren van serotonine in de hersenen op kanker-anorexie en mogelijk ook op het zogenaamde vegetatief depressieve syndroom van de cachectische kankerpatient, te doorgronden. Hier ligt nog een onderzoeksgebied braak. 


\section{References}

1 Abbott W.E. and Albertson, K.

"The Effect of Starvation, Infection and Injury on the Metabolic Process and Body Composition".

Ann. N.Y. Acad. Sci.: 110: 941 -964, 1963.

2 Abrams, R., Essman, W.B., Taylor, M.A. and Fink, M.

"Concentratition of 5-Hydroxy-indoleacetic Acid, Homovanillic Acid, and Tryptophan in the Cerebrospinal Fluid of Depressed Patients Before and After E.C.T.".

Biol. Psychiat.: 11 (1), 1976.

3 Albert, D.J., Storlien, L.H., Albert, J.G. and Mah, C.J.

"Obesity following Disturbance of the Ventromedial Hypothalamus:

A Comparison of Lesions, Lateral Cuts and Anterior Cuts".

Physiol. Behav.: 7: 135-141, 1971.

4 Anand, B.K. and Brobeck, J.R.

"Hypothalamic Control of Food Intake in Rats and Cats".

Yale J. Biol. Med.: 24: 123-140, 1951.

5 Anand, B.K. and Dua, S.

"Feeding Responses Induced by Electrical Stimulation of the Hypothalamus in Cats".

Indian J. Med. Res.: 43: 113-122, 1955.

6 Anand, B.K., Chhina, G.S., Sharma, K.N., Dua, S. and Singh, B.

"Activity of Single Neurons in the Hypothalamic Feeding Centers:

Effect of Glucose".

Ann. J. Physiol.: 207: 1146-1154, 1964.

7 Andersson, B. and Larsson, B.

"Influence of Local Temperature changes in the Preoptic Area and Rostral Hypothalamus on the Regulation of Food and Water Intake".

Acta Physiol. Scand: 52: 75-89, 1961.

8 Aprison, M.H. and Hingtgen, J.N.

"Serotonin and Behaviour: a Brief Summary:

Fed. Proc.: 31 (1): 121-129. 1972.

9 Asher, W.L.

"Effect on Human Chorionic Gonadotrophin on Weight Loss, Hunger and Feeling of Well-being".

Am. J. Clin. Nutr.: 26: 211-218, 1973. 
10 Auerbach, V.H. and Waisman, H.A.

"The Metabolism of Aromatic Amino Acids in Leukemic Rats".

Cancer Res.: 18: 536-542, 1958.

11 Babson, A.L. and Winnick, T.

"Protein Synthesis in Tumor-Bearing Rats".

Proc. Am. Assoc. Carc. Res.: Abst. 1954, 2-3.

12 Badger, T.M. and Tumbleson, M.E.

"Protein-Caloric Malnutrition in Young Miniature Swine: Brain Free Amino Acids".

J. Nutr.: 104: 1329-1338, 1974.

13 Badger, T.M. and Tumbleson, M.E.

"Protein-caloric Malnutrition in Young Miniature Swine: Brain Free Amino Acids".

J. Nutr.: 104: 1339-1348, 1974.

14 Baile, C.A., Simpson, C.W., Krabill, L.F. and Martin, F.H.

"Adrenergic Agonists and Antagonists and Feeding in Sheep and Cattle".

Life Sci.: 11: 661-668, 1972.

15 Bailli, P., Millar, F.K. and Pratt, A.

"Food and Water Intakes and Walker Tumor Growth in Rats with Hypothalamic Lesions".

Am. J. Physol.: 209 (2): 293-300, 1965.

16 Balagura, $S$.

"Neurochemical Regulation of Food Intake". In: "The Hypothalamus".

Ac. Press., N.Y. - Londen.

17 Barrett, A.M. and McSharry, L.

"Inhibition of Drug-Induced Anorexia in Rats by Methysergide".

J. Pharm. Pharmacol.: 27: 889-895, 1975.

18 Baxter, M.G., Miller, A.A. and Soroko, F.E.:

"The Effect of Cyproheptadine on Food Consumption in the Fasted Rat". Br. J. Pharmacol.: 39: 229-230, 1970.

19 Beaton, J.R.

"Effect of Increased Metabolism and of Hyperphagia on Dietary Amino Acid Imbalance in the Rat".

Canad. J. Physiol. Pharmacol: 45: 1011-1019, 1967.

20 Begg. R.W.

"Systemic Effects of Tumors in Rats".

Cancer Res.: 11: 341-344, 1951.

21 Begg, R.W. and Dickinson, T.E.

"Systemic Effects of Tumors in Force-Fed Rats".

Cancer Res: 11: 409-412, 1951.

22 Begg. R.W.

"Tumor-Host Relations".

Advan. Cancer Res.: 5: 1-51, 1958. 
23 Bender, D.A.

"The Effects of Chlorpromazine of Serum Tryptophan, Brain Tryptophan Uptake and Brain Serotonin Synthesis in the Rat".

Biochem. Pharma.: 25: 1743-1746, 1976.

24 Benjamin, F. and Romney, S.L.

"Disturbed Carbohydrate Metabolism in Endometrial Carcinoma".

Cancer (Philadelphia): 17: 386-390, 1964.

25 Bergen, S.S. Jr.

"Appetite Stimulating Properties of Cyproheptadine".

Am. J. Dis. Childr.: 108: 270-273, 1964.

26 Berkum, M.M., Kessen, M.L. and Miller, N.E.

"Hunger Reducing Effects of Food by Stomach Fistula versus Food by Mouth Measured by Consummatory Response".

J. Comp. Physial. Psychol.: 45: 550-554, 1952.

27 Bianchine, J.R.

"Metabolism of Methysergide (MS) in the Rabbit and Man".

Fed. Proc.: 27: 238, 1968.

28 Bianchine, J.R. and Eade, N.R.

"Vasoactive Substances and Fibrosis".

Res. Clin. Stud. Headache: 2: 60-85, 1969.

29 Biggio, G., Fadda, F., Fanni, P., Tagliamonte, A. and Gessa, G.L.

"Rapid Depletion of Serum Tryptophan, Brain Tryptophan, Serotonin and 5-Hydroxy-indoleacetic Acid by a Tryptophan-Free Diet".

Life Sci.: 14: 1321-1329, 1974.

30 Bloxam, D.L. and Warren, W.H.

"Error in the Determination of Tryptophan by the Method of Dencla and Dewey. A. Revised Procedure".

Anal. Biochem.: 60: 621-625, 1974.

31 Blundell, J.E., Latham, C.J. and Leshem, M.B.

'Biphasic Action of a 5-HT Inhibitor on Fenfluramin Induced Anorexia". J. Pharm. Pharmac.: 25: 492, 1973.

32 Bobillier, P.. Petitjean, F., Salvert, D., Ligier, M., and Seguin, S.

"Differential Projections of the Nucleus Raphe Dorsalis and Nucleus Raphe Centralis as Revealed by Autoradiography".

Brain Res.: 85: 205-210, 1975.

33 Bodansky, 0.

"TRP Metabolism". In: "Biochemistry of Human Cancer".

Acad. Press, New York, San Francisco, Londen: 134-157, 1975.

34 Bodansky, $O$.

"Metabolism of Hydroxyproline". In: "Biochemistry of Human Cancer". Acad. Press, New York, San Francisco, Londen: 289-290, 1975.

35 Bogdanski, D.F., Weissbach, $H$. and Udenfried, $S$.

"Pharmacological Studies with the Serotonin Precursor 5-Hydroxy

Tryptophan". J. Pharmacol. Exp. Ther. 122: 183-194, 1958. 


\section{Booth, D.A.}

"Effects of Intrahypothalamic Glucose Injection on Eating and Drinking Elicited by Insulin".

J. Comp. Physiol. Psychol.: 65: 13-16, 1968.

37 Brackenridge, D.J.

"The Tyrosine and Tryptophan Content of Blood-serum in Malignant Disease".

Clin. Chim. Acta: 5: 539-543, 1960.

38 Bray, G.A. and York, D.A.

"Studies on Food Intake of Genetically Obese Rats".

Am. J. Physiol.: 233: 176-197, 1972.

39 Bray, G.A. and Gallagher, T.F. Jr.

"Manifestations of Hypothalamic Obesity in Man: A Comprehensive Investigation of Eight Patients and a Review of the Literature".

Medicine: 54: 301-330, 1975.

40 Breisch, S.T., Zemlan, F.P. and Hoebel, B.G.

"Hyperphagia and Obesity Following Serotonin Depletion by Intraventricular P-Chlorophenylalanine".

Science: 192: 382-385, 1976.

41 Brennan, M.F.

"Uncomplicated Starvation versus Cancer Cachexia".

Cancer Res.: 37: 2359-2364, 1977.

42 Brobeck, J.R., Tepperman, J. and Long, C.N.H.

"Experimental Hypothalamic Hyperphagia in the Albino Rat". Yale J. Biol. Med.: 15: 831-853, 1943.

43 Cabanac, $M$.

"Physiological Role of Pleasure".

Science: 173: 1103-1107, 1971.

44 Carey, R.J.

"A Comparison of the Food Intake Suppression Produced by Giving Amphetamine as an Aversion Treatment versus as an Anorexic Treatment".

Psychopharmacology: 56: 45-48, 1978.

45 Carlisle, H.J. and Stellar, E.

Caloric Regulation and Food Preference in Normal, Hyperphagic and Aphagic Rats".

J. Comp. Physiol. Psychol.: 69: 107-114, 1969.

\section{Carlson, A.J.}

"The Control of Hunger in Health and Disease".

Published by: University of Chicago Press, Chicago, 1912.

47 Carroll, B.J.

"Psychiatric Disorders and Steroids".

In: "Neuroregulators and Psychiatric Disorders". Uschin, E., Hamburg, D.A. and Barchas, J.D. (Eds.). N.Y. Oxford University Press, 1977. 
48 Chakrabarty, A.S., Pillai, R.V., Anand, B.K. and Baldev, S.

"Effect of Cyproheptadine on the Electrical Activity of the Hypothalamic Feeding Centres".

Brain Res.: 6: 561-569, 1967

49 Chalmers, T.M. Kekwick, A. and Pawan, G.L.S.

"On the Fat-Mobilizing Activity of Human Urine".

Lancet: 1: 866-869, 1958.

50 Chase, T.N. and Murphy, D.L.:

"Serotonin and Central Nervous System Function".

Ann. Rev. Pharmacal.: 13: 181-197, 1973.

51 Cheraskin, E.

"Effect of Diet upon Radiation Response in Cervical Carcinoma of the Uterus",

Acta Cytol: : 12: 433-438, 1968.

52 Clark, C.M. and Goodblad, G.A.J.

"Muscle Protein Biosynthesis in the Tumor-Bearing Rat. A Defect in the Post-initiation Stage of Translation".

Biochem. Biophys. Acta: 378: 230-240, 1975.

53 Clineschmidt, B.V., McGuffin, J.C. and Werner, A.B.

"Role of Monoamines in the Anorexigenic Actions of Fenfluromine. Amphetamine and P-Chloromethamphetamine".

Eur. J. Pharmacol.: 27: 313-323, 1974.

54 Coppen, A.J., Grupta, R.K., Eccleston, E.G., Wood, K.M.,

Wakeling, A. and Sousa de, V.F.A.

"Plasma-Tryptophan in Anorexia Nervosa".

The Lancet: $961,1976$.

55 Costa, G.

"Cachexia, the Metabolic Component of Neoplastic Disease".

Progr. Exp. Tumor Res.: 3: 321-369, 1963.

56 Curzon, G., Friedel, J. and Knott, P.H.

"The Effect of Fatty Acids on the Binding of Tryptophan to Plasma Protein". Nature: 242: 198-200, 1973.

57 Curzon, G., Green, A.R.

"Rapid Method for Determination of 5-HT and 5-HIAA in small Regions of Rat Brain".

Br. J. Pharmacol. Chemother.: 37: 689-697, 1970.

58 Curzon, G. and Marsden, C.A.

"Metabolism of a Tryptophan Load in the Hypothalamus and Other Brain Regions".

J. of Neurochem.: 25: 251-256, 1975.

59 Dafny, N., Jacobs, R.H. and Jacobson, E.D.

"Gastrointestinal Regulation of Appetite".

Surg. Res.: 36: 45A, 1975. 
60 Debons, A.F., Silver, L., Cronkite, E.P., Johnson, H.A., Brecher, G., Tenzer, D. and Schwartz, I.L.

"Localization of Gold in Mouse Brain in Relation to Gold Thioglucose Obesity".

Am. J. Physiol.: 202: 743-750, 1962.

61 Debons, A.F., Krimsky, II, Likuski, H.J., From, A and Cloutier, R.J. "Gold Thioglucose Damage to the Satiety Center: Inhibition in Diabetes". Am. J. Physiol.: 214: 652-658, 1968.

62 De Montis, M.G., Olianas, M.C., Haber, B. and Tagliamonte, A.

"Increase in Large Neutral Amino Acid Transport into Brain by Insulin".

J. Neurochem.: 30: 121-124, 1978.

63 Descarries, L., Beaudet, A., etc.

"Serotonin Nerve Terminals in Adult Rat Neocortex".

Brain Res.: 100: 563-588, 1975.

64 Delvin, T.M. and Pruss, M.P.

"Oxidative Phosphorilation in Transplanted Novikoff Hepatoma of the Rat".

Fed. Proc.: 17: 211, 1958.

65 Dencla, W.D. and Dewey, H.K.

"The Determination of TRP in Plasma, Liver and Urine".

J. Lab. Clin. Med.: 69: 160-169, 1967.

66 De Wijs, W.D.

"Abnormalities of Taste as a Remote Effect of a Neoplasm".

Ann. N.Y. Acad. Sci.: 230: 427-434, 1974.

67 De Wijs, W.D. and Walters, K.

"Abnormalities of Taste Sensation in Cancer Patients".

Cancer: 36: 1888-1896, 1975.

68 De Wijs, W.D.

"Anorexia in Cancer Patients".

Cancer Res.: 37: 2354-2358, 1977.

69 Dickerson, J.W.T. and Pao, S.K.

"The Effect of a Low Protein Diet and Exogenous Insulin on Brain TRP and its Metabolites in the Weanling Rat".

J. Neurochem.: 25: 559-564, 1975.

70 Diez, J.A., Sze, P.Y. and Ginsburg, B.E.

"Tryptophan Regulation of Brain Tryptophan Hydroxylase".

Brain Res.: 104: 396-400, 1976.

71 Doepfner, $W$.

"Biochemical Observations on LSD-25 and Deseril".

Experentia (Basel): 18: 256, 1962.

72 Dole, V.P., Dahl, L.K., Schwartz, I.L., Cotzias, J.H., Thaysen, J.H. and Harris, C.

"Dietary Treatment of Hypertension III. The Effect of Protein on Appetite and Weight". J. Clin. Invest.: 32: 185-191, 1953. 
73 Doumas, B.T. and Watzen, W.A.

Albumin Standards and the Measurement of Serum Albumin with Bromcresol Green".

Clin. Chim. Acta: 31:87-96, 1971.

74 Doty, R.W.

"Neural Organization of Deglution".

In: "Handbook of Physiology".

Code, C.F. (Ed.) Sect. 6, 4:1861-1902, Washington, D.C.:

Am. Physiological Society, 1968.

75 Edozien, J.C.

"The Free Amino Acids of Plasma and Urine in Kwashiorkor".

Clin. Sci.: 31: 153-166, 1966.

76 Epstein, A.N.

"Reciprocal Changes in Feeding Behaviour Produced by Intrahypothalamic Chemical Injections".

Am. J. Physiol:: 199: 969-974, 1960.

77 Etienne, P., Young, S.N. and Sourkes, T.L.

"Inhibition by Albumin of TRP Uptake by Rat Brain".

Nature: 262: 144-145, 1976.

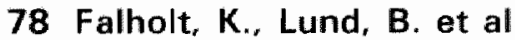

'An Easy Colorimetric Micro Method for Routine Determination of Free Fatty Acids in Pldsma".

Clin. Chim. Acta: 46: 105-111, 1973.

79 Farkas, M., Dunner, D.L. and Fieve, R.R.

"Tryptophan in Depression".

Biol. Psychiat.: 11 (3), 1976.

80 Feldman, J.M., Plouk, J.W., et al

"Plasma Amino Acids in Patients with the Carcinoid Syndrome".

Cancer: 38: 2127-2131, 1976.

81 Felig. $P$.

"The Glucose - Alanine Cycle".

Metabolism: 22: 170-207, 1973.

82 Fenninger, L.D. and Mider, G.B.

"Energy and Nitrogen Metabolism in Changer".

Adv. Cancer Res.: 2: 229-252, 1954.

83 Fernando, J.C.R., Knott, P.J. and Curzon, G.

"The Relevance of Both Plasma Free Tryptophan and Insulin to Rat Brain Tryptophan Concentration".

J. Neurochem.: 27: 343-345, 1976.

84 Fernstrom, J.D. and Wurtman, R.J.

"Brain Serotonin Content: Physiological Dependence on Plasma

Tryptophan Levels".

Science: 173: 149-152, 1971. 
85 Fernstrom, J.D. and Wurtman, R.J.

"Effect of Chronic Corn Consumption on Serotonin Content of Rat Brain". Nature (New Biol.): 234: 62-64, 1971.

86 Fernstrom, J.D. and Wurtman, R.J.

"Brain Serotonin Content: Increase Following Ingestion of Carbohydrate Diet".

Science: 174: 1023-1025, 1971.

87 Fernstrom, J.D. and Wurtman, R.J.

"Nutrition and the Brain".

Sci. Am.: 230: 84-92, 1974.

88 Fernstrom, J.D. and Wurtman, R.J.

"Brain Serotonin Content: Physiological Regulation by Plasma Neutral Amino Acids".

Science: 178: 414-416, 1972.

89 Fernstrom, J.D., Hirsch, M.J., Madras, B.K. and Sudarsky, L. "Effects of Skim Milk. Whole Milk, and Light Cream on Serum TRP binding and Brain Tryptophan Concentrations in Rats".

J. Nutr.: 105: 1359-1362, 1975.

90 Fernstrom, J.D.

"Effects of the Diet on Brain Neurotransmitters".

Metab. Clin. Exp.: 26 (2): 207-223, 1977.

91 Fischer, J.E., Rosen, H.M., Ebeid, A.M., James, J.H., Keane, J.M. and Soeters, P.B.

'The Effect of Normalisation of Plasma Amino Acids on Hepatic Encephalopathy in Man".

Surgery: 80: 77-91, 1976.

92 Flemming, D.G.

"Food Intake Studies in Parabiotic Rats".

Ann. N.Y. Acad. Sci.: 157: 985-1002, 1969.

93 Fonberg, E. and Delgade, J.M.

"Avoidance and Alimentary Reactions during Amygdale Stimulation".

J. Neurophysiol.: 24: 651-664, 1961.

94 Fuller, R.W. and Wong. D.T.

"Inhibition of Serotonin Reuptake".

Fed. Proc.: 36: 2154-2158, 1977.

95 Funderburk, W.H., Hazelwood, J.C., Ruckart, R.T. and Ward, J.W.

"Is 5-Hydroxy-tryptamine Involved in the Mechanism of Action of Fenfluramine?".

J. Pharm. Pharmac.: 23: 468-469, 1971.

96 Ghosh, M.N. and Parvathy, S.

"The Effect of Cyproheptadine on Water and Food Intake and on Body Weight in the Fasted Adult and Weanling Rats".

Br. J. Pharmac.: 48: 328-329, 1973. 
97 Gibbs, J., Young, R.C. and Smith, G.P.

"Cholecystokinin Elicits Satiety in the Rat with Open Gastric Fistulas". Nature: 245: 323-325, 1973.

98 Glacheva, L., Manchando, S.K., Box, B. and Stevenson, J.A.F.

"Gastric Motor Activity during Feeding Induced by Stimulation of the Lateral Hypothalamus in the Rat".

Canad. J. Physiol. Pharmacol.: 50: 1091, 1972.

99 Glick, Z. and Maver, J.

"Hyperphagia Caused by Cerebral Ventricular Infusion of Phloridzin".

Nature: 219: 1374, 1968

100 Glicksman, A.S. and Rawson, R.W.

"Diabetes and Altered Carbohydrate Metabolism in Patients with Cancer". Cancer: 9: 1127-1134, 1956.

101 Gold, J.

"Cancer Cachexia and Gluconeogenesis".

Ann. N.Y. Acad. Sci: 230: 103-110, 1974.

102 Gold, R.M.

"Hypothalamic Hyperphagia Produced by Parasagittal Knife Cuts".

Physiol. Behav.: 5: 23-25, 1970.

103 Gold R.M.

"Hypothalamic Obesity: the Myth of the Ventromedial Nucleus".

Science: 182: 488-489, 1973.

104 Goodlad, G.A.J.

"Protein Metabolism and Tumor Growth".

In: "Mammalian Protein Metabolism". Monroe, H.N. Alison, J.B. (Eds.) 2: 415-444.

Acad. Press Inc., New York, 1964.

105 Goodner, C.J., Ogilvie, J.T. and Koerker, D.T.

"The Metabolism of Glycerol by Hypothalamic and Pituit Tissues in Vitro in the Rat".

Proc. Soc. Exp. Biol. Med.: 143: 616-622, 1973.

106 Gordon, G.S., Fitzpatrick, M.E. and Lubick, W.P.

"Identification of Osteolytic Steroids in Human Breast Cancer".

Trans. Ass. Amer. Physicians: 80: 183-188, 1967.

107 Goudie, A.J., Thornton, W. and Wheeler, T.J.

"Effects of Lilly 110140, a Specific Inhibitor of 5-Hydroxytryptamine Uptake, on Food Intake and on 5-Hydroxytryptophan - Induced Anorexia. Evidence for Serotoninergic Inhibition of Feeding".

J. Pharm. Pharmac.: 28: 318-320, 1976.

108 Grossman, M.I., Cummins, G.M. and Ivy, A.C.

"The Effects of Insulin on Food Intake after Vagotomy and Sympathectomy".

Am. J. Physiology: 149: 100-102, 1947. 
109 Grossman, S.P.

"Direct Adrenergic and Cholinergic Stimulation of Hypothalamic Mechanisms".

Am. J. Physiol.: 202: 872-882, 1962.

110 Grossman, S.P.

"Neurophysiologic Aspects: Extrahypothalamic Factors in the Regulation of Food Intake".

Adv. Psychosom. Med.: 7: 49-72, 1972.

111 Haigler, H.J. and Aghajanian, G.K.

"Serotonin Receptors in the Brain".

Fed. Proc.: 36 (8): 2159-2164, 1977.

112 Halaris, A.E. and De Met, E.M.

"Active Uptake of $\left({ }^{3} \mathrm{H}\right)$ 5-HT by Synaptic Vesicles form Rat Brain".

J. Neurochem.: 31: 591-597, 1978.

113 Hamilton, C.L. and Brobeck, J.R.

"Food Intake and Activity of Rats with Rostral Hypothalamic Lesions".

Proc. Soc. Expl. Biol. Med.: 122: 270-272, 1966.

114 Harper, A.E. and Spivey, H.E.

"Relationship between Food Intake and Osmotic Effect on Dietary Carbohydrate".

Am. J. Physiol.: 193: 483-487, 1958.

115 Harper, A.E., Leung, P., Yoshida, A. and Rogers, Q.R.

"Some New Thoughts on Acids Inbalance".

Fed. Proc.: 23: 1087-1092, 1964.

116 Harper, A.E.

Protein and Amino Acids in the Regulation of Food Intake".

In: "Hunger: Basic Mechanisms and Clinical Implications".

Novin, D., Wyrwicka, W., Brory, G. and Rols, A.

Raven Press, New York, 1975.

117 Hetherington, A.W.

"Non-Production of Hypothalamic Obesity in Rat by Lesions Rostral or Dorsal to Ventromedial Hypothalamic Nuclei".

J. Comp, Neurol.: 80: 33-45, 1944.

118 Henkin, R.I.

"New Aspects in the Control of Food Intake and Appetite".

Ann. N.Y. Acad. Sci: 231: 321-334, 1975.

119 Hervey, G.R.

"Physiological Mechanisms in the Regulation of Energy Balance".

In: "Anorexia Nervosa and Obesity". Robertson, R.F. (Ed.).

publ. R.C.P. Edinburgh, 42: 7-17, 1973.

120 Hery, F., Chouvet, G., Kan, J.P., Pujol, J.F. and Glowinski, J.

"Daily Variations of Various Parameters of Serotonin Metabolism in the Rat Brain. II: Circadian Variations in Serum and Cerebral TRP Levels: Lack of Correlation with 5-HT Turnover". Brain Res: 123: 137-145, 1977. 
121 Hetherington, A.W. and Ranson, S.W.

"Experimental Hypothalamic Hypophyseal Obesity in the Rat".

Proc. Soc. Exp. Biol. Med: 41: 465-466, 1939.

122 Hilf, R., Goldberg, H., Michel, I., Orlando, R.A. and Archer, F.L. "Enzymes, Nucleic Acids and Lipids in Human Breast Tissue and Normal Breast Tissue".

Cancer Res.: 30: 1874-1882, 1970.

123 Hirsch, J. and Itallie, I, van

"The Treatment of Obesity".

Am. J. Chir. Nutr.: 26: 1039, 1973.

124 Hoebel, B.G. and Teitelbaum, P.

"Hypothalamic Conrtrol of Feeding and Self Stimulations",

Science: 135: 375-377, 1962.

125 Hoebel, B.G. and Teitelbaum, P.

"Weight Regulation in Normal and Hypothalamic Hyperphagic Rats".

J. Comp. Physiol. Psychol: 61: 189-193, 1966.

126 Holland, J.C.B.

"Anorexia and Cancer: Psychological Aspects".

C.A. (A Cancer Journal for Clinicians): 27 (6): 363-367, 1977.

127 Holland, J.C., Rowland, J. and Plumb, M.

"Psychological Aspects of Anorexia in Cancer Patients".

Cancer Res.: 37: 2425-2428, 1977.

128 Holloway, S.A. and Stevenson, J.A.F.

"Effect of Glucagon on Food Intake and Weight Gain in the Young Rat". Can. J. Physiol. Pharmacol.: 42: 867-869, 1964.

129 Holt, L.E. Jr., Snijderman, S.E., Norton, P.M., Roitman, E. and Finch, J.

"The Plasma Aminogram in Kwashiorkor".

The Lancet: 2: 1343-1348, 1963.

130 Jacobs, H.L. and Sharma, K.N.

"Taste Versus Calories: Sensory and Metabolic Signals in the Control of Food Intake".

Ann. N.Y. Acad. Sci.: 157: 1084-1125, 1969.

131 James, H.J., Hodgman, J.M., Funovics, J.M., Yoshimura, N. and Fischer, J.E.

"Brain Tryptophan, Plasma Free Tryptophan and Distribution of Plasma Neutral Amino Acids".

Metabolism: 28 (4): 471-476, 1976. 
132 James, J.H., Escourrou, J. and Fischer, J.E.

"Blood-Brain Neutral Amino Acid Transport Activity in Increased after Portocaval Anastomosis".

Science: 200: 1395-1397, 1978.

133 Janowitz, H.D. and Grossman, M.I.

'Some Factors Affecting Food Intake of Normal Dogs and Dogs with Oesophagostomy and Gastric Fistulas".

Am. J. Physiol.: 159: 143-148, 1949.

134 Jespersen, $\mathrm{S}$. and Scheel-Krüger, J.

"Antagonism by Methysergide of the 5-Hydroxytriptonine - like Action of Toxic Doses of Fenfluramine in Dogs".

J. Pharmacol.: 22: 637-638, 1970.

135 Jespersen, S, and Scheel-Krüger, J.

"Evidence for a Difference in Mechanism of Action Between Fenfluramine and Amphetamine - Induced Anorexia".

J. Pharm. Pharmac.: 25: 49-54, 1973.

136 Jouvet, $M$.

"Biogenic Amines and the States of Sleep".

Science: 163: 32, 1969.

137 Kalyanasundaram, $\mathrm{S}$.

"Effect of Dietary Protein and Caloric Deficiency on Tryptophan Levels in Developing Rat Brain".

J. Neurochem.: 27: 1245-1247, 1976.

138 Kannengiesser, M., Hunt, P.F. and Raynaud, J.

"Comparative Action of Fenfluramine on Uptake and Release of Serotonin and Dopamin".

Eur. J. Pharmacol.: 35: 35-43, 1976.

139 Kare, M.R.

"Digestive Functions of Taste Stimuli". In: Pfaffman, C. (Ed.), "Olfaction and Taste".

p. 586-592, N.Y. Rockefeller University Press, 1969.

140 Kelley, J.J. and Waisman, H.A.

'Quantitative Plasma Amino Acid Values in Leukemic Blood:

Blood: 12: 635-643, 1957.

141 Kennedy, G.C.

"The Role of Depot Fat in the Hypothalamic Control of Food Intake in the Rat".

Proc. Roy. Soc. London Ser. B.: 140: 578-592, 1953. 
142 Kennedy, G.C. and Parrott, D.M.V.

'The Effect of Increased Appetite and of Insulin on Growth in th Hypophysectomized Rat".

J. Endocrinol: 17: 161-166, 1958

143 Koe, B.K. and Weissman, A.

"p-Chlorophenylalaline: a specific depletor of brain serotonin".

J. Pharmacol. Exp. Therap.: 154: 499, 1966.

144 Koe, B.K.

"Tryptophan Hydroxylase Inhibitors".

Fed. Proc. 30: (3): 886-896, 1971.

145 Koella, W.P. Czicman, J.S.

Mechanism of the E.E.G.-synchronizing Action of Serotonin".

Am. J. Physiol. 211: 926-934, 1966.

146 Knott, P.J., and Curzon, G.

"Effect of Increased Rat Brain Tryptophan on 5-Hydroxytryptamine and 5-Hydroxy Indolyl Acetic Acid in the Hypothalamus and other Brain Regions". J. Neurochem.: 22: 1065-1071, 1974.

147 Krause, R., James, J.H., Ziparo, V., and Fischer, J.E.

"Brain TRP and the Neoplastic Anorexia-Cachexia Syndrome". Cancer: 44: 1003-1008, 1979.

148 Krause, R., James, J.H., Humphrey, C. and Fischer, J.E.

"Plasma and Brain Amino Acids in Walker-256 Carcino-sarcoma - bearing Rats".

Cancer Res.: 39: 3065-3069, 1979.

149 Krieger, D.T., and Martin, L.

"Effectiveness of Cyproheptadine in Decreasing Plasma ACTH Concentrations in Nelson's Syndrome".

J. Clin. Endocrinol. Metab.: 43: 1179-1182, 1976.

150 Kruk, Z.L.

"Dopamine and 5-Hydroxytryptamine lahibit Feeding in Rats".

Nature New Biol.: 246: 52-53, 1973.

151 Kubota, Y., Ueki, H., Shoji, S., and Shigematsu, H.

"Biochemical Studies on Cachexia due to Cancer. I: Parietal Purification and Properties of the Hypoalbuminemic Substance".

J. Pharm. Soc. Jap.: 93 (7): 887-892, 1973.

152 Leibowitz, S.F.

"Reciprocal Hunger-Relating Circuits Involving Alpha- and BetaAdrenergic Receptors located, respectively in the Ventromedial and Lateral Hypothalamus".

Proc. Nat. Acad. Sci. U.S.A.: 67: 1063-1070, 1970.

153 Leibowitz, S.F.

"Ingestion in the Satiated Rat: Role of Alpha and Beta Receptors in Mediating Effects of Hypothalamic Adrenergic Stimulation".

Physiol. Behav.: 14: 743-754, 1975. 
154 Leibowitz, S.F.

"Brain Catecholaminergic Mechanisms for Control of Hunger".

In: "Hunger": Basic Mechanisms and Clinical Implications: Novin. D.

Wyrwicka, W. and Bray, G.A. (Eds.).

Raven Press, New York, 1975.

155 Leibowitz, S.F.

"Paraventricular Nucleus: a Primary Site Mediating Adrenergic Stimulation of Feeding and Drinking".

Pharmac. Biochem. Behav.: $8(2): 163-175,1978$.

156 Leibowitz, S.F.

"Identification of Catecholamine Receptor Mechanisms in the Perifornical Lateral Hypothalamus and their Role in Mediating Amphetamine and LDopa Anorexia". In: "Central Mechanisms of Anorectic Drugs': Garattini, S., and Samanin, R. (Eds.). Raven Press, New York, 1978.

157 Le Magnen, J.

"Advances in Studies on the Physiological Control and Regulation of Food Intake". Progress in Physilogical Psychology": Stellar, E., and Spraque, J.M. (Eds.).

New York, Acad. Press: 4: 203-262, 1971.

158 Le Magnen, J., Devos, M., Gandilliere, J., Louis-Sylvestre, J. and Tallou, $\mathbf{S}$.

"Role of a lipostatic mechanism in regulation of feeding and energy balance in rats".

J. Comp. Physial. Psychol.: 84: 1-23, 1973.

159 Leung. Ph. M.B., and Rogers, G.R.

"Food Intake: Regulation by Plasma Amino Acid Pattern".

Life Sci.: 8 (2): 1-9, 1969.

160 Levine, R., and Haft, D.E.

"Carbohydrate Homeostasis I an II".

N. Engl. J. Med.: 283: 175-183 and 237-246, 1970.

161 Levison, M.J. Frommer, G.P., and Vancer, W.B.

"Palatability and Caloric Density as Determinants of Food Intake in Hyperphagic and Normal Rats".

Physiol. Beh.: 10: 455-462, 1973.

162 Little, A.D.

"Biology of the Walker 256 Carcinosarcoma". In: 'Progress Report to National Cancer Institute", 1966.

163 Long. C.L., Kinney, J.M. et al.

"Non-Suppressability of Gluconeogenesis by Glucose in Septic Patients". Metabolism: 25: 193-201, 1976.

164 Lytle, L.D.

"Control of Eating Behaviour".

In: 'Nutrition and the Brain", Wurtman, R.J., and Wurtman, J.J. (Eds.).

Raven Press, New York: pp.-2-145, 1977. 
165 Madras, B.K., Cohen, E.L., Fernstrom, J.D., Larin, F., Munro, H.N., Wurtman, R.J.

"Dietary Carbohydrate Increases Brain Tryptophan and Decreases Free Plasma Tryptophan".

Nature: 224: 34-35, 1973.

166 Madras, B.K., Cohen, E.L., Messing, R. Munro, H.N., and Wurtman, R.J.

"Relevance of free tryptophan in serum to brain tissue tryptophan concentration".

Metabolism: 23: 1107-1116, 1974.

167 Mandell , A.J., and Knapp, S.

"Regulation of Serotonin Biosynthesis in Brain: Role of the High Affinity Uptake of Tryptophan into Serotonin Neurons".

Fed. Proc. 36: 2142-2148, 1977.

168 Margules, D.L., and Olds, J.

"Identical", "Feeding" and "Rewarding" Systems in the Lateral Hypothalamus of Rats".

Science: 135: 374-375, 1962.

169 Margules, D.L.

"Alpha-Adrenergic Receptors in Hypothalamus for the Suppression of Feeding Behaviour by Satiety".

J. Comp. Physiol. Psychol: 73: 1-12, 1970.

170 Marks, P.A., and Bishop, J.S.

"Glucose Methabolism in Subjects with Neoplastic Disease: Reponse to Insulin and Glucose Tolerance.

Follow-up Studies".

Proc. Amer. Ass. Cancer Res.: 2: 228-229, 1957.

171 Marliss, E.B.

"An Overview of Amino Acid Metabolism: the Determinants of Protein Homeostasis in Parenteral Nutrition".

In: "Clinical Nutrition Updata - Amino Acids", published by:

A.M.A. Chicago, lllinois, p. 34-45, 1977.

172 Marrazzi, M.A.

"Hypothalamic Glucoreceptor Response - Biphasic Nature of Unit Potential Change".

In: "Hunger: Basic Mechanisms and Clinical Implications: Novin, D. Wyrwicka, W. and Bray, G.A. (Eds.), Raven Press, New York, 1975.

173 Martel, F.

"Etude de la Distribution des Acides Aminés Sanguins chez Sujets Cancéreuses".

Laval Médical: 54-62, Jan. 1959.

174 Martin, F.H., and Baile, C.A.

"Feeding Elicited in Sheep by Intrahypothalamic Injections of $\mathrm{PGE}_{1}$ ".

Experentia: 29: 306-307, 1973. 
175 Matsutaka, H., Aikawa, T., Yamamoto, H., and Iskikawa, F. "Gluconeogenesis and Amino Acid Metabolism: III: Uptake of Glutamine and Output of Alanine and Ammonia by Non-Hepatic splanchnic organs of Fasted Rats and their Metabolic Significance".

J. Biochem: 74: 1019-1029, 1973.

176 Mayer, J.

"Glucostatic Mechanism of Regulation of Food Intake".

New Engl. J. Med.: 249: 13-16, 1953.

177 Mayer, J.

"Hunger and the Hypothalamus".

Clin. Res. Proc: : 5: 123-126, 1957.

178 McConnell, S.D., and Henkin, R.I.

"Altered Preference for Sodium Chloride, Anorexia and Changes in Plasma and Urinary Zinc in Rats Fed a Zinc-Deficient Diet".

J. Nutr.: 104: 1108-1114, 1974.

179 McCoy, T.A., Maxwell, M. and Neuman, R.E.

"The Amino Acid Requirements of the Walker Carcino-Sarcoma 256 in Vitro".

Cancer Res: 16: 979-984, 1956.

180 McCoy, T.A., Maxwell, H. and Kruse, P.F. Jr.

"The Amino Acid Requirements of the Jensen Sarcoma in Vitro".

Cancer Res.: 19: 591, 1959.

181 McHugh, P.R., Moran, T.H., and Barton, G.H.

"Satiety: A Graded Behavioral Phenomenon Regulating Caloric Intake". Science: 190: 167-169, 1975.

182 MacKenzie, R.G., Trulson, M.E.

"Does insulin act directly on the brain to increase tryptophan levels?". J. Neurochem. 30: 1205-1208, 1978.

183 McLennan, $J$.

in: "Synaptic Transmission" W.B. Sanders Co. Philadelphia, 1963 p-23.

184 Mellinkoff, S.M. Frankland, M., Boyle, D., and Greipel, M.

"Relationship Between Serum Amino Acid Concentration and Fluctuations in Appetite".

J. Appl. Physiol.: 8: 535-538, 1956.

\section{Mellinkhoff, S.M.}

"Digestive System".

Ann. Rev. Physiol.: 19: 175-204, 1957.

186 Mickelsen, O., Takahaski, H., and Craig, C.

"Experimental Obesity: 1. Production of Obesity in Rats by Feeding High Fat Diets".

J. Nutr:: 57: 541-554, 1955. 
187 Mider, G.B., Sherman, C.D. Jr. and Morton, J.J.

"The Effect of Walker Carcinoma 256 on the Lipid Content of Rats".

Cancer Res.: 14: 222-224, 1954.

188 Mider, G.B.

"Some Tumor-Host Relationships".

Proc. Can. Cancer Res. Conf., Ist Conf., Honey Harbor.

Ontario, 1954, p. 120-137.

189 Millar, F.K., White, J. et al.

"Walker Carcinosarcoma 256 Tissue as a Dietary Constituent: Stimulation of Appetite and Growth in the Tumor-bearing Rat".

J. Nat. Cancer Inst.: 19: 957-967, 1957.

190 Miller, N.E., Bailey, C.J., and Stevenson, J.A.F.

"Decreased "Hunger" but increased Food Intake Resulting from

Hypothalamic Lesions".

Science: 112: 256-259, 1950.

191 Modigh, K.

"The Relationship between the Concentrations of TRP and 5-HIAA in Rat Brain and Cerebrospinal Fluid".

J. Neurochem.: 25: 351-352, 1975.

192 Mogenson, G.J.

"Neural Mechanisms of Hunger" Current Status and Future Prospects. In: "Hunger: Basic Mechanisms and Clinical Implications". Novin, D. Wyrwicka, W., and Bray, G.A. (Eds.).

New York, Raven Press, 1975.

193 Morgane, P.J., and Kosman, A.J.

"Relationship of the Middle Hypothalamus to Amygdalar Hyperphagia". Am. J. Physiol.: 198: 1315-1318, 1960.

194 Morrison, S.D.

"Diurnal Distribution of Motor Activity and Feeding during Growth of Tumor".

Cancer Res.: 34: 1632-1635, 1974.

195 Müller, P.S., and Watkin, D.M.

"Plasma Unesterified Fatty Acid Concentration in Neoplastic Disease". J. Lab. Clin. Med.: 57: 95-108, 1961.

196 Muller. P.S., and Evans, V.H.

"Responses of Plasma Glycerol Concentration to Epinephrine, Norepinephrine, Glucose, Insulin in Man".

J. Lab. Clin. Med.: 61: 953-961, 1963.

197 Myers, R.D., Bender, S.A. and Cristic, M.K.

"Feeding Produced in the Satieted Rat by Elevating the Concentration of Calcium".

Science: 176: 1124-1125, 1972. 
198 Nanni, G., and Casu, A.

"In vitro Uncoupling of Oxidative Phosphorilation in Normal Liver

Mitochondria by Serum of Sarcoma Bearing Rats".

Experentia: 17: 402-404, 1961.

199 Navarro, R., Gavina, F.

"Some Alterations in the Amount of Blood Amino Acids in the Wistar Rats Inoculated with the 256-Walker Carcinoma".

R. Esp. Fisiol.: 22 (3): 135-140, 1966.

200 Nicholalidis, S.

"Early Systemic Response to Food and Water Balance:

Functional Physiological Diets".

Ann. N.Y. Acad. Sci.: 157: 1176-1203, 1969.

201 Nijima, A.

"Afferent Impulse Discharge from Glucoreceptors in the Liver of the Guinea Pig".

Ann. N.Y. Acad. Sci: 157: 690-700, 1969.

202 Niskanen, P., Huttunen, M., Tamminen, T., and Jäästeläinen, J. "The Daily Rhythm of Plasma Tryptophan and Tyrosine in Depression". Brit. J. Pschiat.: 128: 67-73, 1976.

203 Noble, R.E.

"Effect of Cyproheptadine on Appetite and Weight Gain in Adults".

J.A.M.A. 209 (13): 2054-2055, 1969.

204 Novin, D., Weele van der, D.A. and Rezek, M.

"Infusion of 2-deoxy-D-Glucose into the Hepatic Portal System Causes

Eating: Evidence for Peripheral Glucoreceptors".

Science: 181: 858-860, 1973.

205 Novin, D.

"Visceral Mechanisms in the Control of Feeding".

In: "Hunger: 'Basic Mechanisms and Clinical Implications": Novin D.,

Wyricka, W., and Bray, G.A. (Eds).

New York, Raven Press, 1975.

206 Oldendorf, W.H., and Braun, L.D.

" $\left({ }^{3} \mathrm{H}\right)$ Tryptamine and $3 \mathrm{H}$-water and Diffusible Internal Standards for Measuring Brain Extraction of Radiolabeled Substances Following Carotid Injection".

Brain Res.: 113: 219-224, 1976.

207 Olds, J., and Milner, P.

"Positive reinforcement produced by electrical stimulation of the septal area and other regions of the rat brain".

J. Comp. Physiol. Psychol.: 47: 419-427, 1954. 
208 Oomura, Y.

"Significance of Glucose, Insulin and Free Fatty Acid on the Hypothalamic Feeding and Satiety Neurons".

In: "Hunger: Basic Mechanisms and Clinical Implications".

Novin, D., Wyrwicka, W. and Bray, P. (Eds),

New York, Raven Press, 1975, p. 145-157.

209 Oomura, $Y$.

"Effects of Glucose and Free Fatty Acid in Chemosensitive Neuron in the Rat Hypothalamus".

In: "Hunger: Basic Mechanisms and Clinical Implications".

Novin, D., Wyrwicka, W., and Bray, G.A. (Eds)

New York, Raven Press, 1975.

210 Paintal, A.S.

"A study of Gastric Stretch Receptors. Their Role in the Peripheral Mechanism of Satiation of Hunger and Thirst.

J. Physiol. London: 126: 255-270, 1954.

211 Panksepp, J., and Booth, D.A.

"Decreased Feeding after Injections of Amino Acids into the Hypothalamus".

Nature: 233: $341-342,1971$.

212 Panksepp, J.

"Hypothalamic Regulation of Energy Balance and Feeding Behavior".

Fed. Proc.: 33: 1150-1165, 1974.

213 Paoleti, R., Sirtori, C. Jr., and Sapno P.F.

"Clinical relevance of drugs affecting tryptophan transport".

Ann. Rev. Pharmacol. 15: 73-81, 1975.

214 Parameswaran, S.V., Steffens, A.B. et al.

"Involvement of a Humoral Factor in Regulation of Body Weight in Parabiotic Rats".

Am. J. Physiol.: 232: R150-R157, 1977.

215 Pardridge, W.M., and Oldendorf, W.H.

"Kinetic Analysis of Blood-Brain Barrier Transport of Amino Acids".

Bioch. et Biophys. Acta: 401: 128-136, 1975.

216 Pardridge, W.M.

"Kinetics of Competitive Inhibition of Neutral Amino Acid Transport Across the Blood - Brain Barrier".

J. Neurochem.: 28: 103-108, 1977.

217 Paximos, G., and Bindra, D.

"Hypothalamic and Midbrain Neural Pathways Involved in Eating,

Drinking, Irritability, Aggression and Copulation in Rats".

J. Comp. Physiol. Psychol.: 82: 1-14, 1973. 
218 Peng, Y., Tews, J.K., and Harper, A.E.

"Amino Acid Imbalance. Protein Intake and Changes in Rat Brain and Plasma Amino Acids".

Am. J. Physiol: 222: 314-321, 1972.

219 Peng, J., Gubin, J., Harper, A.E., Vavich, M.G. and Kemmerer, A.R. "Food Intake Regulation: Amino Acid Toxicity and Changes in Rat Brain and Plasma Amino Acids".

J. Nutr.: 103: 608-617, 1973.

220 Penick, S.B., and Hinkle, L.

"The Effect of Glucagon, Phenmetrazine and Epinephrine on Hunger, Food Intake and Plasma Nonesterified Fatty Acids".

Am. J. Clin. Nutr.: 13: 110-114, 1963.

221 Pérez-Cruet, J., Chase, T.N., and Murphy, D.L.

"Dietary Regulation of Brain TRP Metabolism by Plasma Ratio of Free Tryptophan and Neutral Amino Acids in Humans".

Nature: 248: 693-695, 1974.

222 Perri, J.

"Nursing View of Cancer Cachexia". Symposion: "Cancer Therapy:

Nutritional Perspective".

Hynannis, Mass., U.S.A., 1978.

223 Plumb. M.H., and Holland, J.

"Comparative Studies of Psychological Function in Patients with Advanced Cancer - 1. Self-Reported Depressive Symptoms".

Psychosom. Med:: 39: 264-276, 1977.

224 Rauscher, F.P., Naszallah, A.H., and Wyatt, R.J.

"Histamine and Schizophrenia".

In: "Neuroregulators and Psychiatric Disorders". Usdin, E., Hamburg, D.A., and Barchas, J.D. (Eds).

New York, Oxford University Press, 1977.

225 Reinhard, J.F. Jr. and Wurtman, R.J.

"Relation between Brain 5-HIAA Levels and the Release of Serotonin into Brain Synapses".

Life Science: 21: 1741-1746, 1977.

226 Rosen, H.M., Soeters, P.B., James, J.H., Hodgman, J., and Fischer, J.E.

"Influences of Exogenous Intake and Nitrogen Balance on Plasma and Brain Amino Acid Concentration".

Metabolism: 27 (4): 393-404, 1978. 
227 Ross, B.D., Hems, R., and Krebs, H.A.

"The Rate of Gluconeogenesis from Various Precursors in Perfused Rat Liver".

Biochem. J. 102: 942, 1967.

228 Rossing, N.

"Albumin Metabolism in Neoplastic Diseases".

Scand. J. Clin. Lab. Invest.: 22: 211-216, 1968.

229 Rudman, D., Vogler, W.R., et al.

"Observation. of the Plasma Amino Acids of Patients with Acute Leukemia".

Cancer Res.: 31: 1159-1165, 1971.

230 Quaade, F.

"On the "Glucostatic" Therapy of Appetite Regulation.

I: Capillovenous Glucose Difference in Normal Obese and Diabetic Persons during Hunger and Satiety".

Am. J. Med. Sci.: 243: 427-437, 1962.

231 Rothwell, N.J., and Stock, M.J.

"A Paradox in the Control of Energy Intake in the Rat".

Nature: 273: 146-147, 1978.

232 Russek, $M$.

"Demonstration of the Influence of an Hepatic Glucosensitive Mechanism on Food Intake".

Physiol. Behavior: 5: 1207-1209, 1970.

233 Saavedra, J.M.

"Distribution of Serotonin and Synthesizing enzymes in Discrete Areas of the Brain".

Fed. Proc.: 36: 2134-2141, 1977.

234 Saller, C.F., and Stricker, E.M.

"Hyperphagia and Increased Growth in Rats after Intraventricular Injection of 5,7 - Dihydroxytryptamine".

Science 192: 385-387, 1976.

235 Salman, W.D.

"The Signifiance of Amino Acid Imbalance in Nutrition".

Am. J. Clin. Nutr: 6 (5): 487-494, 1958.

236 Samanin, R., Ghezzi, D., Valzelli, L., and Garatini, S.

"The Effects of Selective Lesioning of Brain Serotonin or Catecholamine Containing Neurons on the Anorectic Activity fo Fenfluramin and Amphetamine".

European J. Pharmacol:: 19: 318-322, 1972.

237 Sanchez, J., and Enjuanes, L.

"Gas-liquid Chromatography of Amino Acids in the Blood of Wistar Rats with Walker-256 Carcinoma".

Oncology: 25: 44-48, 1971. 
238 Sanders-Busch, E., and Massari, V.J.

"Actions of Drugs that Deplete Serotonin".

Fed. Proc.: 36: 2149-2153, 1977.

239 Schlottmann, H., and Rubenow, W.

Über den Wassergehalt der Gewebe Normaler und Krebskranker Ratten".

Z. Krebsforsch.: 36: 120-125, 1932.

240 Schwartz, J.J.

"Histamin as a Transmittor in Brain".

Life Sci.: 17: 503-517, 1975.

241 Sclafani, A.

"Neural Pathways Involved in the Ventromedial Hypothalamic Lesion Syndrome in the Rat".

J. Comp. Physiol. Psychol.: 77: 70-96, 1971.

242 Sclafani, A., and Berner, C.N.

"Hyperphagia and Obesity Produced by Parasagittal and Coronal

Hypothalamic Knife Cuts: Further Evidence for a Longitudinal Feeding Inhibitory Pathway".

J. Comp. Physiol. Psychol.: 91: 1000-1018, 1977.

243 Setler, P.E., and Smith, G.P.

"Increased Food Intake Elicited by Adrenergic Stimulation of the

Diencephalon in Rhesus Monkeys".

Brain Res.: 65: 459-473, 1974.

244 Sharma, K.N., Anand, B.K., Dua, S., and Singh., B.

"Role of Stomach in Regulation of Activities of Hypothalamic Feeding Centers".

Am. J. Physiol:: 201: 593-598, 1961.

245 Siperstein, M.D., Fagan, V.M., and Morris, H.P.

"Further Studies on the Deletion of the Cholesterol Feedback System in Hepatomas".

Cancer Res.: 26: 7-11, 1966.

\section{Snijder, S.H.}

"Catecholamines and Serotonin".

In: "Basic Neurochemistry", p. 89-104, published by Little, Brown and Co., Boston, 1972.

247 Southgate, P.J., Mayer, S.R., Boxall, E., and Wilson, A.B.

"Some 5-Hydroxy-tryptamine like Actions of Fenfluramine:

a Comparison with $(+)$ - amphetamine and Diethylpropion".

J. Pharm. Pharmac.: 23: 600-605, 1971.

248 Spector, N.H., Brobeck, J.R., and Hamilton, C.L.

"Feeding and Care Temperature in Albino Rats; Changes Induced by Preoptic heating and Cooling".

Science: 161: 286-288, 1968. 
249 Steinfeld, J.L.

"1131 Albumin Degration in Patients with Neoplastic Diseases".

Cancer: 13: 974-984, 1960.

250 Steffens, A.B.

"Blood Glucose and FFA levels in Relation to the Meal Pattern in the Normal Rat and the VMH Hypothalamic Lesion Rat",

Physiol. Behav.: 4:212-225, 1969.

251 Stevenson, J.A.F., Box, B.M., and Wright, R.B.

"The Effect of a Cold Environment on Malignant Anorexia".

Can. J. Biol. Physiol.: 41; 531-532, 1961.

252 Stricker, E.M., Rowland, N. and Saller, C.F.

"Homeostasis during Hypoglycemia: Central Control of Adrenal Secretion and Periphereal Control of Feeding".

Science: 196: 79-81, 1977.

253 Stricker, E.M.

"Hyperphagia" (Physiology in Medicine).

N. Eng. Med. J.: 298 (18): 1010-1013, 1978.

254 Strominger, J.L., and Brobeck, J.R.

"A Mechanism of Regulation of Food Intake".

Yale J. Biol. Med.: 20: 545-552, 1953.

255 Stunkard, A.J., and Wolff, H.G.

"Studies on the Physiology of Hunger.

1. The Effect of Intravenous Administration of Glucose on Gastric Hunger Contractions in Man".

J. Clin. Invest.: $35:$ 954-963, 1956.

256 Sullivan, L.W., and Smith, T.C.

"Influence of Estrogens on Body Growth and Food Intake".

Proc. Soc. Exp. Biol. Med.: 96: 60-64, 1957.

257 Sylven, B.

"Factors Produced by Tumor Cells which Contribute to the Death of Cancer Patients".

Carlo Erba Foundation Lecture Series: 26, february 1969.

258 Taliamonte, A., Biggio, G., Vargiu, L., and Gessa, G.L.

"Free Tryptophan in Serum Controls Brain Tryptophan Level and Serotonin Synthesis".

Life Sci.: 12 (2): 277-287, 1973.

259 Tagliamonte, A., Tagliamonte, S., Perez-Cruet, J., Stern, S., and Gessa, G.L.

"Effect of Psychotropic Drugs on Tryptophan Concentration in Rat Brain". J. Pharmacol. Exp. Ther:: 177: 475-480, 1971. 
260 Ter Haar, M.B.

"Circadian and Estrual Rhythms in Food Intake in the Rat".

Hormones and Behaviour: 3: 213-220, 1972.

261 Theologides, $A$.

"Pathogenesis of Cachexia in Cancer".

Cancer: 29: 484-488, 1972.

262 Theologides, $A$.

"The Anorexia-Cachexia Syndrome. A New Hypothesis".

Ann. N.Y. Acad. Sci: 230: 14-22, 1974.

263 Theologides, A.

"Anorexia-Producing Intermediary Metabolites".

Am. J. Clin. Nutr.: 29: 552-558, 1976.

264 Theologides, $A$.

"Cancer Cachexia". In: "Nutrition and Cancer".

M. Winick (Ed.) New York, published by John Wiley \& Sons Inc.:

75-94, 1977.

265 Tower, D.B.

"The Effects of 2-Deoxy-D-glucose on Metabolism of Slices of Cerebal Cortex Incubated in Vitro".

J. Neurochem.: 3: 185, 1958.

266 Ueki, H., Tsunemi, S., Tanaka, M., Yamashita, S., and Kubota, Y. "Biochemical Studies on Cachexia due to Cancer. II. Extration of Hypoalbuminergic Substance from Ehrlich Ascites Carcinoma Cells from Tissue of Mice".

J. Pharm. Soc. Jap.: 94 (1): 143-146, 1974.

267 Wade, G.N., and Zucker, I.

"Modulation of Food Intake and Locomotor Activity in Female Rats by Diencephalic Hormone Implants".

J. Comp. Physiol. Psychol.: 72: 328-336, 1970.

268 Wannemacher, R.W., and Yatvin, M.B.

"Protein Reserves and Growth of the Walker Carcinoma in Rats".

J. Nutr. 85: 893-899, 1965.

269 Warnold, I., Lundholm, K., and Scherstén, T.

"Energy Balance and Body Composition in Cancer Patients".

Cancer Res.: 38: 1801-1807, 1978.

270 Waterhouse, C., Kemperman, J.H., and Stomont, J.M.

"Alterations in Triglyceride Metabolism as Produced by Dietary Change".

J. Lab. Clin. Med.: 63: 605-620, 1964. 
271 Weisenfeld, S., Hecht, A., and Goldner, M.G.

"Tests of Carbohydrate Metabolism in Carcinomatosis".

Cancer (Philadelphia): 15: 18-27, 1962.

272 Wick, A.N., Drury, D.R., Nakada, H.I. and Wolfe, J.B.

"Localisation of the Primary Metabolic Block Produced by

2-deoxyglucose".

J. Biol. Chem.: 224, 963, 1957.

273 Williams, L.R., Cohen, M.S.

"Altered Taste Thresholds in Lung Cancer".

Am. J. Clin. Nutr.: 31: 122-125, 1978.

274 Wilson, E.A., Spraque, A.D., et al.

"Free Serum Amino Acids in Patients with Advanced Cervical Carcinoma".

Gynecologic Oncology: 4: $311-313,1977$

275 Wolfe, R.R., Allsop, J.R., and Burke, J.F.

"Experimental Sepsis and Glucose Metabolism: Time Course of

Response".

Surg. Forum: XXVIII: 42-43, 1977

276 Wolfe, R.R., Allsop. J.R. and Burke, J.F.

"Fallibility of the Intravenous Glucose Tolerance Test as a Measure of Endogenous Glucose Turnover".

Metabolism: 27 (2): 217-226, 1978.

277 Wolgin, D.L., Cytawa, J., and Teitelbaum, P.

"The Role of Activation in the Regulation of Food Intake".

In: "Hunger: Basic Mechanisms and Clinical Implications".

Novin, D., Wyrwicka, W., and Bray G.A. (Eds.)

New York, Raven Press, 1975.

278 Wu Chung and Bauer, J.M.

"A. Study of Free Amino Acids and of Glutamine Synthesis in Tumor Bearing Rats".

Cancer Res.: 20: 848-857, 1960.

279 Wurtman, R.J., and Fernstrom, J.D.

"Effects of the Diet on Brain Neurotransmitters".

Nutr. Rev.: 32: 193-200, 1974.

280 Wurtman, R.J. and Fernstrom, J.D.

"Control of Brain Neurotransmitter Synthesis by Precursor Availability and Nutritional State".

Biochem. Pharmacol.: 25: 1691, 1976. 
281 Wurtman, R.J., and Wurtman, J.J.

"Nutrition and the Brain".

Published by Raven Press New York: 2: 63-66, 1977.

282 Wurtman, R.J., and Wurtman, J.J.

"Nutrition and the Brain".

Published by Raven Press New York: 2: 104-107, 1977.

283 Wurtman, J.J., and Wurtman, R.J.

"Fenfluramin and Fluoxetine Spare Protein Consumption while

Suppressing Caloric Intake by Rats".

Science: 198: 1178-1180, 1977.

284 Yuwiler, A., Oldendorf, W.H., Geller, E. and Braun, L.

"Effect of Albumin Binding and Amino Acid Competition on Tryptophan Uptake into Brain".

J. Neurochem.: 28: 1015-1023, 1977.

285 Zender, R., and Courvoisier, B.

"Etude Comparatieve des Acides Aminés Plasmatiques Libre dans les Cas de Tumeurs Osseuses Malignes et chez les Sujets Sains".

Clin. Chim. Acta: 27: 259-265, 1970.

286 Ziparo, V., James, J.H., and Fischer, J.E.

"The effect or oral administration of branched chain amino acids on plasma and brain amino acids of rats with portacaval anastomosis". Manuscript in preparation. 


\section{CURRICULUM VITAE}

Ruud Krause was born on the 19th of May, 1945 in Burgkirchen, Austria. He graduated from high school in Lumbumbashi, Zaire (1960): from H.B.S.-A in Haarlem, The Netherlands (1962) and from H.B.S.-B in The Hague. The Netherlands (1964).

In 1965 he went to medical school at the University of Amsterdam and graduated in 1970 .

Before starting his internship, he was a research assistant the Department of Anaesthesiology of the Wilhelmina Gasthuis in Amsterdam. He became licenced in March 1973.

His internships were interrupted by a clinical fellowship in the Antoni van Leeuwenhoek Ziekenhuis (Dutch Cancer Institute), in Amsterdam.

From 1973 to 1974 he worked as a surgical resident in the Medical Centre of Geleen. The Netherlands (head: dr. Jacques Daniels).

In 1974 he started his official residency in Surgey in St. Annadal Hospital of Maastricht (State University Hospital), The Netherlands (head: Prof. dr. Lemmens, later Prof. dr. Greep).

This residency period was interrupted by an eighteen months clinical and research fellowship at the Department of Surgery of the Massachussets General Hospital, Harvard Medical School, Boston, U.S.A. (head: Prof. dr. Josef E. Fischer).

From January 1979 on, his residency program has been resumed in Maastricht, The Netherlands. 